\title{
Revisiting 30 years of biofunctionalization and surface chemistry of inorganic nanoparticles for nanomedicine
}

\author{
João Conde ${ }^{1 * \dagger}$, Jorge T. Dias ${ }^{2+}$, Valeria Grazú ${ }^{2 *}$, Maria Moros $^{2}$, Pedro V. Baptista $^{3}$ and \\ Jesus M. de la Fuente ${ }^{2,4,5}$ \\ 1 Harvard-MIT Division for Health Sciences and Technology, Institute for Medical Engineering and Science, Massachusetts Institute of Technology, \\ Cambridge, MA, USA \\ ${ }^{2}$ Nanotherapy and Nanodiagnostics Group, Instituto de Nanociencia de Aragon, Universidad de Zaragoza, Zaragoza, Spain \\ ${ }^{3}$ CIGMH, Departamento de Ciências da Vida, Faculdade de Ciências e Tecnologia, Universidade Nova de Lisboa, Caparica, Portugal \\ ${ }^{4}$ Fundacion ARAID, Zaragoza, Spain \\ ${ }^{5}$ Key Laboratory for Thin Film and Microfabrication Technology of the Ministry of Education, Department of Bio-Nano Science and Engineering, \\ Institute of Nano Biomedicine and Engineering, Research Institute of Translation Medicine, Shanghai Jiao Tong University, Shanghai, China
}

\section{Edited by:}

Jean-Michel Lavoie, Université de

Sherbrooke, Canada

\section{Reviewed by:}

Victor Sans Sangorrin, University of Glasgow, UK

Leonie Rouleau, Université de

Sherbrooke, Canada

\section{*Correspondence:}

João Conde, Harvard-MIT Division for Health Sciences and Technology, Institute for Medical Engineering and Science, Massachusetts Institute of Technology, 45 Carleton Street, E25-438, Cambridge, MA 02139, USA

e-mail: jdconde@mit.edu

Valeria Grazú, Nanotherapy and Nanodiagnostics Group, Instituto de Nanociencia de Aragon, Universidad de Zaragoza, Campus Rio Ebro,

Edifício ID, Mariano Esquillor $s / n$, 50018 Zaragoza, Spain

e-mail:vgrazu@unizar.es

tThese authors have contributed equally to this work.
In the last 30 years we have assisted to a massive advance of nanomaterials in material science. Nanomaterials and structures, in addition to their small size, have properties that differ from those of larger bulk materials, making them ideal for a host of novel applications. The spread of nanotechnology in the last years has been due to the improvement of synthesis and characterization methods on the nanoscale, a field rich in new physical phenomena and synthetic opportunities. In fact, the development of functional nanoparticles has progressed exponentially over the past two decades. This work aims to extensively review 30 years of different strategies of surface modification and functionalization of noble metal (gold) nanoparticles, magnetic nanocrystals and semiconductor nanoparticles, such as quantum dots. The aim of this review is not only to provide in-depth insights into the different biofunctionalization and characterization methods, but also to give an overview of possibilities and limitations of the available nanoparticles.

Keywords: biofunctionalization, chemistry surface, gold nanoparticles, magnetic nanoparticles, quantum dots

\section{INTRODUCTION}

Every object with at least one characteristic dimension between 1 and $100 \mathrm{~nm}$ can be defined as "nanomaterial." The importance of nanomaterials (e.g. nanoparticles, NPs) for science and technology has highly increased in the last years (Surendiran et al., 2009). When dealing with such a small structure, the size-related properties, the shape and inter-particle distance to the core, the charge, the dielectric properties of the conjugated system (including refractive index and polarizability), the dielectric medium surrounding the particle (solvent) and the composition moieties are extremely important and may sturdily influence the physical and chemical characteristics of the nanomaterials. This means that these distinct properties, such as quantum confinement in semiconductor nanocrystals or surface plasmon resonance (SPR) in some metal NPs, may influence physical and chemical behavior of nanomaterials (Bellucci, 2009; Doria et al., 2012).

The unbelievable development of nanotechnology in the last 30 years has allowed the release of new and efficient synthetic routes toward the production and functionalization of different NPs, composed of a variety of materials including noble metals [e.g. gold and silver (Conde et al., 2012c; Doria et al., 2012; Dreaden et al., 2012)], semiconductors [e.g. CdSe and CdTe (Murray et al., 1993), $\mathrm{TiO}_{2}$ (Sudhagar et al., 2012), InP (Xu et al., 2006)], magnetic compounds (Pankhurst et al., 2003), and their combinations, such as core-shell (Cao et al., 2001) and alloy NPs (Doria et al., 2010).

The unique characteristics of these NPs, such as high surface-to-volume ratio or size-dependent optical and magnetic properties, are drastically different from those of their bulk materials and hold pledge in the clinical field (Kim, 2007; Heath and Davis, 2008). Technological advances in nanoparticle synthesis/functionalization are producing significant advances in molecular detection and imaging, target and multifunctional therapeutics and in prevention/control of diseases. Through the development of new imaging agents, novel multifunctional targeted devices capable of overcoming biological barriers for 
direct delivery of therapeutic agents to diseased cells and tissues, and innovative monitoring sensors for predictive molecular changes, increase the processes' efficiency while minimizing costs (Baptista, 2009; Minelli et al., 2010; Ma et al., 2011; Conde et al., 2012c). Besides being an area of intense upfront basic research, nanotechnology holds the key to future technological applications. It is a burgeoning field as more and improved techniques are becoming available for clinical therapy and diagnostics with increased sensitivity and efficiency at lower costs (Baptista et al., 2008; Lammers et al., 2011).

In spite of these advantages, NPs do have limitations. For example, their small size and large surface area can lead to particle-particle aggregation and may result in limited loading of functional components and burst release. In fact, only NPs with the appropriate size and surface chemistry are not immediately recognized by the immune system and show increased circulation times (Gil and Parak, 2008; Shvedova et al., 2010). Nevertheless, their unique and broad-based optical properties, their ease of synthesis and facile surface chemistry and, most importantly, their appropriate size scale are overcoming these drawbacks and have been generating much eagerness in clinical diagnostics and therapy (Sperling et al., 2008).

Here we will review different strategies of biofunctionalization and characterization methods of inorganic nanoparticles, as well as their main advantages and limitations. Our aim is to discuss the challenges of working with nanoparticles while giving an overall overview of the state-of-the-art.

\section{INORGANIC NANOPARTICLES GOLD NANOPARTICLES}

Historically, colloidal gold has been used since ancient times mainly as a method for glass staining. However, it was not until Faraday's work that gold nanoparticles (AuNPs) began to be studied in a scientific approach (Faraday, 1857). Since then, AuNPs have generated ever-increasing interest and in the last few decades more and more controllable synthesis methods and applications in diverse nanosystems have been developed (Wagner et al., 2000; Edwards and Thomas, 2007).

AuNPs, also known as colloidal gold, are a suspension of sub-micrometer-sized gold metal particle in a fluid and can be obtained with diameters between 3 and $200 \mathrm{~nm}$. AuNPs have gained increasing interest due to their special features, such as extraordinary optical and electronic properties, high stability and biological compatibility, controllable morphology and size dispersion, and easy surface functionalization (Sperling et al., 2008).

The optical properties of AuNPs are significant because absorption and emission are within the visible range of light (ElSayed, 2001). Of particular interest is the light extinction process in the UV-visible range, which occurs when an electromagnetic wave passes through a metal particle exciting its electronic or vibrational states (Kreibig and Vollmer, 1995). This phenomenon induces dipole moments that oscillate at the respective frequency of the incident wave, dispersing secondary radiation in all directions. This collective oscillation of the free conduction electrons is called localized surface plasmon resonance (LSPR). The SPR is the collective oscillation of the electrons in the conduction band. The oscillation frequency is usually in the visible region giving rise to the strong SPR absorption (Schultz et al., 2000; Jain et al., 2006; Huang et al., 2007; Murphy et al., 2008).

Size also provides important control over many of the physical and chemical properties, including luminescence, conductivity, and catalytic activity. AuNPs' absorption and scattering proportions depend on the AuNPs size (Cao et al., 2002). AuNPs with a diameter smaller than $20 \mathrm{~nm}$ essentially show absorption, but when the size increase to $80 \mathrm{~nm}$ the ratio of scattering to absorption also increases. As the size of the AuNPs increases, light can no longer polarize the nanoparticles homogeneously and higher order modes at lower energy dominate. This causes a red-shift and broadening of the surface plasmon band. Small AuNPs, like those with $13 \mathrm{~nm}$ of diameter, absorb green light, which corresponds to a strong absorption band at $520 \mathrm{~nm}$ in the visible light spectrum. However, solutions of AuNPs appear red in color. For smaller AuNPs (i.e., $5 \mathrm{~nm}$ diameter), surface electrons are oscillated by the incoming light in a dipole mode, but the SPR is very sensitive to the composition, size, shape, inter-particle distance and environment (dielectric properties) of the AuNPs (Pellegrino et al., 2005; Sperling et al., 2006).

In all synthesis methods reported so far, a reducing and a stabilizing agent is added to prevent the particles from aggregating. The type of stabilizer affects the selection of further biofunctionalization strategies, as for certain strategies a good colloidal stability at a broad range of $\mathrm{pH}$ and ionic strength is required. Although a wide variety of nanoparticles can be stabilized by a large range of stabilizers (ligands, surfactants, polymers, dendrimers, biomolecules) (Sperling and Parak, 2010), the most robust nanoparticles are covered by thiol molecules using the strong gold-S bond between the soft acid Au and the soft thiolate base (Giersig and Mulvaney, 1993). Thus, if a bifunctional thiolated stabilizer or even a mixture of them is used (e.g. thiolatedPEG molecules having carboxylic, amine, azide groups, etc.), then it is possible to stabilize and introduce chemical functionalities in a single step. This allows further attachment of biomolecules in a controlled way by covalent immobilization strategies that we will discuss in the following sections.

\section{MAGNETIC NANOPARTICLES}

Magnetic nanoparticles (MNPs) constitute an important class of nanomaterials widely studied for their potential use in biomedicine fields, such as imaging, cell labeling, hyperthermia and drug and gene delivery (Pankhurst et al., 2003; Barakat, 2009; Berry, 2009). MNPs can be classified as metal, alloys or oxides, and are generally based on elements such as iron, cobalt, nickel, or manganese among others (Pankhurst et al., 2009). From the aforementioned, iron-based NPs are the most studied, since iron is believed to be biocompatible (Hanini et al., 2011). Other elements, such as cobalt or nickel are reported to be more toxic (Fang and Zhang, 2009). Iron oxide NPs (IONPs) are composed of magnetite $\left(\mathrm{Fe}_{3} \mathrm{O}_{4}\right)$ or maghemite $\left(\gamma-\mathrm{Fe}_{2} \mathrm{O}_{3}\right)$, nanocrystallites.

Most of MNPs' applications are a consequence of their magnetic properties, which greatly differ from those of the bulk material. When small enough, MNPs present superparamagnetic behavior at room temperature, meaning that they become magnetized upon exposure to an external magnetic field but lack remnant magnetization once the external field is removed (Jun 
et al., 2008). Consequently, MNPs do not agglomerate in the absence of the magnetic field, which is essential for in vivo applications (Yoo et al., 2011). This characteristic is rather important in applications, such as magnetic hyperthermia. The MNPs' capacity of converting the energy of an alternate magnetic field into heat (Rosensweig, 2002) and the extra sensitiveness of tumor cells to an increase in temperature (van der Zee, 2002) are the two pillars of magnetic hyperthermia in cancer. Since the late 50's, when Gilchrist et al. (1957) first reported the use of MNPs to heat tissue samples, to nowadays, magnetic hyperthermia has evolved considerably and is a key area of interest in cancer therapy with several studies showing the benefit of employing magnetic materials in hyperthermia strategies (Jordan et al., 1993, 2001; Johannsen et al., 2010; Laurent et al., 2011). Several groups have reported noteworthy results in clinical trials where magnetic hyperthermia shows effectiveness in tumor cell destruction with impressive targeting, thus minimizing significantly side effects (Johannsen et al., 2005; Liu et al., 2011; Zhao et al., 2012b).

There are a wide variety of methodologies used for MNP synthesis, including physical or wet chemical approaches. Concerning wet chemical approaches, there are some methodologies, such as coprecipitation (Perez et al., 2002) or reverse micelles precipitation (Liu et al., 2000) that provide directly water soluble MNPs with an organic layer with chemical moieties for narrow size distribution of MNP. However, common synthetic strategies traditionally render MNPs soluble only in organic solvents. Their use in bioapplications imply an additional step where adequate chemical moieties are introduced by several strategies (e.g. use of amphiphilic polymers, silanization, replacing and/or modifying the surfactant layer) in order to allow silanization, their water transference and further biofunctionalization.

\section{OUANTUM DOTS}

Quantum dots (QDs) are nanoparticles composed of semiconductor materials from III-V or II-VI groups of the periodic table, such as $\mathrm{ZnS}, \mathrm{ZnSe}$, CdS, CdSe, CdTe, InP, and others (Donega, 2011). Their reduced size induces a shift of the electronic excitations to higher energy, concentrating the oscillator strength into just a few transitions, conferring unique quantum-confined photonic and electronic properties (Alivisatos, 1996; Alivisatos et al., 2005). Although physically larger than organic dyes and fluorescent proteins, their cumulative optical properties offer great biological utility. With tunable core sizes, it is possible to attain a broad adsorption profile, narrow size, and symmetric photoluminescence spectra depending of the fundamental materials. QDs also show strong resistance to photobleaching and chemical degradation, as well as significant photostability and high quantum yields (Ghanem et al., 2004; Xu et al., 2006; Algar et al., 2011).

Their potential as biological labels was first demonstrated by Nie and Alivisatos groups in 1998, turning the focus into bioapplications of QDs. The method relies on a ligand exchange strategy is based on the replacement of the original hydrophobic ligands adsorbed onto the surface of QDs with biofunctional molecules, such as protein transferrins. These QDs were susceptible to effective receptor-mediated endocytosis in cultured HeLa cells. Since these first demonstrations of QDs potential, their unique properties have been continuously optimized and applied in a plethora of bioapplications, ranging from fluorescent probes, biosensors to therapeutics and theranostic agents (Akerman et al., 2002; Smith et al., 2006; Li et al., 2009; Liu et al., 2010; Ruan et al., 2012; Singh et al., 2012).

Once QDs that show paramount optical properties are those synthesized in organic media, numerous methods have been developed for creating hydrophilic QDs (Medintz et al., 2008). The first approach is commonly designated as "ligand exchange" (Gill et al., 2008), where the hydrophobic layer of the organic solvent may be replaced by biofunctional molecules containing a soft acidic group (i.e., thiol, sodium thiolycolate) and hydrophilic groups (i.e., carboxylic, aminic groups) (Wang et al., 2008). A second approach usually consists in adding a particular shell to the nanoparticles that can be further functionalized with additional biomolecules or polymers (Koole et al., 2008; Zhang et al., 2008).

\section{BIOFUNCTIONALIZATION OF INORGANIC NANOPARTICLES}

Nanoparticles with unique and broad-based optical properties, ease of synthesis and facile surface chemistry and functionalization within appropriate size scale are generating much enthusiasm in biotechnology and biomedicine, with particular emphasis in clinical diagnostics and therapy. However, for the biological application of these NPs, it is necessary their functionalization with one or several biomolecule (Figure 1), such as DNA/RNA, oligonucleotides (i.e., ssDNA/RNA, dsDNA/RNA), peptides and antibodies, fluorescent dyes, polymers (i.e., PEGs), drugs, tumor

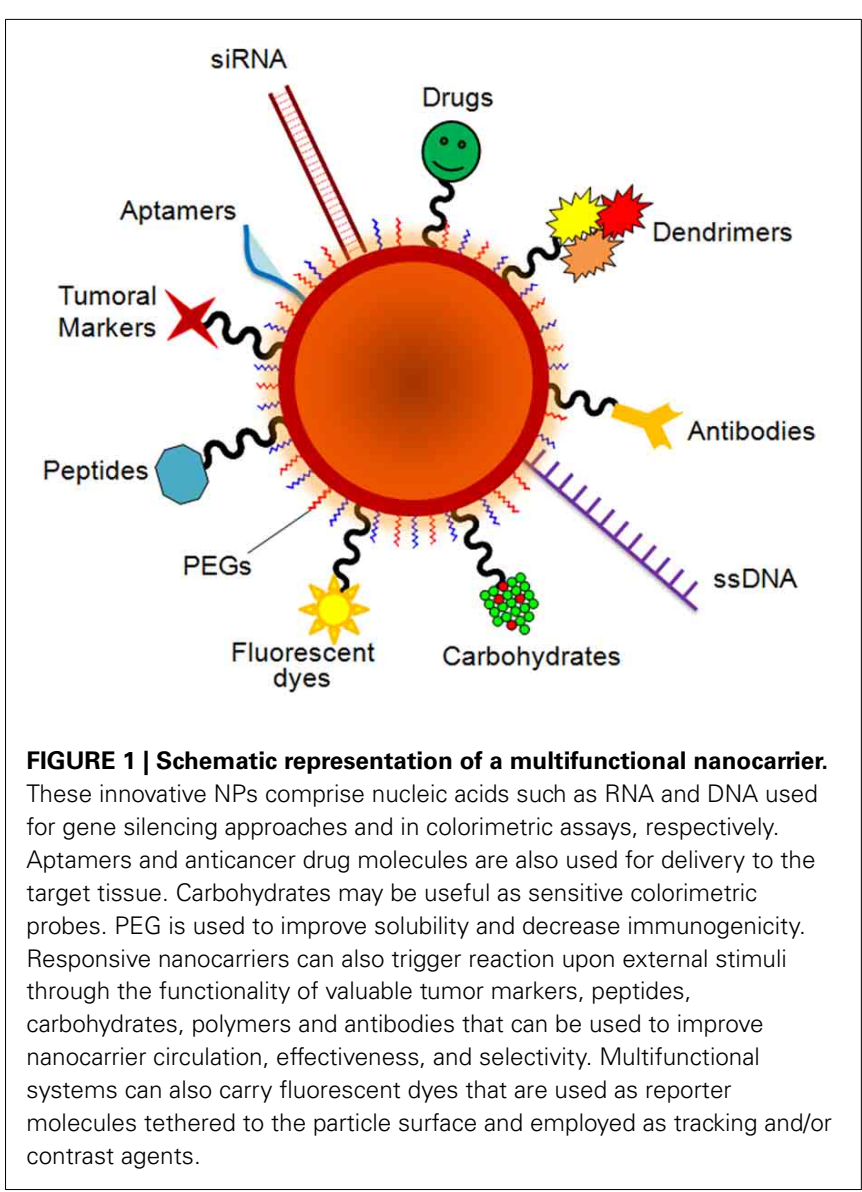


markers, enzymes and other proteins that will introduce the required bio-functionalities.

Ultimately, the conjugation strategy is directly dependent on a numbers of factors such as size, surface chemistry and shape, as well as the type of ligands and functional groups to exploit in the functionalization. Also, the type of biological molecule and the final application of the nanoparticle conjugate are crucial when evaluating the conjugation strategy. Next, we summarize the most frequently used biofunctional molecules used to introduce one or several biological activities to the NP.

\section{COMMON BIOFUNCTIONAL SPECIES}

\section{Polymer coatings-poly(ethylene glycol)}

For their use as potential delivery devices in vivo, the aforementioned inorganic nanoparticles must have long plasma half-lives. In this sense, poly(ethylene glycol) (PEG) is the most widely used macromolecule to prolong nanocarriers half-life. In fact, PEGs have a strong effect on nanoparticle structure, stabilization and biodistribution both in vitro and in vivo (Akerman et al., 2002; Daou et al., 2009; Boeneman et al., 2010; Maldiney et al., 2011). These long-circulating nanoparticles have the ability to circulate for a prolonged period of time and target a particular organ, as carriers of DNA in gene therapy, or to deliver proteins, peptides and drugs (Langer, 2000; Bhadra et al., 2002; Kommareddy et al., 2005; Lee and Kim, 2005).

For systemic applications, the development of surface functionalized and long-circulating NPs as cellular probes and delivery agents is highly desired for passive targeting to tumors and inflammatory sites. PEG-modification of NPs affords long circulating property by evading macrophage-mediated uptake and removal from the systemic circulation. Owing to its simple structure and chemical stability, it is a prototype of an inert and biocompatible polymer (Sperling and Parak, 2010; Verma and Stellacci, 2010). When bound to surfaces, PEG prevents other molecules to bind by steric effects. In fact, the molecules are not attracted by electrostatic forces and cannot penetrate the hydrated PEG layer, producing an inert hydrophilic surface. Moreover, PEG modified nanoparticles are more stable at high salt concentrations and in biological environments, avoiding non-specific binding to proteins and cells (Sperling and Parak, 2010). This is particularly important for in vivo applications because once the NPs are in the bloodstream, a portion of the plasma proteins that can adsorb to the surface (opsonins), may promote NPs recognition by the mononuclear phagocyte system (MPS), and consequently lead to rapid removal of the NPs from circulation (Bertrand and Leroux, 2012). To date, there is a general consensus that to prolong NPs half-life in the organism, PEGs' molecular weight, grafting density and chain architecture must be optimized (Li and Huang, 2010; Grazú et al., 2012). For instance, Xie and coworkers showed that MNPs functionalized with PEG with molecular weights higher than $3000 \mathrm{Da}$ were not taken up by macrophages in vitro, while extensive uptake was observed for PEG 600-coated MNPs (Xie et al., 2007).

Consequently, functionalization of NPs with a high density of PEG of an adequate length not only increases the colloidal stability of the modified NPs but also their plasma half-life. However, to provide PEGylated NPs with targeting and therapeutic activity, as well as with the ability of crossing different biological membranes, they must be conjugated with a variety of biologically relevant ligands, such as cell/tumor penetrating peptides, tumor markers, and therapeutic agents (siRNAs, drugs). Concerning gold NPs, one of the main strategies is to assemble PEG and mixed biomolecule/PEG monolayers on the nanoparticles' surface. Liu et al. showed an escalation in the NPs' stability with increasing PEG length, decreasing nanoparticle diameter, increasing PEG mole fraction and mixed monolayers prepared via the sequential addition of PEG followed by a peptide. In this manner, NPs were more stable than those prepared via simultaneous co-adsorption. These modified NPs were able to target the cytoplasm of HeLa cells, being the cellular uptake quantified using inductively coupled plasma optical emission spectrometry (Liu et al., 2007). Sanz et al. also obtained polyvalent PEGylated AuNPs with a similar strategy. The authors developed an approach to attach specific biomolecules to the AuNPs' surface and their effect in the functionalization with other specific derivatives. The effect of biofunctional spacers, such as thiolated PEG chains and a positive peptide (TAT) in dsRNA loading on AuNPs was reported. The authors hypothesized that the loading of oligonucleotides onto the AuNP surface may be controlled by ionic and weak interactions positioning the entry of the oligonucleotide through the PEG layer, by a synergistic effect of the TAT peptide and PEG chains with specific functional groups, enhancing the dsRNA loading onto AuNPs (see Figure 2) (Sanz et al., 2012).

Another approach to link biomolecules to PEGylated AuNPs is making use of PEG as a spacer. This requires the use of bifunctional PEG chains that contain thiol at one end and a suitable functional moiety at the other (e.g. amino, carboxylate groups). Recently, Oh et al. described a different approach, where in a one-phase synthesis AuNPs were conjugated with PEG ligands yielding a narrow size distribution of highly stable NPs in the presence of high salt concentrations over a wide range of $\mathrm{pHs}$ (Oh et al., 2010b). One way or another, functional moieties of PEG ligands allow for further coupling of target biomolecules. Consequently, surface modification of gold clusters through PEG spacers (Kanaras et al., 2002; Simpson et al., 2011) would allow the modified nanoparticles to remain in the systemic circulation for prolonged periods and provide flexibility for efficient interaction with a target. Besides, using a combination of different bifunctional PEG spacers, gold nano-platforms can be multifunctionalized with a variety of biologically-relevant ligands such as cell penetrating peptides, fluorescent dyes, tumor markers and siRNA (Conde et al., 2012a).

PEGylated QDs have also been successfully produced for effective in vitro and in vivo circulation (Skaff and Emrick, 2003; Hu et al., 2010; Prow et al., 2012; Yang et al., 2012b). Recently, Poulose et al. developed highly biocompatible PEG functionalized in cadmium chalcogenide luminescent QDs (CdS, CdSe, and CdTe) as an imaging tool for early diagnosis of cancer by targeting a cancer cell line (Poulose et al., 2012).

Although PEG is really useful to prolong NPs' blood half-life, it is known that in some cases PEG can hamper cargo release or hide other functional domains once the NP accumulates at the desired target area (Sawant and Torchilin, 2012). Inclusion of 

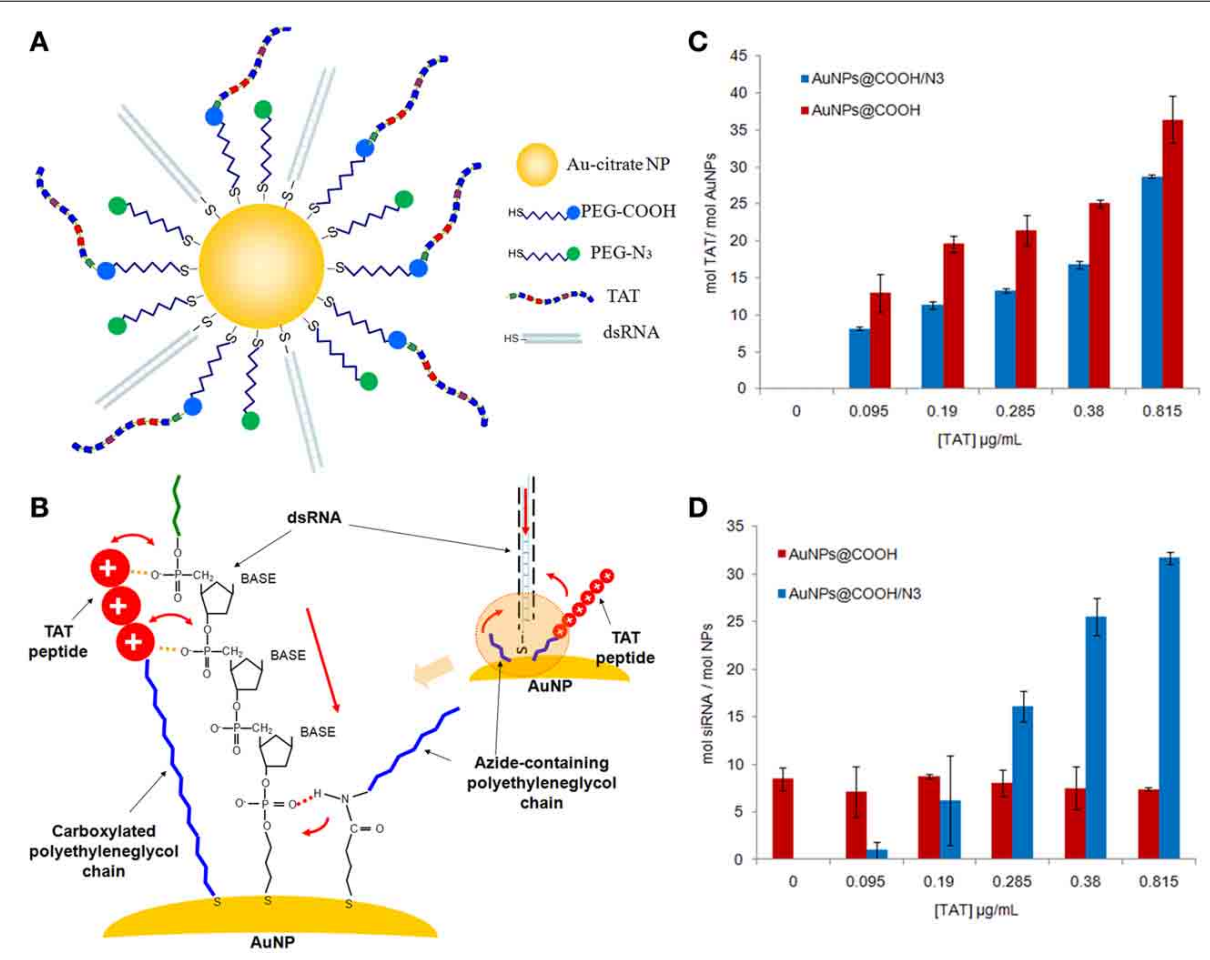

FIGURE 2 | Polyvalent PEGylated gold nanoparticles. (A) Bioconjugation of the surface-modified gold nanoparticles with different thiol-PEG layer composition (SH-EG(7)-CH $-\mathrm{CH}-\mathrm{COH}$ and $\mathrm{SH}-\left(\mathrm{CH}_{2}\right)_{3}-\mathrm{CONH}-\mathrm{EG}(6)-\mathrm{CH}_{2}-\mathrm{N}_{3}$ ), TAT peptide and thiol-dsRNA oligonucleotide. (B) Mechanism for the enhancement of the dsRNA loading on AuNPs functionalized with PEG chains and TAT peptide. The azide group has a resonant structure with a positively polarized behavior that can attach the negatively charged thiolated oligonucleotide to the gold surface. The azide-containing chain also encloses an amide group near the gold surface that could play a role in approaching the thiol group of the oligonucleotide to the gold surface. This amide group could form a hydrogen bond with one of the hydroxyl groups of the ribose group near the thiol group on the oligonucleotide. (C) Determination of the number of TAT chains bound to AuNPs by the EDC reaction as a function of the initial peptide concentration in the reaction mixture. Blue bars AuNP@COOH/N $/ \mathrm{N}_{3}$ and red bars AuNP@COOH. (D) Loading of thiolated oligonucleotide (HS-dsRNA) on AuNPs functionalized with TAT peptide and with both PEG-azide and PEG-COOH and only with PEG-COOH. Blue bars AuNP@COOH/N $\mathrm{N}_{3}$ and red bars AuNP@COOH (Sanz et al., 2012). Reproduced with permission from Sanz et al. (2012), Copyright 2013. stimulus-sensitive detachable PEG is a possible solution to overcome these drawbacks, so that cargoes can be released or other ligands unveiled in response to microenvironmental conditions. For instance, Harris et al. functionalized MNPs with a PEG tethered by an MMP-2 cleavable substrate (Harris et al., 2008), being MMP-2 a protease upregulated in angiogenesis and metastasis. Once NPs reached the tumor, the polymer was cleaved, unveiling the cell penetrating peptide, resulting in increased uptake by cells when compared to non-cleavable PEG.

\section{Fluorescent dyes}

Several studies report on the modulation of fluorophores at the vicinity of nanoparticles (Kang et al., 2011; Rosa et al., 2011), which has found application in a variety of systems to detect biologically relevant targets.

Several methods based on the quenching of fluorescence have been proposed for DNA detection consisting of fluorophorelabeled ssDNA electrostatically adsorbed onto AuNPs (Ray et al., 2006), where the presence of a complementary target triggers desorption of the newly formed dsDNA from the nanostructures due to the electrostatic variation between ssDNA and $\mathrm{dsDNA}$, and fluorescence emission is restored. Also, fluorescence quenching of fluorophores close to gold nanocarriers functionalized with thiol-modified oligonucleotides has been explored in different conformations (Wu et al., 2006; Tang et al., 2008). Tang et al. proposed a method to probe hydroxyl radicals using an AuNP-oligonucleotide-FAM system where the hydroxyl radical promotes strand breakage and consequent release of FAM, restoring the previously quenched fluorescence (see Figure 3) (Tang et al., 2008). The same quenching mechanism was used to detect specific DNA strands using two probes (one with an AuNP label and another labeled with TAMRA) that hybridize to two DNA sequences near each other (Wu et al., 2006), bringing the fluorophore and AuNP close enough to quench fluorescence emission.

Proteins have also been probed through nanoparticle fluorescence-mediated systems, especially for protein detection via quenching, through the interaction with fluorescent AuNPs (Mayilo et al., 2009; He et al., 2010; Lacerda et al., 2010). Due to their efficient proximity-dependent fluorescence quenching they can be used per se or as part of more elaborate conjugates (i.e., with QDs) (Pons et al., 2007). One example is the work of De et al. where the interaction between AuNPs and the green fluorescent protein (GFP) was employed to detect proteins in 



FIGURE 3 | Fluorescent-AuNPs. (A) Chemical structure of a FAM-DNA-AuNP and schematic illustration of its FRET-based operating principles. (B-E) Confocal fluorescence and phase-contrast images of living cells. (B) Fluorescence image of macrophages incubated with the probe for $30 \mathrm{~min}$ at $37^{\circ} \mathrm{C}$. (C) Fluorescence image of probe-stained macrophages stimulated with PMA for $1 \mathrm{~h}$ at $37^{\circ} \mathrm{C}$. (D) Bright field image of live macrophages shown in (C), confirming their viability. (E) AO staining of probe-loaded macrophages, confirming their viability (Tang et al., 2008). Reproduced with permission from Tang et al. (2008), Copyright 2013. biological matrices, such as serum (De et al., 2009). By correlating the variation in fluorescence intensity with specific proteins of interest, they were able to identify proteins such as fibrinogen, human serum albumin and immunoglobin G, among others with over $97 \%$ accuracy.

In essence, fluorescent-nanoparticle systems can be used for sensing by exploring a typical FRET in order to provide efficient in vivo detection and tumor targeting. These nanocarriers symbolize an important class of materials with unique features suitable for biomedical imaging applications such as increased sensitivity in detection, high quantum yields for fluorescence and a bounty of novel applications in optics and nanophotonics for molecular diagnostics (Conde et al., 2012d).

QDs are often used as fluorescent molecules per se, since they are semiconductor nanoparticles with narrow, tunable, symmetrical emission spectra and high quantum yields (Weller, 1993; Bruchez et al., 1998). These characteristics were evidenced by $\mathrm{Wu}$ et al. using QDs modified with different cellular antigens enabling the simultaneous detection of two different targets in the same cell (Wu et al., 2003). It was also shown their higher brightness and photobleaching resistance when compared to organic dyes. These properties make QDs exceptional substitutes as fluorescence labels (Xing et al., 2006; Smith et al., 2010; Smith and Nie, 2012).

The inclusion of dyes onto MNPs allows the creation of multifunctional NPs, which might be used for MRI and optical imaging. These dual MNPs allow for multimodal imaging, which implies that the limitations of one imaging modality could be compensated by the other, creating a complementary effect (Louie, 2010). For instance, Medarova and co-workers reported the synthesis of a multifunctional MNP that included nearinfrared optical imaging dye, peptides for membrane translocation and synthetic siRNA targeting a specific gene (Medarova et al., 2007). In vivo accumulation of the MNPs was assessed by MRI and optical imaging and the silencing efficiency was also probed by in vivo optical imaging.

\section{Nucleic acids}

Watson and Crick first described DNA as two helical chains each coiled around the same axis, consisting of simple and repeating units called nucleotides with backbones made of sugars and phosphate groups joined by ester bonds that run in opposite directions to each other. The importance of this molecule within living cells is undisputable (Watson and Crick, 1953). Besides their biological function, nucleic acids can be employed as polymeric molecules which will bind specifically to targets thanks to Watson-Crick base pairing (Fichou and Ferec, 2006).

Mirkin et al. (1996) described the use of a cross-linking method that relies on the detection of single-stranded oligonucleotide targets using two different gold nanoprobes, each of them functionalized with a DNA-oligonucleotide complementary to one half of the given target. This functionalization was achieved using the strong affinity of thiol or disulfide groups to the gold surface of the NPs, forming quasi-covalent bonds. By modifying a nucleic acid molecule with a thiol group in either the $5^{\prime}$ or the $3^{\prime}$ end it is possible to fine-tune the DNA assembly into the gold surface (Hurst et al., 2006), controlling variables such as salt concentration, oligo/NP ratio or nanoparticle size. This phenomenon indicates the potential of AuNPs modified with DNAs to be applied in biosensing or as DNA probes for diagnosis (Cao et al., 2005). These assays became an important mark in detection once they have PCR-like sensitivity, selectivity for target sequences, capacity for massive multiplexing, and most importantly, have the ability to be performed at the point of care.

Using a fluorescence-based method, Demers et al., have determined the number of thiol-derivatized single-stranded oligonucleotides bound to AuNPs and their extent of hybridization with complementary oligonucleotides in solution (Demers et al., 2000). Also, using a fluorescence method, Conde et al. reported the potential of a single molecular nanoconjugate to intersect all RNA pathways: from gene specific downregulation to silencing the silencers, i.e., siRNA and miRNA pathways, by using gold nanobeacons (Figure 4). These nanoconjugates functionalized 

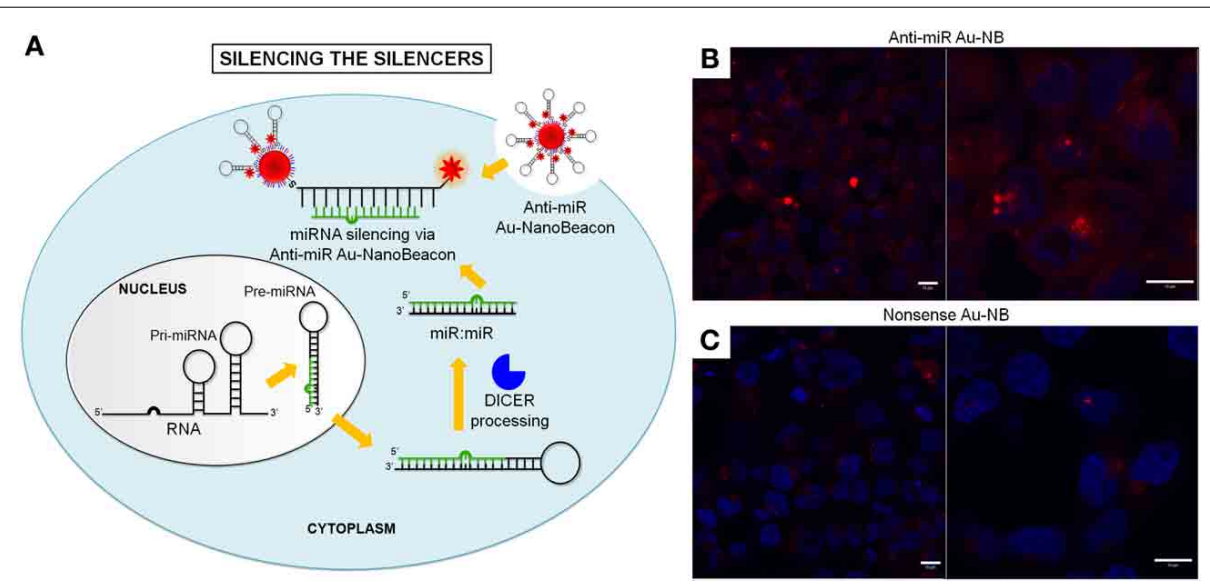

FIGURE 4 | Silencing the Silencers with hairpin-DNA-AuNPs-Gold nanobeacons. (A) Specific Au-nanobeacons are capable of intersecting miRNA pathway, leading to recovery of previously downregulated gene expression while simultaneously discriminating cells where silencing is occurring. The fluorescence signal may allow for tracking cell internalization and sub-cellular localization. The Au-nanobeacons' potential for anti-cancer therapeutics via the silencing of the silencers is demonstrated by blocking the endogenous microRNA pathway via an Anti-miR Au-nanobeacon complementary to the mature microRNA-21 (miR-21), commonly upregulated in cancer phenotypes. (B,C) Au-nanobeacons silencing of endogenous silencers-silencing of miR-21. Confocal imaging (scale bar, $10 \mu \mathrm{m}$ ) shows internalization of $50 \mathrm{nM}$ (B) Anti-miR Au-nanobeacon $50 \mathrm{nM}$ and (C) Nonsense Au-nanobeacon. Target (mature miR-21) recognition leads to change of Anti-miR Au-nanobeacon conformation in the cytoplasm with concomitant fluorescence signal (red, Cy3) encircling the cell nuclei (blue, DAPI) (Conde et al., 2013b). Reproduced with permission from Conde et al. (2013b), Copyright 2013. with a fluorophore labeled hairpin-DNA are capable of efficiently silencing single gene expression, exogenous siRNA and an endogenous miRNA while yielding a quantifiable fluorescence signal directly proportional to the level of silencing. Inhibition of gene expression was achieved with concomitant increase of the gold nanobeacons' fluorescence that can be used to assess the silencing effect (Rosa et al., 2012; Conde et al., 2013a,b, 2014b).

Moreover, AuNPs functionalized with ssDNA are also capable of specifically hybridizing to a complementary target for the detection of a particular nucleic acid sequence in biological samples (Sato et al., 2003; Storhoff et al., 2004; Baptista et al., 2005; Thaxton et al., 2006). The impact of advances in these nanoparticle-based assays for specific detection of bioanalytes of clinical interest is particularly relevant in biodiagnostics, making them ideal candidates for developing biomarker platforms.

However, nucleic acid molecules are also capable of establishing ionic interaction in gold surface. It has been shown that both thiol-ssDNA and dsDNA stabilize gold nanoparticle dispersions, but possible non-specific interactions between the hydrophobic DNA bases and the gold surface promote interparticle interactions and cause aggregation within a short period of time (Cardenas et al., 2006). The charge repulsion among DNA strands and between DNA and AuNPs can be reduced by adding salt, reducing $\mathrm{pH}$ or by using non-charged peptide nucleic acid (PNA) (Zhang et al., 2012b).

Moreover, Conde et al. reported the design of two approaches (see Figure 5) for the binding of siRNA molecules to multifunctional AuNPs: (Figure 5A) the binding of the negatively charged siRNA through ionic interactions to the modified gold surface (ionic approach) and (Figure 5B) the use of thiolated siRNA for the binding to the nanoparticle through the strong interaction gold-thiol (covalent approach) (Conde et al., 2012a). The covalent approach was evaluated in a lung cancer mouse model to evaluate the inflammatory response and therapeutic siRNA silencing via RGD-nanoparticles. This study reported the use of siRNA/RGD gold nanoparticles capable of targeting tumor cells in two lung cancer xenograft mouse models, resulting in successful and significant $c-M y c$ oncogene downregulation followed by tumor growth inhibition and prolonged survival of the animals (Conde et al., 2013c).

Modulation of the physicochemical properties of the gold nanocarriers can be easily achieved by adequate synthetic strategies and give AuNPs advantages over conventional detection methods currently used in clinical diagnostics and therapy. Simple and inexpensive methods based on these bio-nanoprobes were initially applied for detection of specific DNA sequences and are currently being expanded to clinical diagnosis (Baptista et al., 2008).

QDs have also been functionalized with nucleic acids and extensively used as DNA sensors (Crut et al., 2005; Dubertret, 2005; Zhang et al., 2005a; Choi et al., 2009; Ye et al., 2009; Zhang and $\mathrm{Hu}, 2010$ ). For in vitro test of target DNA, QDs based FRET pairs turned out to be of great use. The method developed by Zhang et al. using QDs-Cy5-labeled reporter oligonucleotide conjugates, capable of detecting low concentrations of DNA in a separation-free format. This system uses QDs linked to DNA probes to capture DNA targets and successfully detect a point mutation (Zhang et al., 2005a).

Owing to their unique optical properties, QDs have also been applied for multiplex detection of analytes with singlemolecule detection. Zhang et al. reported the use of a single QD-based nanosensor for multiplex detection of HIV-1 and HIV2 at single-molecule level in a homogeneous format (Zhang and $\mathrm{Hu}, 2010)$. These QD-based nanosensors have several advantages such as extremely low sample consumption, high sensitivity, short analysis time and have the potential to be applied for rapid 




point-of-care testing, gene expression studies, high-throughput screening, and clinical diagnostics.

When modified with DNA, QDs were successfully employed in the detection of respective complementary DNA strands via FRET. Sub-nanomolar detection limits have been reported (Zhou et al., 2008a; Singh and Strouse, 2010). The strategy success is directly related to the covalent coupling of the nucleic acid molecule to the $\mathrm{QD}$, controlling the donor-acceptor distance, fundamental in FRET-based biosensors.

QDs can also be used in gene delivery. Jin-Ming Li et al. developed a series of QDs functionalized with $\beta$-cyclodextrin coupled to amino acids. Using the $\beta$-cyclodextrin as a vector for delivering doxorubicin (DOX) and electrostatically binding MDR1 siRNA, this strategy allowed for simultaneous chemotherapy and gene silencing. The authors observed that in HeLa cells it was possible to induce apoptosis due to the intracellular accumulation of Dox and also reduced levels of MDR1 gene expression. These multifunctional QDs are promising vehicles for the co-delivery of nucleic acids and chemotherapeutics, as well as for real-time tracking of treatment (Li et al., 2012).
QDs-siRNA conjugates have also been used for imaging and gene silencing approaches (Derfus et al., 2007; Tan et al., 2007; Yezhelyev et al., 2008; Zhao et al., 2010; Li et al., 2011, 2012). For example, Yezhelyev et al. developed multifunctional nanoparticles for siRNA delivery and imaging based on the use of QDs and proton-absorbing polymeric coatings (proton sponges). The authors demonstrated a dramatic improvement in gene silencing efficiency and simultaneous reduction in cellular toxicity, when compared with existing transfection agents. Additionally, QD-siRNA nanoparticles are also dual-modality optical and electron-microscopy probes, allowing real-time tracking and ultrastructural localization of QDs during delivery and transfection (Yezhelyev et al., 2008).

MNPs have also been frequently used as platforms for the delivery of DNA or siRNA, as they can be used to track their biodistribution by MRI. For instance, Kumar et al. synthesized multifunctional MNPs by attaching a near-infrared optical dye Cy5.5 and a peptide that targets the tumor specific antigen mucin1 to cross-linked dextran coated SPIONs (Kumar et al., 2010). The delivery of the nanosystem to tumors in mice was imaged either in vivo or ex vivo by MRI and optical imaging.

On the other hand, the functionalization of plasmid DNA and siRNA to MNPs has been widely reported, as MNPs are used as tools for magnetofection, that is to say, the enhanced delivery of nucleic acids associated to MNPs using external magnetic fields (Scherer et al., 2002; Dobson, 2006; Plank et al., 2011). Using magnetofection the transfection efficiency can be highly improved when compared with transfections carried out with non-magnetic gene delivery systems in a variety of primary cells and cell lines (Mykhaylyk et al., 2007; Prijic and Sersa, 2011). Although magnetofection results are promising in vitro, and several studies have reported the systemic delivery of nucleic acids using MNPs in vivo, not many of them use an external magnetic field to enhance the accumulation of the MNPs in the targeted area (Plank et al., 2011). Thus far, the most promising application of magnetofection as an in vivo cancer therapy has been reported by Namiki et al. (2009). The authors formulated oleic acid-coated MNPs assembled with cationic lipid shells, and functionalized them with an appropriate siRNA sequence to knock down the epidermal growth factor receptor (EGFR) mRNA, as it is overexpressed in tumor blood vessel endothelium. After systemically injecting the complex to mice tumors, the authors found a 50\% reduction in tumor mass when a magnetic field was applied compared to the control group without magnetic field.

\section{Peptides}

Peptides are short chains of amino acid monomers linked by amide bonds and are distinguished from proteins on the basis of size, once they only contain $\sim 50$ amino acids or less. Peptides can be found naturally or synthetically and have the potential for the stabilization and biofunctionalization of NPs. For instance Wang et al. demonstrate that multiple functional peptide stabilized AuNPs are readily obtained in a one-step surface coating procedure and that the surface functionalities can be selectively addressed on a microarray. The authors developed a straightforward route to stable AuNPs, both with single and with dual biological functionality. The particles exhibit the specific recognition 
properties of the biological cargo without any indication of nonspecific binding or particle aggregation (Wang et al., 2005).

The stability conferred by peptide ligands usually depends on their length, hydrophobicity, and charge and in some cases resulted in further improved stability. Actually, Levy et al. designed a pentapeptide ligand, CALNN, which converts citrate stabilized AuNPs into extremely stable, water-soluble AuNPs with some chemical properties analogous to those of proteins. These peptide-capped AuNPs can be freeze-dried and stored as powders that can be subsequently redissolved to yield stable aqueous dispersions (Levy et al., 2004).

Biofunctional peptide sequences include "membrane translocation signals" like the HIV-TAT peptide sequence (de la Fuente and Berry, 2005; Berry et al., 2007; Conde et al., 2012a), which is capable of transporting nanoscale materials across cellular membranes and "nuclear locating signals" that could be used for further intracellular targeting (Nativo et al., 2008; Chithrani, 2010). In fact, de la Fuente et al. developed AuNPs functionalized with HIV-Tat peptide used to achieve cytoplasm and the cell nucleus. One of the major drawbacks of these cell penetrating peptides is that they are not cell specific and that they can remain entrapped in endosomes (Gump and Dowdy, 2007). To overcome these limitations, fusogenic peptides that are able to escape from endosomes or homing peptides capable of reaching specific tissues or cells have been developed ( $\mathrm{Li}$ et al., 2004; Ruoslahti et al., 2010).

QDs labeled with these types of peptides have been extensively prepared using various strategies (Chen and Gerion, 2004; Cai and Chen, 2008; Curnis et al., 2008). For example, Akerman et al. show that ZnS-capped CdSe QDs coated with a lung-targeting peptide accumulate in the lungs of mice after intravenous injection, whereas two other peptides specifically direct QDs to blood or lymphatic vessels in tumors (Akerman et al., 2002). Curnis et al. also found that a cyclic Ciso DGRC peptide coupled to QDs could bind alphavbeta 3 integrin and co-localize with several antibodies in human renal cell carcinoma tissue sections, indicating that this peptide could efficiently recognize endothelial cells of angiogenic vessels (Curnis et al., 2008). Cai et al. also used a thiolated arginine-glycine-aspartic acid (RGD) peptide to conjugate to the QDs and applied the QDs peptide bioconjugates for tumor vasculature targeted imaging (Cai and Chen, 2008). However, if crossing the vascular wall is needed, these RGD peptides need to be improved. The Ruoshlati group reported a cyclic peptide iRGD that can combine the tumor-homing RGD sequence with a tissue penetration motif (Sugahara et al., 2009). Therefore, the homing sequence directs the peptide to the tumor vascular endothelium, while the tissue penetration motif, once activated by a protease, binds to a different receptor (neuropilin-1), which mediates extravasation and tissue penetration. As a proof of concept, iRGD peptide-linked iron oxide nanoworms could be detected by MRI throughout a tumor once injected in vivo to mice. Recently, the same group combined two different peptides with the magnetic nanoworms to image and treat mice with glioblastoma, one of the most difficult tumors to treat (Agemy et al., 2011). While the CGKRG peptide targets the NPs to tumor vascular cells and into their mitochondria, the other peptide acts as a pro-apoptotic drug. By co-injecting these NPs with iRGD, most of the tumors were eradicated or their development delayed in two glioblastoma mouse models.

Despite the extraordinary rapid development in strategies for nanoparticle conjugation with peptides, relatively little is known about NP behavior in the immune system, which is responsible for maintaining body integrity and preventing external invasion. Bastus et al. described the interaction between murine bone marrow macrophages and gold nanoparticle peptide conjugates. In the presence of conjugates, macrophage proliferation was stopped and pro-inflammatory cytokines were induced. Furthermore, macrophage activation by AuNPs conjugated to different peptides appeared to be rather independent of peptide length and polarity, but dependent on peptide pattern at the nanoparticle surface (Bastus et al., 2009).

\section{Proteins/antibodies}

In Bionanotechnology, specific functions of proteins such as antibody-antigen detection may also be very useful. Antibodies (Abs) or immunoglobulins are a group of proteins that have a very similar structure with four chains assembled in a $\mathrm{Y}$ shaped form, containing two identical domains for antigen recognition (Fab fragment), and two identical domains with effector functions (Fc fragment). The main advantage of Abs or their fragments is that the antigen-binding region is highly specific and different among Abs (Arruebo et al., 2009). Therefore, different specificity can be obtained using distinct Abs. However, attachment of Abs to the surface of NPs can impair this function if the antigen binding sites are sterically blocked upon conjugation. For this reason, the Abs orientation is extremely important to produce effective and bioactive antibody-nanoparticles.

In fact, de la Fuente et al. recently demonstrated that the combination of a good $\mathrm{Ab}$ orientation along with the property of a gold nanoprism to generate heat when illuminated with the correct wavelength enable visual detection of carcinoembryonic antigen (CEA) by plasmonic-driven thermal sensing with sensitivities up to the attomolar range in serum samples (Polo et al., 2013).

Immunoassays use the specificity and sensitivity of the antibody-antigen interaction in order to detect and quantify the amount of a specific analyte present in a sample. Effective conjugated antibodies can be used to constitute the desired functionality of the nanocarrier itself for immunoassays (Han et al., 2003). Actually, Putman et al. described the use of immunogold labels as cell-surface markers of human lymphocytes in atomic force microscopy. The AFM images reveal the colloidal gold particles on the cell surface, with and without silver enhancement. Individual immunogold particles are clearly resolved from the cell surface thus determining the location of antigens (Putman et al., 1993).

$\mathrm{Ni}$ et al. described an immunoassay readout method based on surface enhanced Raman scattering (SERS). The method exploits the SERS-derived signal from reporter molecules that are co-immobilized with biospecific species on gold colloids. This concept is demonstrated in a dual analyte sandwich assay, in which two different antibodies covalently bound to a solid substrate specifically capture two different antigens from an aqueous sample. The captured antigens in turn bind selectively to their corresponding detection antibodies. The detection antibodies are conjugated with gold colloids that are labeled with different 
Raman reporter molecules, which serve as extrinsic labels for each type of antibody (Ni et al., 1999).

More recently, Conde et al. developed a highly sensitive probe for in vivo tumor recognition with the capacity to target specific cancer biomarkers such as EGFR on human cancer cells and xenograft tumor models. The authors used $\sim 90 \mathrm{~nm}$ AuNPs capped by a Raman reporter, encapsulated and entrapped by larger polymers and a Food and drug Administration (FDA) antibody-drug conjugate-Cetuximab (Erbitux $\left.{ }^{\circledR}\right)$. These smart SERS gold nanoantennas present a high Raman signal both in cancer cells and in mice bearing xenograft tumors and the Raman detection signal is accomplished simultaneously by extensive tumor growth inhibition in mice. This approach seems to be an innovative and efficient theranostics system for both tumor detection and tumor cell inhibition at the same time (Conde et al., 2014a).

QD-Antibody conjugates have also been widely used for preparing bioconjugated QDs for in vitro bioassay applications (Goldman et al., 2002; Hua et al., 2006; Tan et al., 2007; East et al., 2011). In fact, Goldman et al. described the preparation and characterization of bioinorganic conjugates made with highly luminescent semiconductor CdSe-ZnS core-shell QDs and antibodies for use in fluoroimmunoassays. QD-antibody conjugates were successfully used in fluoroimmunoassays for detection of a protein toxin (staphylococcal enterotoxin B) and a small molecule (2,4,6-trinitrotoluene) (Goldman et al., 2002).

Concerning magnetic NPs, bioseparation is one of the main applications of MNP-Ab conjugates. In fact, magnetic separation of red blood cells using magnetic microspheres was reported as early as 1977 (Molday et al., 1977). MNPs are used to purify and concentrate different types of analytes in complex samples, such as hormones in biological samples, antibiotics or bacteria in food (Kuo et al., 2012; Svobodova et al., 2012; Xu et al., 2012). One of the best known systems that employ MNPs for separation and concentration is the bio-bar code technology originally described by Nam et al. (2003). In this case, Abs specific for a target protein are functionalized on the surface of MNPs, by sandwiching the target between these MNPs and an amplifier AuNPs that is loaded with a secondary $\mathrm{Ab}$ and oligonucleotides. When the specific target is sandwiched between the MNP and the AuNP, magnetic separation of the complexed probes allows for the concentration of the target within the sample. Afterwards, the oligonucleotides are released and detected, giving rise to a substantial amplification of the signal, and therefore lowering the detection limit to attomolar concentrations (Goluch et al., 2006). In fact, the first point-of-care nano-enabled medical diagnostic tool approved by the FDA, known as Verigene System and commercialized by Nanosphere Inc., is based on this biosensing strategy.

MNPs conjugated with Abs are also useful for the development of a new class of diagnostics nanosensors, called magnetic relaxation switches (MRS). MRS have the potential to provide sensitive and selective detection of a variety of molecular interactions with minimal or no sample preparation (Perez et al., 2002). These assays exploit the fact that when MNPs recognize and bind biological targets, they cluster, changing the spin-spin relaxation times of water protons (T2). These changes in T2 between dispersed and aggregated states of the MNPs can be monitored by nuclear magnetic resonance (NMR) (Min et al., 2012). One of the greatest advantages of these biosensors is that they employ radiofrequency radiation which penetrates biological samples regardless of their optical properties, and therefore can be used in complex samples such as blood. Using this technology, Lee et al. reported the first micro NMR biosensor, where tumor cells could be detected employing MNPs functionalized with Abs on microliter sample volumes and in multiplexed format (Lee et al., 2008). Since then, the sensitivity of these biosensors has been greatly improved using other highly magnetic MNPs (Lee et al., 2009), so that molecular profiling of cancer cells obtained by fine-needle aspirates biopsies within $60 \mathrm{~min}$ is possible nowadays. Using different markers, the authors reported $96 \%$ accuracy for establishing a cancer diagnosis (Haun et al., 2011).

Other proteins have also been successfully conjugated with NPs (Mattoussi et al., 2000; So et al., 2006a,b; Xia et al., 2008; Roullier et al., 2009). Mattoussi et al. first described the electrostatic interactions between negatively charged lipoic acid capped QDs and a positively charged recombinant protein (Mattoussi et al., 2000). Prasuhn et al. also developed a QD protein FRETbased biosensors used as caspase 3 proteolytic and $\mathrm{Ca}^{2+}$ sensors (see Figure 6) (Prasuhn et al., 2010).

Similar to nucleic acids, proteins are known for their specific binding interactions and can act together with a wide range of substrates and synthetic analogs. Consequently, high molecular weight peptide ligands show potential for wide biological applications and for stabilization and biofunctionalization of nanocarriers.

\section{Enzymes}

Enzymes, as highly specialized protein catalysts, are commonly used in biofunctionalization due to their potential in biotechnology and biomedicine, because of the convenience in handling, ease of separation from the reaction mixture and reuse, as well as low product cost. The immobilization in NPs often reduces diffusion limitations and/or enhances the catalytic activity of the enzymes.

An important focus of the research on AuNPs based biosensors is in enzyme electrodes. One recurrent example is glucose biosensors. Zhang et al. (2005b) described the assembly of a gold electrode modified via Au-S bond with AuNPs, where a cystamine monolayer is chemisorbed, thus exposing an array of amino groups. These are further reacted with aldehyde groups of periodate oxidized glucose oxidase via Scchiff base reaction. In this study, the NPs showed to act as conduction intermediates facilitating electron transfer, with little effect on enzyme activity. It was also shown that the sensitivity was improved as well as the affinity for glucose, hence lowering the detection limits.

In another study, MNPs were modified with Nphosphonomethyl iminodiacetic acid for immobilization of urease. Thus, the surface coating was conferred with carboxyl groups to which urease had been immobilized through carbodiimide reaction (Sahoo et al., 2011). The advantage of using MNPs is the possibility of product isolation by a permanent magnet, thus reducing costs. The authors also reported that the thermal stability of the urease was increased, showing that MNPs may be a promising material for storage and enzyme immobilization. 

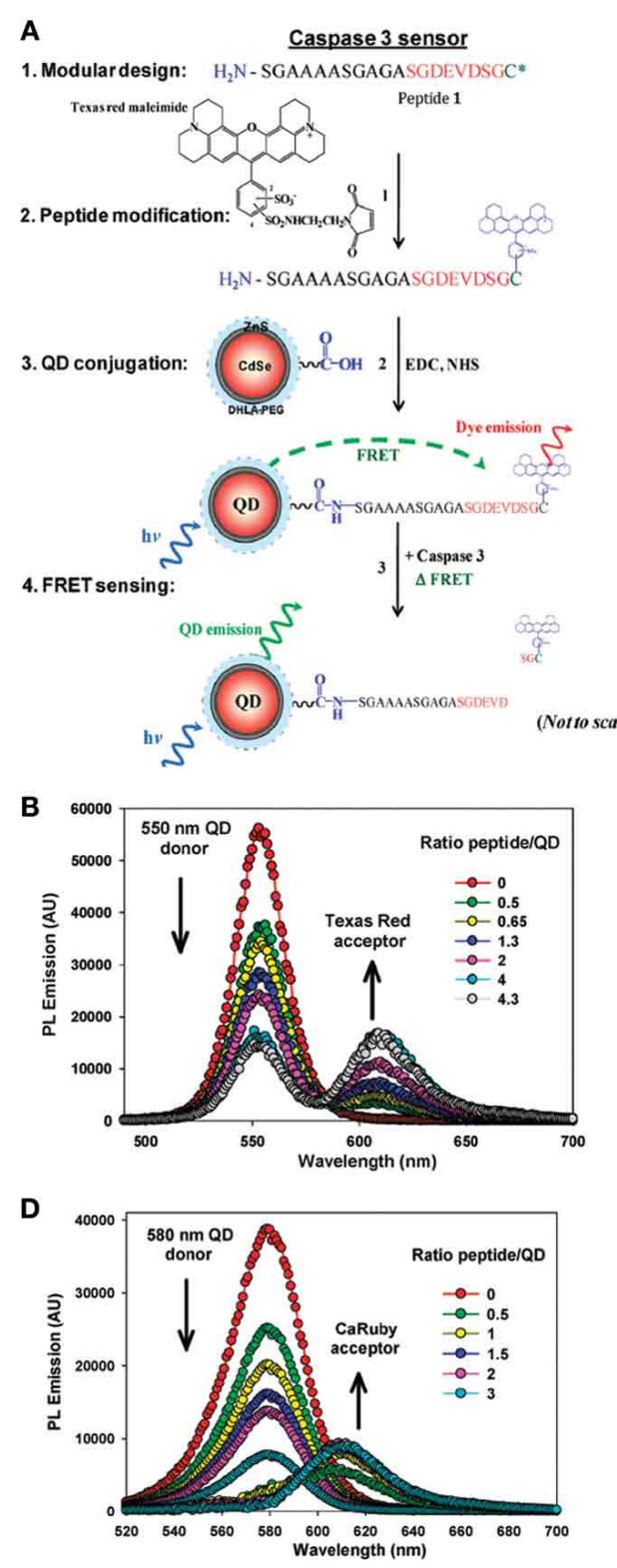

FIGURE 6 | Quantum dot protein biosensors. (A) Schematic showing the common design, chemical and sensing elements, including FRET-based biosensors: (1) peptide modularity, (2) peptide labeling, (3) attachment to QDs, and (4) FRET-based sensing for both the caspase 3 proteolytic sensor (left) and $\mathrm{Ca}^{2+}$ sensor (right). The 4-pendant carboxyl groups that interact with $\mathrm{Ca}^{2+}$ ions are shown in red on the $\mathrm{CaRbCl}$ structure. Within the $\mathrm{Ca}^{2+}$ sensor peptide sequence, Aib is the synthetic amino acid $\alpha$-aminoisobutyric acid. Reactive dye structures are shown where appropriate along with the chemical linkages attaching them to the peptides. (B) Representative, superimposed spectra collected from $550 \mathrm{~nm}$ emitting QD donors surface functionalized with 85:15 DHLAPEG600-COOH/DHLA-PEG750-OMe ligands and covalently conjugated to increasing molar ratios of Texas Red-labeled substrate peptide.



C


Samples excited at $350 \mathrm{~nm}$. (C) Proteolytic assay data from exposing a constant concentration of $550 \mathrm{~nm}$ emitting QDs conjugated to 4 Texas Red substrate peptides to a constant concentration of caspase 3 enzyme. Derived $\mathrm{Km}$ and $\mathrm{Vmax}$ values are given. An $\mathrm{R}^{2}=0.98$ was obtained for the fitting of the curve. (D) Representative, superimposed, and deconvoluted spectra collected from $580 \mathrm{~nm}$ emitting QD donors self-assembled with increasing $\mathrm{CaRbCl}$-acceptor labeled peptides. Samples were excited at $350 \mathrm{~nm}$.

(E) Normalized acceptor/donor PL area ratios for $580 \mathrm{~nm}$ QDs self-assembled with $\sim 2 \mathrm{CaRbCl}$-acceptor labeled peptides exposed to selected ionic materials. The ratio from the native unexposed sensor was set to an initial value of 1 for comparison purposes (Prasuhn et al., 2010). Reproduced with permission from Prasuhn et al. (2010), Copyright 2013.
When using enzyme-based biosensors the main concern is reusability of the enzyme. Khoshnevisan et al. reported the use of MNPs to circumvent this dilemma when using cellulase. The enzyme was incubated with the MNPs and binding confirmed by
FT-IR. The authors show that immobilization grants higher stability to the enzyme, thus confirming that the use of MNPs in this type of biosensors can be of great benefit (Khoshnevisan et al., 2011). 
Imaging QDs in vivo is arduous due to the need of an external source of light, which produces strong background autofluorescence from ubiquitous endogenous chromophores. So et al. proposed the ideal QD, where it would emit light with no requirement for external excitation (So et al., 2006b). By modifying QDs with Renilla reniformis luciferase the authors discard the need of external excitation due to the phenomenon of bioluminescence resonance energy transfer (BRET). BRET occurs naturally and it is analogous to FRET, but the donor energy comes from a chemical reaction catalyzed by the donor enzyme. The polymer coated CdSe/ZnS core-shell QDs dotted with carboxylate groups were incubated with $R$. reniformis luciferase, where through carbodiimide reaction the amino groups of the enzyme were coupled to the carboxylates. Thus, with a simple modification the authors were able to mimic the natural BRET system with self-illuminating QDs (So et al., 2006b).

\section{Carbohydrates}

Carbohydrates are, together with nucleic acids and proteins, important molecules for life. Much is already known about the structure, interactions and function of nucleic acids and proteins, however, the role of carbohydrates in the cell is less clear (de la Fuente and Penades, 2006). A characteristic feature of the biological interactions where carbohydrates are involved is their extreme low affinity that has to be compensated by multivalent presentation of the ligands. Although individual carbohydrate interactions are relatively weak, nature utilized multivalent interactions between the cell surface ligands and their biological receptors to modulate biological events such as the ones related to cell adhesion, normal tissue growth and repair, viral/bacterial infection, signaling transduction, trapping of leucocytes, and cancer transfer. So the decoding of carbohydrate interactions opens up the possibility to employ nanoparticles in diagnostics and/or therapy (Dong, 2011). In fact, the unique physical, chemical and optical properties of the nanocarriers with carbohydrate coating comprise a series of advantages that range from ensuring water solubility, biocompatibility and stability to targeting properties (Garcia et al., 2010).

Among them, gold glyconanoparticles (glycoNPs) have drawn attention owing to their well-defined features, such as watersoluble carbohydrate-functionalized nanoclusters with a promising potential for chemical glycobiology, biomedicine, diagnostics and clinical applications. In the last 10 years, Penades and coworkers have extensively reported a pioneer integration of a glyconanotechnology strategy based on the use of nanoparticles to study and evaluate carbohydrate-carbohydrate, carbohydrateprotein interactions (Figure 7) (de la Fuente et al., 2001, 2006; Barrientos et al., 2003; de la Fuente and Penades, 2004, 2006), which could be used as potential tools in anti-adhesive therapy (Rojo et al., 2004), for cell-cell adhesion studies (de la Fuente et al., 2005), prevention of pathogen invasion (Reynolds et al., 2012) and for exploring blood-brain barrier permeability via neuropeptide conjugation (Frigell et al., 2014).

Smaller carbohydrates, such as lactose, glucose and mannose (Otsuka et al., 2001; Reynolds et al., 2006; Schofield et al., 2007; Martinez-Avila et al., 2009) can be thiolated for attachment to AuNPs via ligand exchange. These nanoparticles may be useful as sensitive colorimetric probes for a variety of metal ions. Mannose and lactose have also been used for the reduction of gold salts and stabilization of the nanoparticles. Schofield et al. have shown that thiolated carbohydrate derivatives can be readily assembled on silver and gold NPs. These metal glycoNPs can be used to develop aggregation based colorimetric bioassays (Schofield et al., 2006).

Magnetic glycoNPs with unique properties have also been reported, although in a more limited number (El-Boubbou and Huang, 2011; Marradi et al., 2013). Once carbohydrates are attached on the MNPs, it is crucial that they retain their biological activity. To explore this, plant lectins can be used, as their interaction with carbohydrates is highly selective. The clustering of the MNPs due to the selective recognition of the lectin can be detected using MRS assays (Moros et al., 2010).

Carbohydrates can also be used to target different cells and/or enhance the cellular uptake of NPs in a highly specific way. For instance, Moros et al. functionalized MNPs with glucose and galactose using EDC and studied their interaction with Vero cells in vitro (Moros et al., 2012). Although these monosaccharides share the same chemical formula, except for the spatial conformation of the hydroxyl group in C-4, the cell entrance pattern was completely different. While MNPs-glucose entered all throughout the cell, MNPs-galactose remained predominantly in the cell periphery. By preparing a library of MNPs functionalized with different monosaccharides, El-Boubbou et al. were also able to detect, differentiate cancer cells and quantitatively profile their carbohydrate binding abilities by MRI (El-Boubbou et al., 2010).

Carbohydrates have been also conjugated to QDs (Chen et al., 2003; Osaki et al., 2004; Kikkeri et al., 2009; Cai et al., 2012; Yang et al., 2012a). For example, Kikkeri et al. synthesized PEGylated QDs capped with D-mannose, D-galactose, and D-galactosamine to study specific carbohydrate-protein interactions in vitro and in vivo. These $\mathrm{QD}$-carbohydrates were produced through covalent coupling by 4-maleimidopropanoic acid NHS ester and used for in vitro imaging and in vivo liver targeting (Kikkeri et al., 2009). Shinchi et al. also developed glycol-QDs by preparing stable sugar-chain-immobilized fluorescent nanoparticles (CdTe/CdS core/shell QDs functionalized with sugar-chain-ligand conjugates, $\beta$-galactose- and $\alpha$-glucose) and their application to the analysis of sugar-chain-protein interactions and cellular imaging (Shinchi et al., 2012).

\section{BIOMOLECULE COUPLING STRATEGIES}

Functionalization of NPs with biomolecules has to face several hurdles and surface modifications can have significant impacts on their physical-chemical properties and therapeutic efficacy, once they might alter surface charge, size, hydrophobicity, and targeting skills. One of the biggest challenges is that NPs need to remain stable in solution while the conjugation takes place. However, many NPs may precipitate while being activated, as their stability depends on a delicate balance between attractive and repulsive forces, which can be modified when using different chemicals for their biofunctionalization. Moreover, due to the huge amount of different NPs and biomolecules reported so far, there are no standardized protocols for NP functionalization. Therefore, the choice of a coupling strategy depends on the 


\section{A}
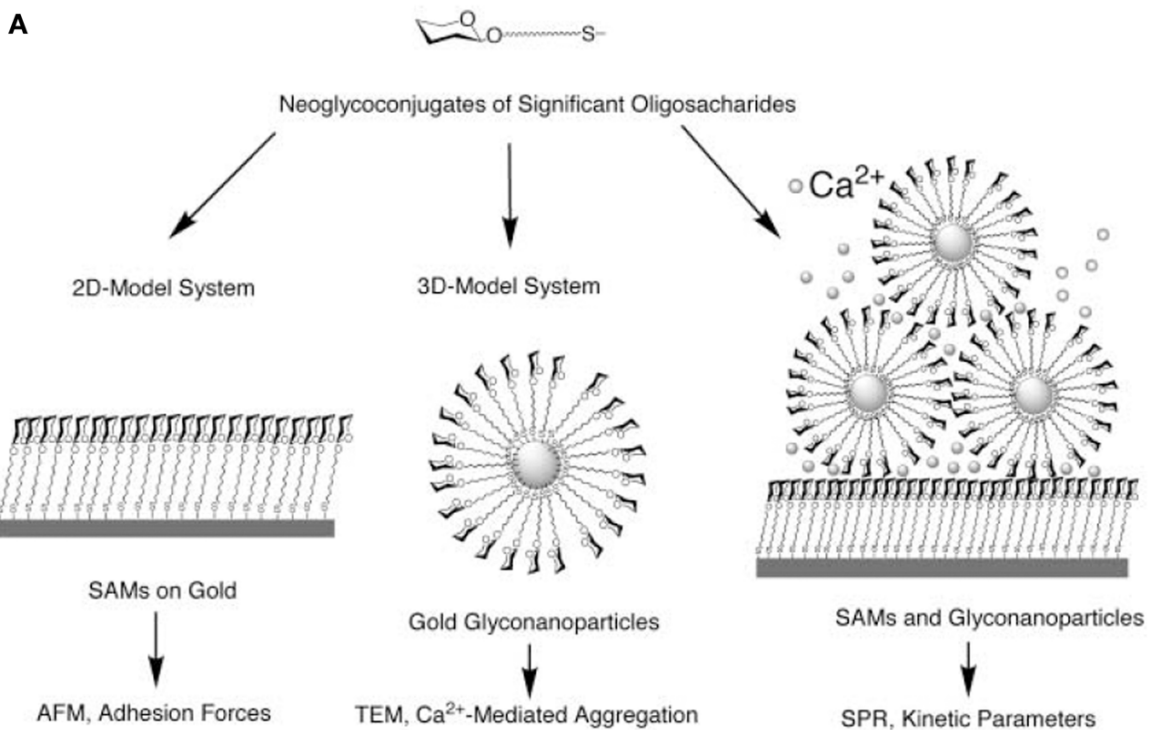

AFM, Adhesion Forces

TEM, $\mathrm{Ca}^{2+}$-Mediated Aggregation

SPR, Kinetic Parameters

B

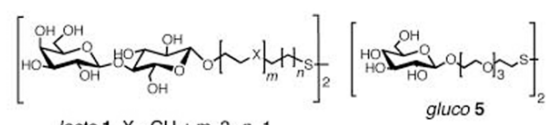

lacto $1, \mathrm{X}=\mathrm{CH}_{2} ; m=3, n=1$ lacto $2, X=0 ; m=3, n=1$
lacto $3, X=0 ; m=6, n=10$

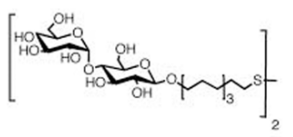

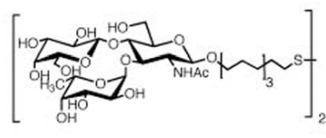

$\operatorname{Le}^{\mathrm{x}} 6$

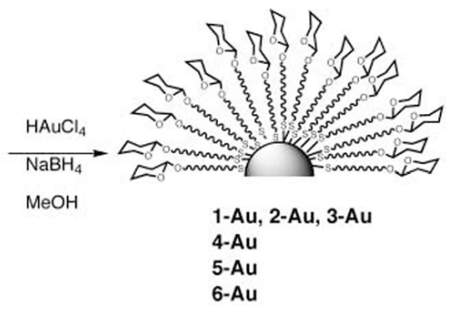

malto 4

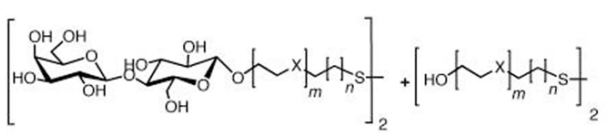

lacto 1, $\mathrm{X}=\mathrm{CH}_{2} ; m=3, n=1(50 \%)$ lacto $3, X=0 ; m=6, n=10 \quad(30 \%)$ lacto $3, X=0 ; m=6, n=10 \quad(15 \%)$

9, $\mathrm{X}=\mathrm{CH}_{2} ; m=3, n=1(50 \%)$ 13. $X=0 ; m=6, n=10 \quad(70 \%)$ lacto $3, X=0 ; m=6, n=10 \quad(5 \%)$

13, $X=0 ; m=6, n=10 \quad(85 \%)$

$13, X=0 ; m=6, n=10 \quad(95 \%)$

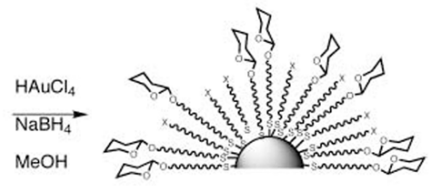

$\mathrm{X}=\mathrm{OH}, 1-\mathrm{Au}-9$

3-Au-13

3-Au-13

3-Au-13

D

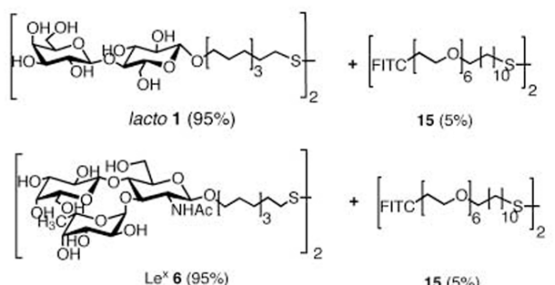

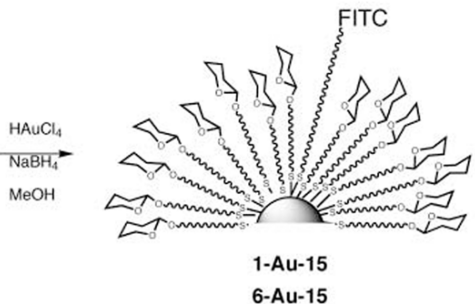

FIGURE 7 | Gold glyconanoparticles. (A) Strategy for studying carbohydrate \pm carbohydrate interactions based on $2 \mathrm{D}$ and $3 \mathrm{D}$ models that mimic carbohydrate presentation at the cell surface. Preparation of
(B) glyconanoparticles; (C) hybrid glyconanoparticles; (D) fluorescence glyconanoparticles (Barrientos et al., 2003). Reproduced with permission from Barrientos et al. (2003), Copyright 2013. stability of the NP, the functional groups, the bioconjugation conditions ( $\mathrm{pH}$, temperature, ionic strength, solvent choice, structure of the surfactant) and the biomolecule to attach, among others. Finally, depending on the conjugated biomolecule, it is important to control the orientation, so that the biomolecule remains active once conjugated to the NP.

Biofunctionalization can be achieved using several techniques, such as physical adsorption and electrostatic binding, specific 
affinity recognition, and covalent coupling, each of which has its own advantages and disadvantages. In this section of the review, the several coupling strategies for biofunctionalization of gold, MNPs and QDs will be examined.

\section{Covalent strategies}

Covalent coupling provides stable and strong binding of the biomolecules to the NPs. Most proteins have amine groups in their surface, so they can be directly conjugated to NPs containing reactive groups such as aldehydes, epoxides or anhydrides (Fuentes et al., 2005; Lu et al., 2008).

On the other hand, coupling of NPs that exhibit amine groups with molecules containing aldehydes or epoxides can also be used. However, some biomolecules such as antibodies, oligonucleotides, carbohydrates or peptides do not include these functional groups, and should be modified prior to the conjugation (Nobs et al., 2004). For instance, carbohydrates present in some antibodies can be oxidized using periodate to generate aldehyde groups that can react with the amino groups present on the NPs surface (Fuentes et al., 2005). Nevertheless, chemical modification may compromise biomolecules' activity, so one of the most frequent ways to conjugate molecules to the NPs is using linker molecules.

EDC coupling reaction. 1-Ethyl-3-(3-dimethylaminopropyl)carbodiimide (EDC) is a zero-length crosslinking agent used to couple carboxyl or phosphate groups to primary amines, which may react with a carboxyl group of a biomolecule, forming an amine-reactive $\mathrm{O}$-acylisourea intermediate. Addition of sulfoNHS stabilizes the amine-reactive intermediate by converting it to an amine-reactive sulfo-NHS ester. The O-acylisourea intermediate may also react with an amine on a second biomolecule, producing a conjugate of the two biomolecules joined by a stable amide bond. This crosslinker has been used in diverse applications, such as conjugation of carboxyl to amine groups in peptides and proteins, forming amide bonds in peptide synthesis, attaching haptens to carrier proteins and form immunogens, labeling nucleic acids through $5^{\prime}$ phosphate groups and creating amine-reactive NHS-esters of biomolecules (Grabarek and Gergely, 1990).

One of the main advantages of EDC coupling is water solubility, which allows direct bioconjugation without prior organic solvent dissolution. On top of that, the excess of reagents and by-products can be easily removed by dialysis or gel-filtration (Sheehan et al., 1965). However, the coupling reaction has to be carried out fast, as the reactive ester that is formed can be rapidly hydrolyzed in aqueous solutions. To increase the stability of this active ester, N-hydroxysuccinimide (NHS) or Nhydroxysulfoxuccinimide (sulfo-NHS) can be used (Jang and Keng, 2008). Key parameters that should be controlled when using $\mathrm{EDC}$ are $\mathrm{pH}$ (as hydrolysis is largely dependent on $\mathrm{pH}$ ), the amount of EDC so that NPs do not aggregate due to loss of electrostatic repulsive forces between NPs, and the ratio EDC/NHS (Nakajima and Ikada, 1995; Sam et al., 2009; Shen et al., 2009).

Using this protocol almost all kinds of molecules (i.e., enzymes, antibodies, peptides, DNA, fluorophores, etc.) may be attached to the nanoparticle surface without prior modification

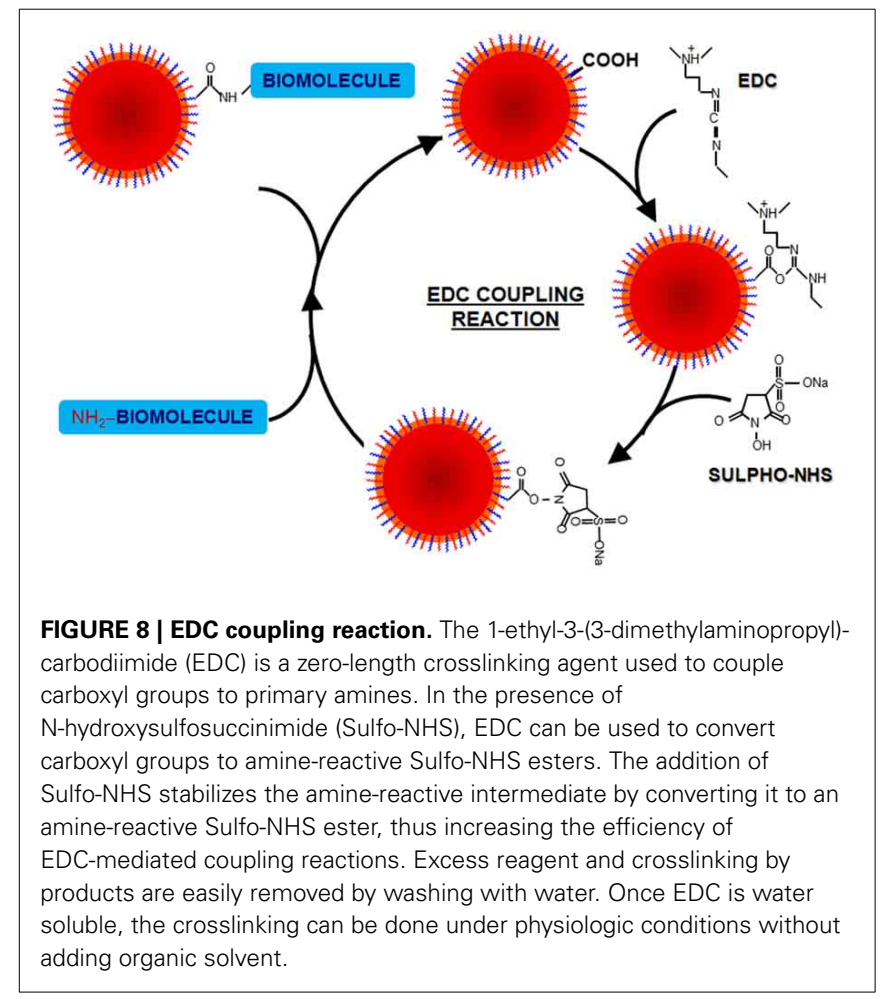

(see Figure 8) (Pandey et al., 2007; Susumu et al., 2007; RostroKohanloo et al., 2009; Conde et al., 2012a; Lavilla et al., 2012). For instance, using the EDC chemistry, Weissleder and coworkers created a library of MNPs decorated with different synthetic small molecules for the development of magnetofluorescent reporters (Weissleder et al., 2005). Using these fluorescent MNPs it was possible to screen against different cell types or among different physiological states of a cell line. On the other hand, Sanz et al. have reported the effect of biofunctional spacers, such as thiolated PEG chains on the loading of RNA molecules and a positive peptide functionalized by EDC coupling reactions on the surface of AuNPs (Sanz et al., 2012). Lin and coworkers also used EDC to attach $\mathrm{CH}_{3} \mathrm{O}-\mathrm{PEG}-\mathrm{NH}_{2}$ to different types of carboxylated NPs (MNPs, QDs) demonstrating that adjusting the ratio $\mathrm{EDC} / \mathrm{NP}$ it was possible to prepare NPs with 0,1 , or 2 attached PEG molecules (Lin et al., 2008). Similarly, Parak and co-workers also used EDC to attach $\mathrm{NH}_{2}-\mathrm{PEG}-\mathrm{NH}_{2}$ molecules, varying the molecular weight of the polymer on the surface of AuNPs (Sperling et al., 2006; Pellegrino et al., 2007). The covalent attaching of biofunctional short PEG molecules to the polymer shell produces very stable particles in electrolytic solution. This approach results in stable water-soluble AuNPs (Sanz et al., 2012) and QDs (Ballou et al., 2004) with functional groups, e.g. $-\mathrm{COOH}$ or $-\mathrm{NH}_{2}$ on the free ends of PEG molecules. By controlling the EDC ratio, aggregation was prevented. Dhar et al. have exploited the rapid intracellular uptake of AuNPs to deliver and activate cisplatin and achieve efficient cytosolic delivery of platinum(IV) prodrug to lung cancer cells. The AuNPs used in this study were functionalized with thiolated oligonucleotides containing a terminal dodecyl amine for conjugation 
with a platinum(IV) compound capable of being tethered to an amine functionalized DNA-AuNP surface via amide linkages (Dhar et al., 2009).

Similarly, conjugation of biomolecules to QDs through coupling reactions with reactive functional groups presented on QDs surface is another common strategy to prepare QD bioconjugates. Actually, carboxylic acid groups can also be added to QDs' surface and subsequently conjugated to biomolecules with primary amine groups through EDC coupling reactions (Cai et al., 2006; Hua et al., 2006; Choi et al., 2009; Wu et al., 2009a; East et al., 2011).

One disadvantage of this type of chemistry is that the presence of both carboxylates and amines on one of the biomolecules to be conjugated with EDC can result in self-polymerization and consequently, loss of effectiveness. For instance, peptides usually contain both types of groups, so if EDC is added in the presence of them, peptides can polymerize. However, Bartczak et al. have used this strategy to coupling of peptides to AuNPs in a onepot way. The authors have shown that the concentration, reaction time, and chemical environment are all critical to achieving the formation of robust, peptide-coated colloidal nanoparticles without aggregation (Bartczak and Kanaras, 2011). Another way to avoid polymerization of the biomolecule is to eliminate the excess of EDC before adding the biomolecule to the NPs solution by magnetic separation in the case of MNPs or gel-filtration for other NPs.

Despite the simplicity of this technique, that does not require prior chemical modification of the biomolecule, it does not guarantee an oriented immobilization in the case of biomolecules with greater structural complexity, such as antibodies. Due to the poor stability of the reactive ester, neutral $\mathrm{pH}$ is traditionally used to link covalently antibodies to carboxylated-NPs. At this $\mathrm{pH}$, immobilization mainly occurs through direct covalent binding of the most reactive amine groups of the antibody. Unfortunately, these are the terminal amine moieties of the four Ab polypeptide chains (pKa around 7-8), which are all located in the antigenbinding domain (Puertas et al., 2011). Recently, Puertas et al. described a smart approach that takes advantage of the existing kinetic differences among ionic adsorption processes and covalent reactions in order to assure the oriented covalent attachment of the Ab using EDC chemistry. Briefly, it requires the selection of the best incubations conditions ( $\mathrm{pH}$, ionic strength) to promote a fast ionic adsorption of the $\mathrm{Ab}$ due to the negative charges of the carboxylic groups of the NP. This ionic adsorption makes possible the orientation of the Ab on the NP surface before irreversible covalent bond formation (Figure 9) (Puertas et al., 2011). Initially, the authors optimized this twostep strategy for magnetic NPs but they have recently extended

A

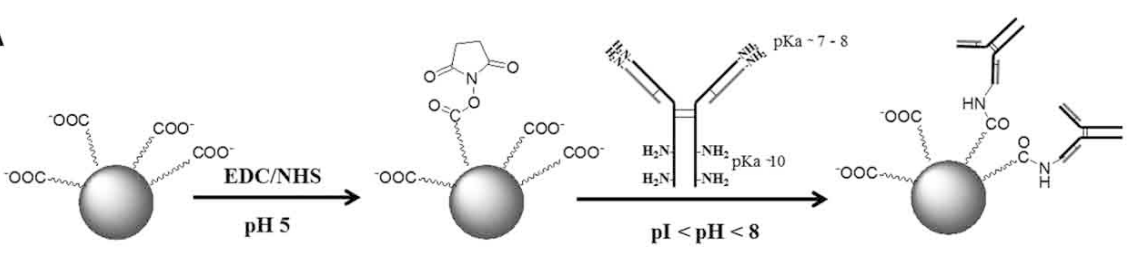

B
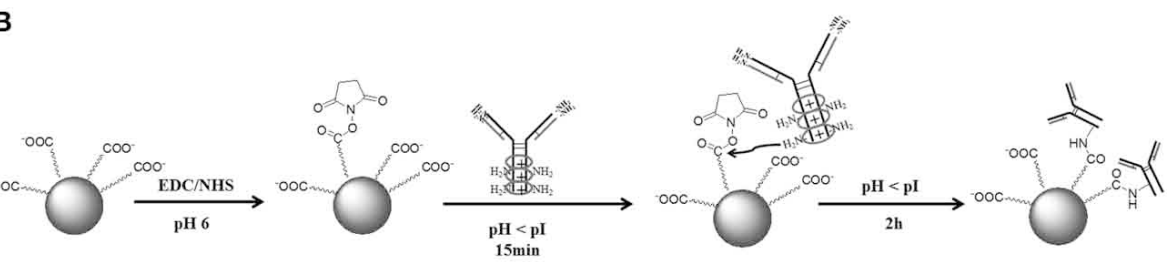

C
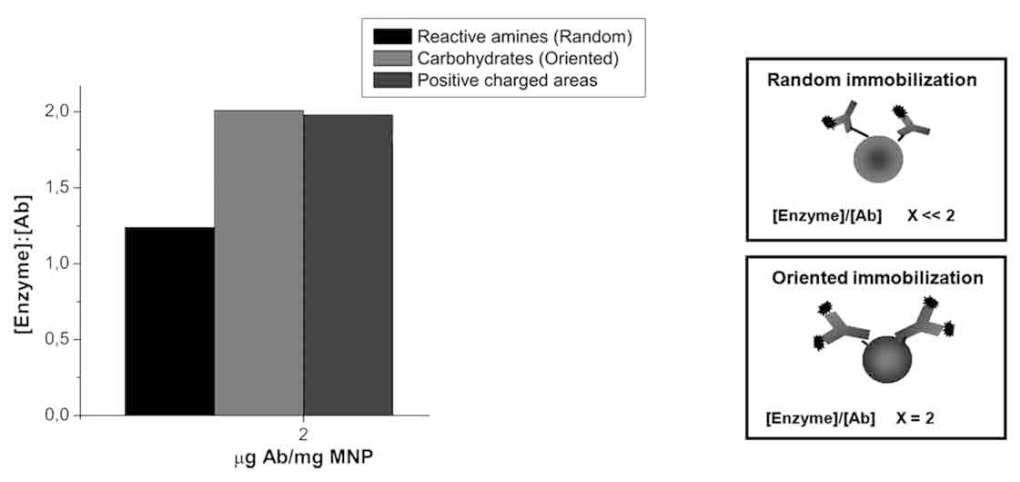

FIGURE 9 | Highly active magnetic nanoparticle-antibody conjugates.

(A) Two-step immobilization mechanism proposed when using Ab that bind to the MNPs through the most reactive amines-random immobilization.

(B) Covalent attachment via the polysaccharide moieties of the antibody to the
MNPs — oriented immobilization. (C) Capacity to capture HRP of the anti-HRP anchored to MNPs by different orientations. The protein content of all anti-HRP-functionalized MNPs was similar (2 $\mu \mathrm{g}$ Ab per mg MNP) (Puertas et al., 2011). Reproduced with permission from Puertas et al. (2011), Copyright 2013. 


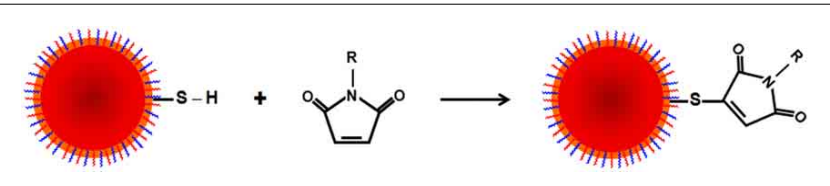

FIGURE 10 | Maleimide coupling reaction. Maleimide reacts with free sulfhydryl group(s), forming stable thioether linkages, at physiological $\mathrm{pH}$. It is useful for bioconjugation of proteins with - $\mathrm{SH}$ groups and the coupling of two thiols to form a disulfide linkage.

application for functionalization of other nanostructured materials, such as gold nanoprisms and carbon nanotubes (Polo et al., 2013).

Maleimide coupling. Maleimide can be used to conjugate primary amines to thiols (Brinkley, 1992) (see Figure 10). The use of maleimide for modification of sulfhydryl groups has been extensively described in the literature (Means and Feeney, 1990). Reaction with sulfhydryl groups generates a stable 3-thiosuccinimidyl ether linkage and occurs normally at $\mathrm{pH}$ 6.5-7.5. One of the main limitations is that the maleimide ring may hydrolyze in aqueous buffer to a non-reactive cismaleamic acid derivative over long reaction times or at $\mathrm{pH}>$ 8.0. Nevertheless, this type of conjugation shows a lot of potential for a great number of biomolecules that bear reactive thiol or amino groups. This may eventually lead to non-specific bonds and crosslinking between functionalized nanoparticles since a single biomolecule may have several thiol groups (Means and Feeney, 1990; Brinkley, 1992).

Maleimide coupling has been used to conjugate several biomolecules to AuNPs, such as peptides (Oh et al., 2010a; Ravi et al., 2012), chemotherapeutic agents (Hwu et al., 2009), dyes (Zhu et al., 2012a), and DNA (Lee, 2011). In fact, Ba et al. presented a versatile and controlled route to immobilize AuNPs on the surface of living cells, while preserving the sensing and optothermal capabilities of the original colloid, by chemically anchoring the nanoparticles to phospholipids in liposomes via maleimide-thiol reactivity (Ba et al., 2010).

Maleimide coupling was also used to couple DNA (Dubertret et al., 2002), PNAs (Srinivasan et al., 2006), proteins (Wolcott et al., 2006; Bonasio et al., 2007; Zhou et al., 2007), and antibodies into QDs (Diagaradjane et al., 2008). To address biocompatibility issues of QDs, Dubertret et al. encapsulated individual nanocrystals in phospholipid block-copolymer micelles conjugated to DNA and demonstrated their function as fluorescent probes (Dubertret et al., 2002). Bonasio et al. also reported the specific and covalent labeling of QDs with a membrane protein and organic fluorophores (Bonasio et al., 2007).

Similarly, MNPs can also be functionalized using the maleimide coupling reaction with PEG (Kuhn et al., 2006), DNA (Nam et al., 2004) or even drugs, such as chlorotoxin (Kievit et al., 2010). Concerning antibodies, this chemistry could be also used with thiol or amino groups on the nanoparticle surface (Lee et al., 2007; Haun et al., 2010). Regarding a thiolated NP, antibodies would bind through their most reactive amine groups and, as previously explained, this could lead to a random orientation with partial loss of the Ab's biological activity.
Instead, maleimide chemistry used with aminated NPs ensures an oriented binding through thiol groups of the Ab. However, as in Abs sulfhydryls are oxidized as disulfides. So it is necessary to selectively reduce the disulfides at the hinge region by a reducing agent (i.e., 2-mercapthoethylamine, mercaptoethanol, dithiotreitol, thiopropyl-agarose). This chemical modification can also be combined with fragmentation of the IgG by the use of proteolytic enzymes (i.e., pepsine, ficin) in order to conjugate small $\mathrm{Ab}$ fragments such as $\mathrm{F}\left(\mathrm{ab}^{\prime}\right) 2$ and $\mathrm{Fab}^{\prime}$.

Click-chemistry reaction. The copper(I)-catalyzed azide-alkyne cycloaddition (CuAAC) click reaction has been recognized as a facile and versatile chemistry for bioconjugation. Azides and alkynes are highly energetic functional groups with particularly narrow distributions of reactivity. Thanks to their weak acid-base properties, they are nearly inert toward biological molecules and toward the reaction conditions found inside living cells. The azide groups are easy to introduce into organic compounds by both nucleophilic and electrophilic processes. One of the most common bioconjugation of azides is the copper catalyzed azide-alkyne cycloaddition (CuAAC) (Wang et al., 2003) (see Figure 11). This reaction features an enormous rate acceleration of $10^{7}-10^{8}$ compared to the uncatalyzed 1,3-dipolar cycloaddition (Himo et al., 2005). This reaction has also been termed the "cream of the crop" of click reactions and is surely responsible for the tremendous popularity of the "click" concept and many simply associate "click chemistry" to mean triazole formation between an azide and alkyne. The reaction occurs at room temperature, showing a high degree of solvent and $\mathrm{pH}$ insensitivity, and high chemoselectivity (the azide and alkyne are inert to react with numerous functional groups under the typically mild reaction conditions). In fact, the reaction succeeds over a broad temperature range, is insensitive to aqueous conditions and occurs in a $\mathrm{pH}$ range between 4 and 12 (Hein and Fokin, 2010; Le et al., 2010). The copper catalyzed azide-alkyne cycloaddition occurs between an organic azide and a terminal acetylene. The cyclic product is a triazole. The copper catalyst allows the reaction to proceed at room temperature and confers regioselectivity (a reaction in which one direction of bond making or breaking occurs preferentially over all other possible directions), with the 1,4 regioisomer being the only product. The reaction start by the incubation with a mixture of copper(II) (e.g. copper(II) sulfate) and a reducing agent (e.g. sodium ascorbate) to produce $\mathrm{Cu}(\mathrm{I})$ in situ (Meldal and Tornoe, 2008; Hong et al., 2009).

Click chemistry sometimes refers to a group of reactions that are fast, simple to use, easy to purify, versatile, regiospecific, and give high product yields. However, the click reaction has a number of limitations. First, like with any cycloaddition, if the azide group is too electron deficient, then it will not undergo the reaction. In other words, the ground state configuration of the azide is far too low to interact with the terminal alkyne (Hein et al., 2008). Secondly, a more common problem is alkyne homocoupling. This phenomenon occurs when an alkyne reacts with a second alkyne instead of the azide. This process can be minimized by using a sterically bulky base that stabilizes the reactive intermediates of the homocoupling reactions. The $\mathrm{Cu}(\mathrm{I})$ saturation is rare but can also be a problem, once the alkynes may 


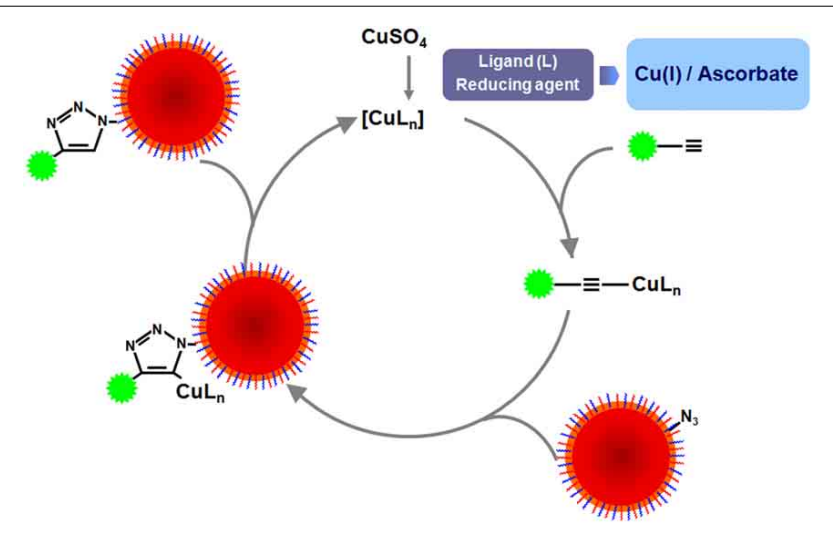

FIGURE 11 | Click chemistry reaction. The copper-catalyzed cycloaddition of azides and alkynes (CuAAC) developed for click chemistry joins an organic azide $\left(\mathrm{N}_{3}\right)$ and alkyne together producing a mixture of 1,4- and 1,5-triazoles.

chelate the $\mathrm{Cu}(\mathrm{I})$-acetylide complex intermediate that contact with the azide group (Hein et al., 2008). Besides these limitations, one of the most obvious disadvantages is the requirement of a copper catalyst. In fact, an excessive intake of copper can lead to drastic consequences for the human body (e.g. hepatitis, neurological disorders, kidney diseases and Alzheimer's disease) (Wang and Guo, 2006; Hein et al., 2008).

Generally, the click-chemistry reaction has been used to couple AuNPs to proteins (Zhu et al., 2012b), enzymes (Brennan et al., 2006; Kim et al., 2010), fluorophores (Voliani et al., 2011), polymers (Boisselier et al., 2008; Zhang et al., 2009), and other small molecules (Fleming et al., 2006). For example, following clickchemistry reaction Fleming et al. were able to conjugate to AuNPs several different alkyne derivatives, such as ferrocene, aniline and PEG (Fleming et al., 2006).

Alkyne-functionalized AuNPs have been also extensively used to detect metal ions in aqueous solutions, such as $\mathrm{Cu}^{2+}$, using click chemistry. This method allows visualization by naked eye of the presence of $\mathrm{Cu}^{2+}$ ions by the aggregation of AuNPs as a result of the $\mathrm{Cu}(\mathrm{I})$-catalyzed conjugation between the two functional groups (Zhou et al., 2008b; Xu et al., 2010; Lin et al., 2012).

Another common type of nanoparticles used for clickchemistry bioconjugation is QDs. QDs need to be coated to other chemical species if they are to be used as biomarkers, therapeutic agents or sensors. In fact, water soluble and water QDs have been successfully coated with polymers via click-chemistry reactions (Beaune et al., 2011; Janczewski et al., 2011; Lai and Guan, 2011; Petryayeva and Krull, 2012; Zhang et al., 2012a). Jańczewski et al. reported the use of click-QDs by producing water solubilization of hydrophobic CdSe/ZnS QDs using amphiphilic polymeric coatings. The authors described the preparation of acetylene- and azide-functionalized QDs for "click" chemistry. The method is universal and applicable to any type of nanoparticle stabilized with hydrophobic ligands able to interact (in water) with the alkyl chains present in the coating (Janczewski et al., 2011).

Interestingly, Hao et al. reported a method for labeling viruses via copper-free click chemistry to QDs. The authors linked virions modified with azide to QDs capable of realizing single-virion tracking, laying the foundation for long-term dynamic visualization of virus infection process (Hao et al., 2012).

Although click chemistry does not appear to be a major type of chemistry for MNPs, some interesting examples can be found in the literature. For instance, Santra and coworkers reported the creation of novel polymeric-metallic nanocomposites when assembling alkylated IONPs with azide polymer fluorescent NPs, obtaining a fluorescence material with enhanced magnetic properties for MRI (Santra et al., 2009). The first example of click MNPs for in vivo applications was reported by Bhatia and coworkers (von Maltzahn et al., 2008). Fluorescent MNPs functionalized with a tumor-targeting peptide (Lyp-1) via click chemistry were able to stably navigate the systemic circulation, extravasate into tumors and penetrate into the interstitial space to specifically bind to receptors on tumor cells. Weisledder group also reported the introduction of ${ }^{18} \mathrm{~F}$ onto azide-modified MNPs using clickchemistry for in vivo PET imaging (Devaraj et al., 2009).

\section{Non-covalent strategies: physical interactions}

Physical interactions include electrostatic, hydrophobic and affinity interactions. These interactions have several advantages, such as the ease of functionalization, speed of binding and that neither the biomolecules nor the NPs must be modified in case of electrostatic and hydrophobic interactions. However, conjugation is less stable and reproducible when compared to covalent methods. Moreover, it is difficult to control the amount and orientation of bound molecules.

Ionic coupling. Ionic adsorption provides a simple and straightforward method to functionalize NPs with biomolecules. In fact, biological and polymeric species with an opposite charge can be coupled to NPs (Conde et al., 2012a) or between different opposite charged NPs (Liu et al., 2012). Ionic binding rate mainly depends on the amount of charges present on the NPs and the biomolecules, as the binding is made by multiple point (multipunctual). Therefore, when binding complex molecules such as antibodies or proteins, the isoelectric point should be considered, as their net charge would depend on it.

Ionic coupling has been traditionally used to adsorb proteins to NPs (Brewer et al., 2005; Hong et al., 2006; Reed and Metallo, 2010; Guo et al., 2011; Brancolini et al., 2012; Strozyk et al., 2012), as some proteins such as serum albumin can stabilize NPs by preventing aggregation (Brewer et al., 2005). Moreover, proteins can be adsorbed to NPs to increase cellular uptake or specificity toward tumor cells (Chang et al., 2012). Negatively charged hyaluronic acid (HA) was also used to self-assemble onto the positively charged QDs through ionic interactions. For this, Bhang et al. developed a simple and novel electrostatic coupling method, which provides a HA-QD conjugate with cancer targeting efficiency to use in diagnostic and imaging applications. These conjugates were also effective for fluorescence staining of lymphatic vessels in vitro and in vivo (Bhang et al., 2009).

Despite the ease of this conjugation method, the native structure of the adsorbed proteins may be affected (Lacerda et al., 2010), which could ultimately result in loss of biological activity or even cellular toxicity (Vertegel et al., 2004; Deng et al., 2011). 

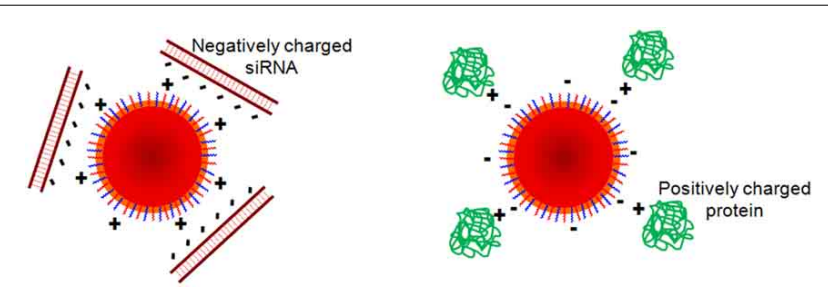

FIGURE 12 | lonic coupling. Coupling of negatively charged siRNA (left) and of positively charged proteins (right) to negatively or positively charged AuNPs.

Other examples of biological applications are the coupling of negatively charged DNA (Thomas and Klibanov, 2003; Ghosh et al., 2008; Conde et al., 2012b) or siRNA (Elbakry et al., 2009; Guo et al., 2010; Conde et al., 2012a; Zhao et al., 2012a) to positively charged NPs (Figure 12) (Huschka et al., 2012). In fact, Conde et al. reported functionalization of siRNA by ionic coupling to a positively charged layer formed by quaternary ammonium groups $\left(\mathrm{R}_{4} \mathrm{~N}^{+}\right)$. Ionic interactions between the negatively charged siRNA backbone (via phosphate groups) and quaternary ammonium positively charged groups ensured binding of siRNA onto the AuNPs' surface for the whole $\mathrm{pH}$ range. Using a hierarchical approach including three biological systems of increasing complexity, in vitro cultured human cells, in vivo freshwater polyp (Hydra vulgaris) and in vivo healthy mice model, these authors identified the most adequate nanoparticles to efficiently transport siRNAs. The results evidenced the importance of a correct design in the functionalization of nanoparticles for biological applications, in particular for complex animal systems, such as mice. The ionic linkage of siRNA on the AuNPs showed efficiency in cells and in Hydra. However, only a covalent bond ensured an active and efficient RNAi mechanism in mice (Conde et al., 2012a). Similarly, Li et al. reported the development of QDs-DNA complexes that are disrupted and DNA released by glutathione (GSH) at intracellular concentrations (Li et al., 2008).

As extensively reviewed by others (Montenegro et al., 2013), conjugation of Abs to NPs may be made with covalent immobilization techniques such as those mentioned before, but also with non-covalent strategies. The most common technique is the electrostatic adsorption of Abs by charge interaction to opposite charged NPs. This ionic adsorption is directly related to the Abs isoelectric point, $\mathrm{pH}$ at which they are neutral. Since it depends mainly on the number of charged groups, the Abs immobilized region will be where the greatest number of charges are present (Jung et al., 2008). This method, although of easy implementation, shows several disadvantages. The main concern is the weak $\mathrm{pH}$ dependent interaction between the Ab and NP. Any changes to the $\mathrm{pH}$ and/or ionic strength may incur in desorption of the Abs molecules. Additionally, the heterogeneous charge distribution and the unexploited charged groups of the Abs can promote non-specific adsorption to matrix proteins, for example competitive displacement caused by serum proteins (van der Voort et al., 2004; Murcia and Naumann, 2005).

Hydrophobic coupling. Hydrophobic interactions have been widely exploited to attach lipophilic drugs to NPs, from where

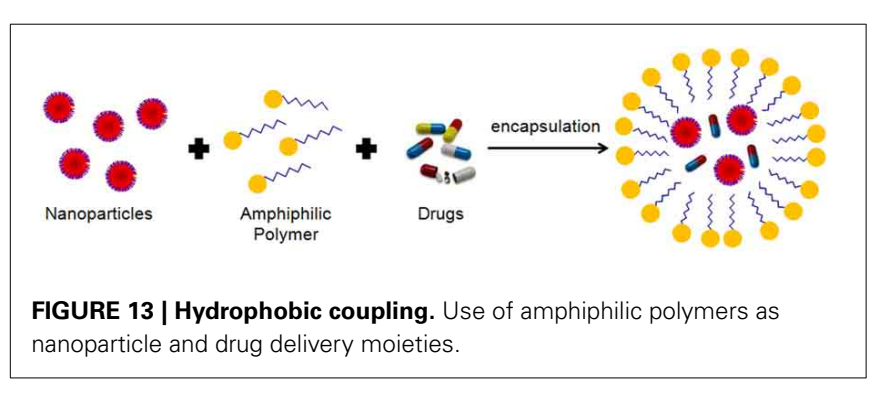

the drug might be released once inside the cells (Wahajuddin and Arora, 2012). For instance, docetaxel has been easily adsorbed to the oleic acid layer that surrounded hydrophobic MNPs prior to their encapsulation in a polymeric vesicle, providing a controlled drug release profile for a month (Ling et al., 2011). Encapsulation of drugs can also be done adsorbing them to hydrophobic polymers or cyclodextrins for instance (Yallapu et al., 2011) (see Figure 13).

Similarly, hydrophobic molecules such as fluorophores can be coupled to NPs. Foy and coworkers coated hydrophobic NPs with amphiphilic polymers, to which they adsorbed five different dyes to determine MNP biodistribution using a mouse xenograft breast tumor model (Foy et al., 2010). Moreover, Kim et al. developed AuNPs functionalized with water-soluble zwitterionic ligands from kinetically stable complexes with hydrophobic drugs and dyes, which are efficiently released into cells (Kim et al., 2009). This coupling method minimizes changes to the surface and allows the creation of NP with dual properties, such as optical and therapeutic, in an easy way.

Proteins and Abs can also be adsorbed to NPs via hydrophobic interactions. However, they often suffer from denaturation, leading to poor reproducibility. Hydrophobic interactions with the hydrophobic surfaces of proteins or Abs force a change in the native structure because of exposure of its inner region, which could ultimately results in loss of activity (Zuo et al., 2010; Shemetov et al., 2012). Moreover, regarding ionic binding, controlling the orientation or the amount of bound molecules is difficult to achieve.

Biotin-avidin system. For NPs conjugation, factors such as solubility, charge and all the aforementioned functional groups confer the biotin a relevant importance (Aslan et al., 2004). Biotinylation of NPs and biological molecules nowadays is fairly common as biotin can be synthesized to have a distal amine, thiol, carboxyl and other functional groups, simplifying the conjugation (Hermanson, 2008). However, to avoid a random immobilization of structural complex biomolecules such as proteins, it is compulsory to achieve a site specific biotinilation. Concerning antibodies, for example, biotinilation must be carried out within its Fc region via the carbohydrates moieties or via thiols obtained after reduction of the disulfides located in the hinge region (Cho et al., 2007).

Genetic engineering has also improved biotinylation by recombinantly introducing biotin labeling sites into fusion proteins (Cronan, 1990; Cull and Schatz, 2000). Nowadays several companies offer biomolecules and NPs modified with biotin or avidin species. The high-affinity of the avidin-biotin interaction 


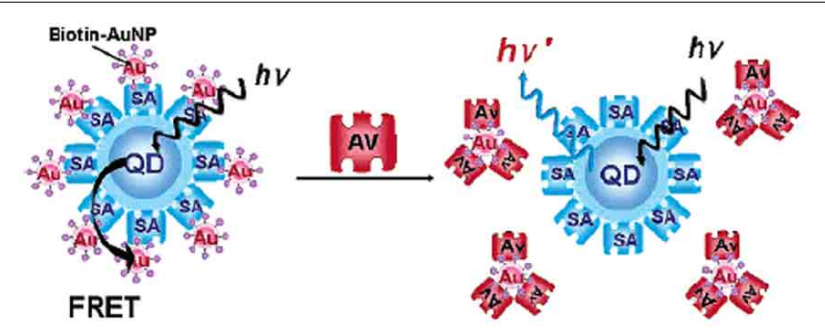

FIGURE 14 | Biotin-avidin system. Schematic of inhibition assay method based on the photoluminescence quenching of SA-QDs by Biotin-AuNPs. SA denotes the streptavidin immobilized on the surface of QDs, and Av is the externally added avidin (Feng et al., 2013). Reproduced with permission from Feng et al. (2013), Copyright 2013.

( $K_{d}$ around $10^{-14}$ ) has made it perfect for the development of NPs-based biosensors. The main method of bioconjugation using avidin-biotin chemistry comprises the functionalization of NPs with avidin, for later incubation with a biotinylated molecule. Since avidin and its variants are zwitterionic molecules, they can be subject to electrostatic adsorption to negatively charged nanoparticles (see section Non-Covalent Strategies: Physical Interactions). The vast number of publications that apply biotinavidin interaction for bioconjugation shows the importance of this strategy. Recently, Feng et al. showed that DNA detection could be improved using streptavidin coated AuNPs (Feng et al., 2013). Another interesting strategy was reported by $\mathrm{Oh}$ et al. where by modulating the FRET efficiency between QDs and AuNPs they were able to detect molecules which inhibited the interaction between streptavidin and biotin (Figure 14) (Oh et al., 2005). By capping the AuNPs with polyamidoamine dendrimers, the biotinylation was possible using sulfo-NHS-biotin.

A similar strategy was employed in the biotinylation of MNPs. To achieve a MNPs-PEG-biotin conjugate the NPs were incubated with a phospholipid-PEG-biotin construct. By coupling $\mathrm{DC}_{14: 0}$ PE (dimyristoylphosphatidylethanolamine) to further activate $\alpha$-biotinylamido- $\omega$-N-hydroxy-succinimidcarbonyl-PEG, the authors could produce MNPs covered with PEG-biotin. The functionalization was confirmed when binding streptavidin alkaline phosphatase the complexes became highly aggregated (Hodenius et al., 2012).

The strong association between avidin and biotin has made this system a reference for the development and troubleshooting of NPs-based biosensors. It is also a crutch for conjugation of other biomolecules onto the surface of NPs. However, it is important to note that avidin is a glycoprotein with a high isoelectric point $(\sim 10)$. This could cause the unspecific binding of other compounds present in complex biological samples. To overcome this problem, it is preferred the use of streptavidin. As it is purified from a bacteria (Streptomyces avidinii) is not a glycoprotein and has much lower isoelectric point (around 5-6). Besides, the tetrameric nature of each (strept) avidin molecule becomes a problem when control of the Ab stoichiometry is needed. To overtake this problem, it is possible to use recombinant monomerics forms of these proteins but taking into account that the affinity for biotin would be much lower (around $10^{-7} \mathrm{M}$ ) (Wu et al., 2009b).

\section{CONCLUSIONS AND FUTURE PERSPECTIVES}

In the near future, it is expected that the design of nanosystems will revolutionize the medical healthcare field by their application in the development of ultrasensitive and multiplexed diagnostic systems, targeted and remotely controlled drug delivery systems for treatment of diseases, in vivo imaging, tissue/organ regeneration and gene therapy solutions. The last three decades have been an exciting period in the synthesis of inorganic nanoparticles with interesting intrinsic properties for their use in such applications. Indeed, many of these synthetic processes have not only demonstrated proof-of-concept feasibility but progressed to full-scale commercial production. However, optimization of appropriate size scale and batch-to-batch reproducible synthetic procedures of NPs with unique optical or magnetic properties is not sufficient to ensure biomedical application. For this, functionalization of the NPs with biomolecules is crucial in order to impart biological recognition and interaction skills.

Selecting the most adequate biofunctionalization strategy is no mean feat, since no universal methodologies exist to cover the wide variety of inorganic nanoparticles and biomolecules available for this purpose. A functionalization protocol that works well for one type of NP may not work for another, since they could be very different in terms of size, charge, surface area, colloidal stability, density and type of reactive groups, etc. Furthermore, biomolecules vary significantly in terms of size, chemical composition, 3D complexity and location of its biological active site. As discussed along this review, in absence of standard functionalization protocols, each particular case (nanoparticle + biomolecule) requires optimization. Thus, in addition to the development of "smart" multifunctionalization strategies, it is vital to focus on the synthesis of "smart" nanoparticles over the next decade. These NPs should be able to deliver a therapeutic agent based on environmental causes or remote stimulus and with the capability to temporarily adapt their size, shape, surface chemistry, wettability and adhesive properties to surrounding environments. These long-term goals would allow an overall impact on the medical field with significant advances in patient screening, monitoring, diagnosis, staging, and treatment.

\section{ACKNOWLEDGMENTS}

João Conde acknowledges Marie Curie International Outgoing Fellowship (FP7-PEOPLE-2013-IOF, Project no. 626386). Pedro V. Baptista thanks CIGMH/FCT/MCES (PEstOE/SAU/UI0009/2011-14). Jesus M. de la Fuente thanks MAT2011-26851-C02-01, Fondo Social Europeo, ERC-Starting Grant 239931-NANOPUZZLE, CDTI-INMUNOSWING, Shanghai 100 People Plan and ARAID for financial support.

\section{REFERENCES}

Agemy, L., Friedmann-Morvinski, D., Kotamraju, V. R., Roth, L., Sugahara, K. N., Girard, O. M., et al. (2011). Targeted nanoparticle enhanced proapoptotic peptide as potential therapy for glioblastoma. Proc. Natl. Acad. Sci. U.S.A. 108, 17450-17455. doi: 10.1073/pnas.1114518108

Akerman, M. E., Chan, W. C. W., Laakkonen, P., Bhatia, S. N., and Ruoslahti, E. (2002). Nanocrystal targeting in vivo. Proc. Natl. Acad. Sci. U.S.A. 99, 12617-12621. doi: 10.1073/pnas.152463399

Algar, W. R., Susumu, K., Delehanty, J. B., and Medintz, I. L. (2011). Semiconductor quantum dots in bioanalysis: crossing the valley of death. Anal. Chem. 83, 8826-8837. doi: 10.1021/ac201331r 
Alivisatos, A. P. (1996). Semiconductor clusters, nanocrystals, and quantum dots. Science 271, 933-937. doi: 10.1126/science.271.5251.933

Alivisatos, A. P., Gu, W. W., and Larabell, C. (2005). Quantum dots as cellular probes. Аnпu. Rev. Biomed. Eng. 7, 55-76. doi: 10.1146/annurev. bioeng.7.060804.100432

Arruebo, M., Valladares, M., and Gonzalez-Fernandez, A. (2009). Antibodyconjugated nanoparticles for biomedical applications. J. Nanomater. 2009:439389. doi: 10.1155/2009/439389

Aslan, K., Luhrs, C. C., and Perez-Luna, V. H. (2004). Controlled and reversible aggregation of biotinylated gold nanoparticles with streptavidin. J. Phys. Chem. B 108, 15631-15639. doi: 10.1021/jp036089n

Ba, H. J., Rodriguez-Fernandez, J., Stefani, F. D., and Feldmann, J. (2010). Immobilization of gold nanoparticles on living cell membranes upon controlled lipid binding. Nano Lett. 10, 3006-3012. doi: 10.1021/nl101454a

Ballou, B., Lagerholm, B. C., Ernst, L. A., Bruchez, M. P., and Waggoner, A. S. (2004). Noninvasive imaging of quantum dots in mice. Bioconjug.Chem. 15, 79-86. doi: 10.1021/bc034153y

Baptista, P. (2009). Cancer nanotechnology - prospects for cancer diagnostics and therapy. Curr. Cancer Ther. Rev. 5, 80-88. doi: 10.2174/157339409788166733

Baptista, P., Doria, G., Henriques, D., Pereira, E., and Franco, R. (2005). Colorimetric detection of eukaryotic gene expression with DNAderivatized gold nanoparticles. J. Biotechnol. 119, 111-117. doi: 10.1016/ j.jbiotec.2005.02.019

Baptista, P., Pereira, E., Eaton, P., Doria, G., Miranda, A., Gomes, I., et al. (2008). Gold nanoparticles for the development of clinical diagnosis methods. Anal. Bioanal. Chem. 391, 943-950. doi: 10.1007/s00216-007-1768-z

Barakat, N. S. (2009). Magnetically modulated nanosystems: a unique drug-delivery platform. Nanomedicine (Lond.) 4, 799-812. doi: 10.2217/ nnm.09.66

Barrientos, A. G., de la Fuente, J. M., Rojas, T. C., Fernandez, A., and Penades, S. (2003). Gold glyconanoparticles: synthetic polyvalent ligands mimicking glycocalyx-like surfaces as tools for glycobiological studies. Chemistry 9 , 1909-1921. doi: 10.1002/chem.200204544

Bartczak, D., and Kanaras, A. G. (2011). Preparation of peptide-functionalized gold nanoparticles using one pot edc/sulfo-nhs coupling. Langmuir 27, 10119-10123. doi: 10.1021/la2022177

Bastus, N. G., Sanchez-Tillo, E., Pujals, S., Farrera, C., Lopez, C., Giralt, E., et al. (2009). Homogeneous conjugation of peptides onto gold nanoparticles enhances macrophage response. ACS Nano 3, 1335-1344. doi: $10.1021 / \mathrm{nn} 8008273$

Beaune, G., Tamang, S., Bernardin, A., Bayle-Guillemaud, P., Fenel, D., Schoehn, G., et al. (2011). Luminescence of polyethylene glycol coated cdsete/zns and inp/zns nanoparticles in the presence of copper cations. Chemphyschem 12, 2247-2254. doi: 10.1002/cphc.201100266

Bellucci, S. (2009). Nanoparticles and Nanodevices in Biological Applications. Berlin; Heidelberg: Springer.

Berry, C. C. (2009). Progress in functionalization of magnetic nanoparticles for applications in biomedicine. J. Phys. D Appl. Phys. 42:224003. doi: $10.1088 / 0022-3727 / 42 / 22 / 224003$

Berry, C. C., de la Fuente, J. M., Mullin, M., Chu, S. W., and Curtis, A. S. (2007). Nuclear localization of HIV-1 tat functionalized gold nanoparticles. IEEE Trans. Nanobiosci. 6, 262-269. doi: 10.1109/TNB.2007.908973

Bertrand, N., and Leroux, J. C. (2012). The journey of a drug-carrier in the body: an anatomo-physiological perspective. J. Control. Release 161, 152-163. doi: 10.1016/j.jconrel.2011.09.098

Bhadra, D., Bhadra, S., Jain, P., and Jain, N. K. (2002). Pegnology: a review of PEGylated systems. Pharmazie 57, 5-29.

Bhang, S. H., Won, N., Lee, T. J., Jin, H., Nam, J., Park, J., et al. (2009). Hyaluronic acid-quantum dot conjugates for in vivo lymphatic vessel imaging. ACS Nano 3 , 1389-1398. doi: 10.1021/nn900138d

Boeneman, K., Deschamps, J. R., Buckhout-White, S., Prasuhn, D. E., BlancoCanosa, J. B., Dawson, P. E., et al. (2010). Quantum dot DNA bioconjugates: attachment chemistry strongly influences the resulting composite architecture. ACS Nano 4, 7253-7266. doi: 10.1021/nn1021346

Boisselier, E., Salmon, L., Ruiz, J., and Astruc, D. (2008). How to very efficiently functionalize gold nanoparticles by "click" chemistry. Chem. Commun. (Camb.) 5788-5790. doi: 10.1039/b812249k

Bonasio, R., Carman, C. V., Kim, E., Sage, P. T., Love, K. R., Mempel, T. R., et al. (2007). Specific and covalent labeling of a membrane protein with organic fluorochromes and quantum dots. Proc. Natl. Acad. Sci. U.S.A. 104, 14753-14758. doi: 10.1073/pnas.0705201104

Brancolini, G., Kokh, D. B., Calzolai, L., Wade, R. C., and Corni, S. (2012). Docking of ubiquitin to gold nanoparticles. ACS Nano 6, 9863-9878. doi: $10.1021 / \mathrm{nn} 303444 \mathrm{~b}$

Brennan, J. L., Hatzakis, N. S., Tshikhudo, T. R., Dirvianskyte, N., Razumas, V., Patkar, S., et al. (2006). Bionanoconjugation via click chemistry: the creation of functional hybrids of lipases and gold nanoparticles. Bioconjug. Chem. 17, 1373-1375. doi: 10.1021/bc0601018

Brewer, S. H., Glomm, W. R., Johnson, M. C., Knag, M. K., and Franzen, S. (2005). Probing BSA binding to citrate-coated gold nanoparticles and surfaces. Langmuir 21, 9303-9307. doi: 10.1021/la050588t

Brinkley, M. (1992). A brief survey of methods for preparing protein conjugates with dyes, haptens, and cross-linking reagents. Bioconjug. Chem. 3, 2-13. doi: 10.1021/bc00013a001

Bruchez, M., Moronne, M., Gin, P., Weiss, S., and Alivisatos, A. P. (1998). Semiconductor nanocrystals as fluorescent biological labels. Science 281, 2013-2016. doi: 10.1126/science.281.5385.2013

Cai, W. B., and Chen, X. Y. (2008). Preparation of peptide-conjugated quantum dots for tumor vasculature-targeted imaging. Nat. Protoc. 3, 89-96. doi: 10.1038/nprot.2007.478

Cai, W. B., Shin, D. W., Chen, K., Gheysens, O., Cao, Q. Z., Wang, S. X., et al. (2006). Peptide-labeled near-infrared quantum dots for imaging tumor vasculature in living subjects. Nano Lett. 6, 669-676. doi: 10.1021/nl052405t

Cai, X. J., Li, X. H., Liu, Y. W., Wu, G. N., Zhao, Y. C., Chen, F., et al. (2012). Galactose decorated acid-labile nanoparticles encapsulating quantum dots for enhanced cellular uptake and subcellular localization. Pharm. Res. 29, 2167-2179. doi: 10.1007/s11095-012-0745-1

Cao, Y., Jin, R., and Mirkin, C. A. (2001). DNA-modified core-shell Ag/Au nanoparticles. J. Am. Chem. Soc. 123, 7961-7962. doi: 10.1021/ja011342n

Cao, Y. C., Jin, R., and Mirkin, C. A. (2002). Nanoparticles with Raman spectroscopic fingerprints for DNA and RNA detection. Science 297, 1536-1540. doi: 10.1126/science.297.5586.1536

Cao, Y. C., Jin, R., Thaxton, C. S., and Mirkin, C. A. (2005). A two-colorchange, nanoparticle-based method for DNA detection. Talanta 67, 449-455. doi: 10.1016/j.talanta.2005.06.063

Cardenas, M., Barauskas, J., Schillen, K., Brennan, J. L., Brust, M., and Nylander, T. (2006). Thiol-specific and nonspecific interactions between DNA and gold nanoparticles. Langmuir 22, 3294-3299. doi: 10.1021/la0530438

Chang, J., Paillard, A., Passirani, C., Morille, M., Benoit, J. P., Betbeder, D., et al. (2012). Transferrin adsorption onto PLGA nanoparticles governs their interaction with biological systems from blood circulation to brain cancer cells. Pharm. Res. 29, 1495-1505. doi: 10.1007/s11095-011-0624-1

Chen, F. Q., and Gerion, D. (2004). Fluorescent CdSe/ZnS nanocrystal-peptide conjugates for long-term, nontoxic imaging and nuclear targeting in living cells. Nano Lett. 4, 1827-1832. doi: 10.1021/nl049170q

Chen, Y. F., Ji, T. H., and Rosenzweig, Z. (2003). Synthesis of glyconanospheres containing luminescent CdSe-ZnS quantum dots. Nano Lett. 3, 581-584. doi: $10.1021 / \mathrm{nl} 034086 \mathrm{~g}$

Chithrani, D. B. (2010). Intracellular uptake, transport, and processing of gold nanostructures. Mol. Membr. Biol. 27, 299-311. doi: 10.3109/ 09687688.2010 .507787

Cho, I. H., Paek, E. H., Lee, H., Kang, J. Y., Kim, T. S., and Paek, S. H. (2007). Site-directed biotinylation of antibodies for controlled immobilization on solid surfaces. Anal. Biochem. 365, 14-23. doi: 10.1016/j.ab.2007.02.028

Choi, Y., Kim, H. P., Hong, S. M., Ryu, J. Y., Han, S. J., and Song, R. (2009). In situ visualization of gene expression using polymer-coated quantum-dot-DNA conjugates. Small 5, 2085-2091. doi: 10.1002/smll.200900116

Conde, J., Ambrosone, A., Sanz, V., Hernandez, Y., Marchesano, V., Tian, F., et al. (2012a). Design of multifunctional gold nanoparticles for in vitro and in vivo gene silencing. ACS Nano 6, 8316-8324. doi: 10.1021/nn3030223

Conde, J., Bao, C., Cui, D., Baptista, P. V., and Tian, F. (2014a). Antibody-drug gold nanoantennas with Raman spectroscopic fingerprints for in vivo tumour theranostics. J. Control. Release 183, 87-93. doi: 10.1016/j.jconrel.2014.03.045

Conde, J., Baptista, P. V., Hernandez, Y., Sanz, V., and de la Fuente, J. M. (2012b). Modification of plasmid DNA topology by "histone-mimetic" gold nanoparticles. Nanomedicine (Lond.) 7, 1657-1666. doi: 10.2217/nnm.12.21

Conde, J., Doria, G., and Baptista, P. (2012c). Noble metal nanoparticles applications in cancer. J. Drug Deliv. 2012:751075. doi: 10.1155/2012/751075 
Conde, J., Larguinho, M., Cordeiro, A., Raposo, L. R., Costa, P. M., Santos, S., et al. (2014b). Gold-nanobeacons for gene therapy: evaluation of genotoxicity, cell toxicity and proteome profiling analysis. Nanotoxicology 8, 521-532. doi: $10.3109 / 17435390.2013 .802821$

Conde, J., Rosa, J., and Baptista, P. (2013a). Gold-nanobeacons as a theranostic system for the detection and inhibition of specific genes. Protoc. Exch. doi: 10. 1038/protex.2013.088

Conde, J., Rosa, J., de la Fuente, J. M., and Baptist, P. V. (2013b). Gold-nanobeacons for simultaneous gene specific silencing and intracellular tracking of the silencing events. Biomaterials 34, 2516-2523. doi: 10.1016/j.biomaterials.2012. 12.015

Conde, J., Rosa, J., Lima, J. C., and Baptista, P. V. (2012d). Nanophotonics for molecular diagnostics and therapy applications. Int. J. Photoenergy 2012, 1-11. doi: $10.1155 / 2012 / 619530$

Conde, J., Tian, F., Hernandez, Y., Bao, C., Cui, D., Janssen, K. P., et al. (2013c). In vivo tumor targeting via nanoparticle-mediated therapeutic siRNA coupled to inflammatory response in lung cancer mouse models. Biomaterials 34, 7744-7753. doi: 10.1016/j.biomaterials.2013.06.041

Cronan, J. E. (1990). Biotination of proteins in vivo - a posttranslational modification to label, purify, and study proteins. J. Biol. Chem. 265, 10327-10333.

Crut, A., Geron-Landre, B., Bonnet, I., Bonneau, S., Desbiolles, P., and Escude, C. (2005). Detection of single DNA molecules by multicolor quantum-dot endlabeling. Nucleic Acids Res. 33:e98. doi: 10.1093/nar/gni097

Cull, M. G., and Schatz, P. J. (2000). Biotinylation of proteins in vivo and in vitro using small peptide tags. Methods Enzymol. 326, 430-440. doi: 10.1016/S00766879(00)26068-0

Curnis, F., Sacchi, A., Gasparri, A., Longhi, R., Bachi, A., Doglioni, C., et al. (2008). Isoaspartate-glycine-arginine: a new tumor vasculature-targeting motif. Cancer Res. 68, 7073-7082. doi: 10.1158/0008-5472.CAN-08-1272

Daou, T. J., Li, L., Reiss, P., Josserand, V., and Texier, I. (2009). Effect of poly(ethylene glycol) length on the in vivo behavior of coated quantum dots. Langmuir 25, 3040-3044. doi: 10.1021/la8035083

de la Fuente, J. M., Alcantara, D., Eaton, P., Crespo, P., Rojas, T. C., Fernandez, A., et al. (2006). Gold and gold-iron oxide magnetic glyconanoparticles: synthesis, characterization and magnetic properties. J. Phys. Chem. B 110, 13021-13028. doi: 10.1021/jp062522s

de la Fuente, J. M., Barrientos, A. G., Rojas, T. C., Rojo, J., Canada, J., Fernandez, A., et al. (2001). Gold glyconanoparticles as water-soluble polyvalent models to study carbohydrate interactions. Angew. Chem. Int. Ed. Engl. 40, 2257-2261. doi: 10.1002/1521-3773(20010618)40:12<2257::AID-ANIE2257>3.0.CO;2-S

de la Fuente, J. M., and Berry, C. C. (2005). Tat peptide as an efficient molecule to translocate gold nanoparticles into the cell nucleus. Bioconjug. Chem. 16, 1176-1180. doi: 10.1021/bc050033+

de la Fuente, J. M., Eaton, P., Barrientos, A. G., Menendez, M., and Penades, S. (2005). Thermodynamic evidence for Ca2+-mediated self-aggregation of Lewis X gold glyconanoparticles. A model for cell adhesion via carbohydrate-carbohydrate interaction. J. Am. Chem. Soc. 127, 6192-6197. doi: $10.1021 / \mathrm{ja} 0431354$

de la Fuente, J. M., and Penades, S. (2004). Understanding carbohydratecarbohydrate interactions by means of glyconanotechnology. Glycoconj. J. 21, 149-163. doi: 10.1023/B:GLYC.0000044846.80014.cb

de la Fuente, J. M., and Penades, S. (2006). Glyconanoparticles: types, synthesis and applications in glycoscience, biomedicine and material science. Biochim. Biophys. Acta 1760, 636-651. doi: 10.1016/j.bbagen.2005.12.001

De, M., Miranda, O. R., Rana, S., and Rotello, V. M. (2009). Size and geometry dependent protein-nanoparticle self-assembly. Chem. Commun. 2157-2159. doi: 10.1039/b900552h

Demers, L. M., Mirkin, C. A., Mucic, R. C., Reynolds, R. A. III., Letsinger, R. L., Elghanian, R., et al. (2000). A fluorescence-based method for determining the surface coverage and hybridization efficiency of thiol-capped oligonucleotides bound to gold thin films and nanoparticles. Anal. Chem. 72, 5535-5541. doi: $10.1021 /$ ac0006627

Deng, Z. J., Liang, M., Monteiro, M., Toth, I., and Minchin, R. F. (2011). Nanoparticle-induced unfolding of fibrinogen promotes Mac-1 receptor activation and inflammation. Nat. Nanotechnol. 6, 39-44. doi: 10.1038/nnano.2010.250

Derfus, A. M., Chen, A. A., Min, D. H., Ruoslahti, E., and Bhatia, S. N. (2007). Targeted quantum dot conjugates for siRNA delivery. Bioconjug. Chem. 18, 1391-1396. doi: 10.1021/bc060367e
Devaraj, N. K., Keliher, E. J., Thurber, G. M., Nahrendorf, M., and Weissleder, R. (2009). 18F labeled nanoparticles for in vivo PET-CT Imaging. Bioconjug. Chem. 20, 397-401. doi: 10.1021/bc8004649

Dhar, S., Daniel, W. L., Giljohann, D. A., Mirkin, C. A., and Lippard, S. J. (2009). Polyvalent oligonucleotide gold nanoparticle conjugates as delivery vehicles for platinum(IV) warheads. J. Am. Chem. Soc. 131, 14652-14653. doi: $10.1021 /$ ja9071282

Diagaradjane, P., Orenstein-Cardona, J. M., Colon-Casasnovas, N. E., Deorukhkar, A., Shentu, S., Kuno, N., et al. (2008). Imaging epidermal growth factor receptor expression in vivo: pharmacokinetic and biodistribution characterization of a bioconjugated quantum dot nanoprobe. Clin. Cancer Res. 14, 731-741. doi: 10.1158/1078-0432.CCR-07-1958

Dobson, J. (2006). Gene therapy progress and prospects: magnetic nanoparticlebased gene delivery. Gene Ther. 13, 283-287. doi: 10.1038/sj.gt.3302720

Donega, C. D. (2011). Synthesis and properties of colloidal heteronanocrystals. Chem. Soc. Rev. 40, 1512-1546. doi: 10.1039/c0cs00055h

Dong, C. M. (2011). Glyconanoparticles for biomedical applications. Comb. Chem. High Throughput Screen. 14, 173-181. doi: 10.2174/138620711794728716

Doria, G., Conde, J., Veigas, B., Giestas, L., Almeida, C., Assuncao, M., et al. (2012). Noble metal nanoparticles for biosensing applications. Sensors(Basel) 12, 1657-1687. doi: 10.3390/s120201657

Doria, G., Larguinho, M., Dias, J. T., Pereira, E., Franco, R., and Baptista, P. V. (2010). Gold-silver-alloy nanoprobes for one-pot multiplex DNA detection. Nanotechnology 21:255101. doi: 10.1088/0957-4484/21/25/255101

Dreaden, E. C., Alkilany, A. M., Huang, X. H., Murphy, C. J., and El-Sayed, M. A. (2012). The golden age: gold nanoparticles for biomedicine. Chem. Soc. Rev. 41, 2740-2779. doi: 10.1039/c1cs15237h

Dubertret, B. (2005). Quantum dots - DNA detectives. Nat. Mater. 4, 797-798. doi: $10.1038 /$ nmat 1520

Dubertret, B., Skourides, P., Norris, D. J., Noireaux, V., Brivanlou, A. H., and Libchaber, A. (2002). In vivo imaging of quantum dots encapsulated in phospholipid micelles. Science 298, 1759-1762. doi: 10.1126/science.1077194

East, D. A., Mulvihill, D. P., Todd, M., and Bruce, I. J. (2011). QD-antibody conjugates via carbodiimide-mediated coupling: a detailed study of the variables involved and a possible new mechanism for the coupling reaction under basic aqueous conditions. Langmuir 27, 13888-13896. doi: 10.1021/la203273p

Edwards, P. P., and Thomas, J. M. (2007). Gold in a metallic divided state-from Faraday to present-day nanoscience. Angew. Chem. Int. Ed. Engl. 46, 5480-5486. doi: 10.1002/anie.200700428

El-Boubbou, K., and Huang, X. (2011). Glyco-nanomaterials: translating insights from the "sugar-code" to biomedical applications. Curr. Med. Chem. 18, 2060-2078. doi: 10.2174/092986711795656144

El-Boubbou, K., Zhu, D. C., Vasileiou, C., Borhan, B., Prosperi, D., Li, W., et al. (2010). Magnetic glyco-nanoparticles: a tool to detect, differentiate, and unlock the glyco-codes of cancer via magnetic resonance imaging. J. Am. Chem. Soc. 132, 4490-4499. doi: 10.1021/ja100455c

El-Sayed, M. A. (2001). Some interesting properties of metals confined in time and nanometer space of different shapes. Acc. Chem. Res. 34, 257-264. doi: 10.1021/ar960016n

Elbakry, A., Zaky, A., Liebkl, R., Rachel, R., Goepferich, A., and Breunig, M. (2009). Layer-by-layer assembled gold nanoparticles for siRNA delivery. Nano Lett. 9, 2059-2064. doi: 10.1021/nl9003865

Fang, C., and Zhang, M. Q. (2009). Multifunctional magnetic nanoparticles for medical imaging applications. J. Mater. Chem. 19, 6258-6266. doi: 10.1039/b902182e

Faraday, M. (1857). Experimental relations of gold (and other metals) to light. Philos. Trans. R. Soc. Lond. 147, 145-181. doi: 10.1098/rstl.1857.0011

Feng, C. L., Dou, X. Q., Liu, Q. L., Zhang, W., Gu, J. J., Zhu, S. M., et al. (2013). Dual-specific interaction to detect DNA on gold nanoparticles. Sensors (Basel) 13, 5749-5756. doi: 10.3390/s130505749

Fichou, Y., and Ferec, C. (2006). The potential of oligonucleotides for therapeutic applications. Trends Biotechnol. 24, 563-570. doi: 10.1016/j.tibtech.2006.10.003

Fleming, D. A., Thode, C. J., and Williams, M. E. (2006). Triazole cycloaddition as a general route for functionalization of Au nanoparticles. Chem. Mater. 18, 2327-2334. doi: 10.1021/cm060157b

Foy, S. P., Manthe, R. L., Foy, S. T., Dimitrijevic, S., Krishnamurthy, N., and Labhasetwar, V. (2010). Optical imaging and magnetic field targeting of magnetic nanoparticles in tumors. ACS Nano 4, 5217-5224. doi: 10.1021/ nn101427t 
Frigell, J., García, I., Gómez-Vallejo, V., Llop, J., and Penadés, S. (2014). 68Galabeled gold glyconanoparticles for exploring blood-brain barrier permeability: preparation, biodistribution studies, and improved brain uptake via neuropeptide conjugation. J. Am. Chem. Soc. 136, 449-457. doi: 10.1021/ja411096m

Fuentes, M., Mateo, C., Guisán, J. M., and Fernández-Lafuente, R. (2005). Preparation of inert magnetic nano-particles for the directed immobilization of antibodies. Biosens. Bioelectron. 20, 1380-1387. doi: 10.1016/j.bios.2004.06.004

Garcia, I., Marradi, M., and Penades, S. (2010). Glyconanoparticles: multifunctional nanomaterials for biomedical applications. Nanomedicine(Lond.) 5, 777-792. doi: 10.2217/nnm.10.48

Ghanem, M. A., Bartlett, P. N., de Groot, P., and Zhukov, A. (2004). A double templated electrodeposition method for the fabrication of arrays of metal nanodots. Electrochem. commun. 6, 447-453. doi: 10.1016/j.elecom.2004.03.001

Ghosh, P. S., Kim, C. K., Han, G., Forbes, N. S., and Rotello, V. M. (2008). Efficient gene delivery vectors by tuning the surface charge density of amino acid-functionalized gold nanoparticles. ACS Nano 2, 2213-2218. doi: $10.1021 / \mathrm{nn} 800507 \mathrm{t}$

Gil, P. R., and Parak, W. J. (2008). Composite nanoparticles take aim at cancer. ACS Nano 2, 2200-2205. doi: 10.1021/nn800716j

Gilchrist, R. K., Medal, R., Shorey, W. D., Hanselman, R. C., Parrott, J. C., and Taylor, C. B. (1957). Selective inductive heating of lymph nodes. Ann. Surg. 146, 596-606. doi: 10.1097/00000658-195710000-00007

Gill, R., Zayats, M., and Willner, I. (2008). Semiconductor quantum dots for bioanalysis. Angew. Chem. Int. Ed. Engl. 47, 7602-7625. doi: 10.1002/anie. 200800169

Giersig, M., and Mulvaney, P. (1993). Preparation of ordered colloid monolayers by electrophoretic deposition. Langmuir 9, 3408-3413. doi: 10.1021/la00036a014

Goldman, E. R., Anderson, G. P., Tran, P. T., Mattoussi, H., Charles, P. T., and Mauro, J. M. (2002). Conjugation of luminescent quantum dots with antibodies using an engineered adaptor protein to provide new reagents for fluoroimmunoassays. Anal. Chem. 74, 841-847. doi: 10.1021/ac010662m

Goluch, E. D., Nam, J. M., Georganopoulou, D. G., Chiesl, T. N., Shaikh, K. A., Ryu, K. S., et al. (2006). A bio-barcode assay for on-chip attomolar-sensitivity protein detection. Lab Chip 6, 1293-1299. doi: 10.1039/b606294f

Grabarek, Z., and Gergely, J. (1990). Zero-length crosslinking procedure with the use of active esters. Anal. Biochem. 185, 131-135. doi: 10.1016/00032697(90)90267-D

Grazú, V., Moros, M., and Sánchez-Espinel, C. (2012). "Chapter 14 Nanocarriers as nanomedicines: design concepts and recent advances," in Frontiers of Nanoscience Nanobiotechnology Inorganic Nanoparticles vs Organic Nanoparticles, eds J. M. de la Fuente and V. Grazu (Oxford, UK: Elsevier), 337-440. doi: 10.1016/B978-0-12-415769-9.00014-5

Gump, J. M., and Dowdy, S. F. (2007). TAT transduction: the molecular mechanism and therapeutic prospects. Trends Mol. Med. 13, 443-448. doi: 10.1016/j.molmed.2007.08.002

Guo, S., Huang, Y., Jiang, Q., Sun, Y., Deng, L., Liang, Z., et al. (2010). Enhanced gene delivery and siRNA silencing by gold nanoparticles coated with chargereversal polyelectrolyte. ACS Nano 4, 5505-5511. doi: 10.1021/nn101638u

Guo, Y. M., Wang, Z., Qu, W. S., Shao, H. W., and Jiang, X. Y. (2011). Colorimetric detection of mercury, lead and copper ions simultaneously using proteinfunctionalized gold nanoparticles. Biosens. Bioelectron. 26, 4064-4069. doi: 10.1016/j.bios.2011.03.033

Han, A., Dufva, M., Belleville, E., and Christensen, C. B. (2003). Detection of analyte binding to microarrays using gold nanoparticle labels and a desktop scanner. Lab Chip 3, 329-332. doi: 10.1039/b310814g

Hanini, A., Schmitt, A., Kacem, K., Chau, F., Ammar, S., and Gavard, J. (2011). Evaluation of iron oxide nanoparticle biocompatibility. Int. J. Nanomedicine 6, 787-794. doi: 10.2147/IJN.S17574

Hao, J., Huang, L. L., Zhang, R., Wang, H. Z., and Xie, H. Y. (2012). A mild and reliable method to label enveloped virus with quantum dots by copper-free click chemistry. Anal. Chem. 84, 8364-8370. doi: 10.1021/ac301918t

Harris, T. J., von Maltzahn, G., Lord, M. E., Park, J. H., Agrawal, A., Min, D. H., et al. (2008). Protease-triggered unveiling of bioactive nanoparticles. Small 4, 1307-1312. doi: 10.1002/smll.200701319

Haun, J. B., Castro, C. M., Wang, R., Peterson, V. M., Marinelli, B. S., Lee, H., et al. (2011). Micro-NMR for rapid molecular analysis of human tumor samples. Sci. Transl. Med. 3:71ra16. doi: 10.1126/scitranslmed.3002048

Haun, J. B., Devaraj, N. K., Hilderbrand, S. A., Lee, H., and Weissleder, R. (2010). Bioorthogonal chemistry amplifies nanoparticle binding and enhances the sensitivity of cell detection. Nat. Biotechnol. 5, 660-665. doi: 10.1038/nnano.2010.148

He, X., Gao, J., Gambhir, S. S., and Cheng, Z. (2010). Near-infrared fluorescent nanoprobes for cancer molecular imaging: status and challenges. Trends Mol. Med. 16, 574-583. doi: 10.1016/j.molmed.2010.08.006

Heath, J. R., and Davis, M. E. (2008). Nanotechnology and cancer. Annu. Rev. Med. 59, 251-265. doi: 10.1146/annurev.med.59.061506.185523

Hein, C. D., Liu, X. M., and Wang, D. (2008). Click chemistry, a powerful tool for pharmaceutical sciences. Pharm. Res. 25, 2216-2230. doi: 10.1007/s11095-0089616-1

Hein, J. E., and Fokin, V. V. (2010). Copper-catalyzed azide-alkyne cycloaddition (CuAAC) and beyond: new reactivity of copper(I) acetylides. Chem. Soc. Rev. 39, 1302-1315. doi: 10.1039/b904091a

Hermanson, G. T. (2008). Bioconjugate Techniques, 2nd Edn. London, UK: Academic Press; Elsevier.

Himo, F., Lovell, T., Hilgraf, R., Rostovtsev, V. V., Noodleman, L., Sharpless, K. B., et al. (2005). Copper(I)-catalyzed synthesis of azoles. DFT study predicts unprecedented reactivity and intermediates. J. Am. Chem. Soc. 127, 210-216. doi: $10.1021 /$ ja0471525

Hodenius, M., Hieronymus, T., Zenke, M., Becker, C., Elling, L., Bornemann, J., et al. (2012). Magnetically triggered clustering of biotinylated iron oxide nanoparticles in the presence of streptavidinylated enzymes. Nanotechnology 23:355707. doi: 10.1088/0957-4484/23/35/355707

Hong, R., Han, G., Fernandez, J. M., Kim, B. J., Forbes, N. S., and Rotello, V. M. (2006). Glutathione-mediated delivery and release using monolayer protected nanoparticle carriers. J. Am. Chem. Soc. 128, 1078-1079. doi: 10.1021/ja056726i

Hong, V., Presolski, S. I., Ma, C., and Finn, M. G. (2009). Analysis and optimization of copper-catalyzed azide-alkyne cycloaddition for bioconjugation. Angew. Chem. Int. Ed Engl. 48, 9879-9883. doi: 10.1002/anie.200905087

Hu, R., Yong, K. T., Roy, I., Ding, H., Law, W. C., Cai, H., et al. (2010). Functionalized near-infrared quantum dots for in vivo tumor vasculature imaging. Nanotechnology 21:145105. doi: 10.1088/0957-4484/21/14/145105

Hua, X. F., Liu, T. C., Cao, Y. C., Liu, B., Wang, H. Q., Wang, J. H. et al. (2006). Characterization of the coupling of quantum dots and immunoglobulin antibodies. Anal. Bioanal. Chem. 386, 1665-1671. doi: 10.1007/s00216-006-0807-5

Huang, X., Jain, P. K., El-Sayed, I. H., and El-Sayed, M. A. (2007). Gold nanoparticles: interesting optical properties and recent applications in cancer diagnostics and therapy. Nanomedicine (Lond.) 2, 681-693. doi: 10.2217/17435889.2.5.681

Hurst, S. J., Lytton-Jean, A. K. R., and Mirkin, C. A. (2006). Maximizing DNA loading on a range of gold nanoparticle sizes. Anal. Chem. 78, 8313-8318. doi: $10.1021 / \mathrm{ac} 0613582$

Huschka, R., Barhoumi, A., Liu, Q., Roth, J. A., Ji, L., and Halas, N. J. (2012). Gene silencing by gold nanoshell-mediated delivery and laser-triggered release of antisense oligonucleotide and siRNA. ACS Nano 6, 7681-7691. doi: 10.1021/nn301135w

Hwu, J. R., Lin, Y. S., Josephrajan, T., Hsu, M. H., Cheng, F. Y., Yeh, C. S., et al. (2009). Targeted Paclitaxel by conjugation to iron oxide and gold nanoparticles. J. Am. Chem. Soc. 131, 66-68. doi: 10.1021/ja804947u

Jain, P. K., Lee, K. S., El-Sayed, I. H., and El-Sayed, M. A. (2006). Calculated absorption and scattering properties of gold nanoparticles of different size, shape, and composition: applications in biological imaging and biomedicine. J. Phys. Chem. B 110, 7238-7248. doi: 10.1021/jp057170o

Janczewski, D., Tomczak, N., Han, M. Y., and Vancso, G. J. (2011). Synthesis of functionalized amphiphilic polymers for coating quantum dots. Nat. Protoc. 6, 1546-1553. doi: 10.1038/nprot.2011.381

Jang, L. S., and Keng, H. K. (2008). Modified fabrication process of protein chips using a short-chain self-assembled monolayer. Biomed. Microdevices. 10, 203-211. doi: 10.1007/s10544-007-9126-7

Johannsen, M., Gneveckow, U., Eckelt, L., Feussner, A., Waldofner, N., Scholz, R., et al. (2005). Clinical hyperthermia of prostate cancer using magnetic nanoparticles: presentation of a new interstitial technique. Int. J. Hyperthermia 21, 637-647. doi: 10.1080/02656730500158360

Johannsen, M., Thiesen, B., Wust, P., and Jordan, A. (2010). Magnetic nanoparticle hyperthermia for prostate cancer. Int. J. Hyperthermia 26, 790-795. doi: $10.3109 / 02656731003745740$

Jordan, A., Scholz, R., Maier-Hauff, K., Johannsen, M., Wust, P., Nadobny, J., et al. (2001). Presentation of a new magnetic field therapy system for the treatment of human solid tumors with magnetic fluid hyperthermia. J. Magn. Magn. Mater. 225, 118-126. doi: 10.1016/S0304-8853(00)01239-7 
Jordan, A., Wust, P., Fahling, H., John, W., Hinz, A., and Felix, R. (1993). Inductive heating of ferrimagnetic particles and magnetic fluids - physical evaluation of their potential for hyperthermia. Int. J. Hyperthermia 9, 51-68. doi: 10.3109/02656739309061478

Jun, Y. W., Seo, J. W., and Cheon, J. (2008). Nanoscaling laws of magnetic nanoparticles and their applicabilities in biomedical sciences. Acc. Chem. Res. 41, 179-189. doi: 10.1021/ar700121f

Jung, Y., Jeong, J. Y., and Chung, B. H. (2008). Recent advances in immobilization methods of antibodies on solid supports. Analyst 133, 697-701. doi: 10.1039/b800014j

Kanaras, A. G., Kamounah, F. S., Schaumburg, K., Kiely, C. J., and Brust, M. (2002). Thioalkylated tetraethylene glycol: a new ligand for water soluble monolayer protected gold clusters. Chem. Commun. (Camb.) 2294-2295. doi: $10.1039 / \mathrm{b} 207838 \mathrm{~b}$

Kang, K. A., Wang, J., Jasinski, J. B., and Achilefu, S. (2011). Fluorescence manipulation by gold nanoparticles: from complete quenching to extensive enhancement. J. Nanobiotechnol. 9:16. doi: 10.1186/1477-3155-9-16

Khoshnevisan, K., Bordbar, A. K., Zare, D., Davoodi, D., Noruzi, M., Barkhi, M., et al. (2011). Immobilization of cellulase enzyme on superparamagnetic nanoparticles and determination of its activity and stability. Chem. Eng. J. 171, 669-673. doi: 10.1016/j.cej.2011.04.039

Kievit, F. M., Veiseh, O., Fang, C., Bhattarai, N., Lee, D., Ellenbogen, R. G., et al. (2010). Chlorotoxin labeled magnetic nanovectors for targeted gene delivery to glioma. ACS Nano 4, 4587-4594. doi: 10.1021/nn1008512

Kikkeri, R., Lepenies, B., Adibekian, A., Laurino, P., and Seeberger, P. H. (2009). In vitro imaging and in vivo liver targeting with carbohydrate capped quantum dots. J. Am. Chem. Soc. 131, 2110-2112. doi: 10.1021/ja807711w

Kim, C. K., Ghosh, P., Pagliuca, C., Zhu, Z. J., Menichetti, S., and Rotello, V. M. (2009). Entrapment of hydrophobic drugs in nanoparticle monolayers with efficient release into cancer cells. J. Am. Chem. Soc. 131, 1360-1361. doi: $10.1021 / \mathrm{ja} 808137 \mathrm{c}$

Kim, K. Y. (2007). Nanotechnology platforms and physiological challenges for cancer therapeutics. Nanomedicine 3, 103-110. doi: 10.1016/j.nano.2006. 12.002

Kim, Y. P., Daniel, W. L., Xia, Z., Xie, H., Mirkin, C. A., and Rao, J. (2010). Bioluminescent nanosensors for protease detection based upon gold nanoparticle-luciferase conjugates. Chem. Commun. (Camb.) 46, 76-78. doi: $10.1039 / \mathrm{b} 915612 \mathrm{~g}$

Koole, R., van Schooneveld, M. M., Hilhorst, J., de Mello Donegá, C., 't Hart, D. C., van Blaaderen, A., et al. (2008). On the incorporation mechanism of hydrophobic quantum dots in silica spheres by a reverse microemulsion method. Chem. Mater. 20, 2503-2512. doi: 10.1021/cm703348y

Kommareddy, S., Tiwari, S., and Amiji, M. M. (2005). Long-circulating nanovectors for tumor-specific gene delivery. Technol. Cancer. Res. Treat. 4, 615-626.

Kreibig, U., and Vollmer, M. (1995). Optical Properties of Metal Clusters. Berlin; Heidelberg: Springer. doi: 10.1007/978-3-662-09109-8

Kuhn, S. J., Finch, S. K., Hallahan, D. E., and Giorgio, T. D. (2006). Proteolytic surface functionalization enhances in vitro magnetic nanoparticle mobility through extracellular matrix. Nano Lett. 6, 306-312. doi: 10.1021/nl052241g

Kumar, M., Yigit, M., Dai, G., Moore, A., and Medarova, Z. (2010). Image-guided breast tumor therapy using a small interfering RNA nanodrug. Cancer Res. 70, 7553-7561. doi: 10.1158/0008-5472.CAN-10-2070

Kuo, H. T., Yeh, J. Z., Jiang, C. M., and Wu, M. C. (2012). Magnetic particle-linked anti hCG B antibody for immunoassay of human chorionic gonadotropin (hCG), potential application to early pregnancy diagnosis. J. Immunol. Methods 381, 32-40. doi: 10.1016/j.jim.2012.04.006

Lacerda, S. H., Park, J. J., Meuse, C., Pristinski, D., Becker, M. L., Karim, A., et al. (2010). Interaction of gold nanoparticles with common human blood proteins. ACS Nano 4, 365-379. doi: 10.1021/nn9011187

Lai, S. J., and Guan, X. L. (2011). Surface modification and application of quantum dots based on polymers. Progress Chem. 23, 941-950.

Lammers, T., Aime, S., Hennink, W. E., Storm, G., and Kiessling, F. (2011). Theranostic nanomedicine. Acc. Chem. Res. 44, 1029-1038. doi: $10.1021 / \operatorname{ar} 200019 \mathrm{c}$

Langer, R. (2000). Biomaterials in drug delivery and tissue engineering: one laboratory's experience. Acc. Chem. Res. 33, 94-101. doi: 10.1021/ar9800993

Laurent, S., Dutz, S., Hafeli, U. O., and Mahmoudi, M. (2011). Magnetic fluid hyperthermia: focus on superparamagnetic iron oxide nanoparticles. Adv. Colloid Interface Sci. 166, 8-23. doi: 10.1016/j.cis.2011.04.003
Lavilla, M., Moros, M., Puertas, S., Grazú, V., Pérez, M. D., Calvo, M., et al. (2012). Specific peptides as alternative to antibody ligands for biomagnetic separation of Clostridium tyrobutyricum spores. Anal. Bioanal. Chem. 402, 3219-3226. doi: $10.1007 / \mathrm{s} 00216-011-5621-\mathrm{z}$

Le, D. C., Wang, C., and Wang, Q. (2010). Fluorogenic click reaction. Chem. Soc. Rev. 39, 1233-1239. doi: 10.1039/b901975h

Lee, H., Sun, E., Ham, D., and Weissleder, R. (2008). Chip-NMR biosensor for detection and molecular analysis of cells. Nat. Med. 14, 869-874. doi: $10.1038 / \mathrm{nm} .1711$

Lee, H., Yoon, T. J., Figueiredo, J. L., Swirski, F. K., and Weissleder, R. (2009). Rapid detection and profiling of cancer cells in fine-needle aspirates. Proc. Natl. Acad. Sci. U.S.A. 106, 12459-12464. doi: 10.1073/pnas.0902365106

Lee, J. H., Huh, Y. M., Jun, Y. W., Seo, J. W., Jang, J. T., Song, H. T., et al. (2007). Artificially engineered magnetic nanoparticles for ultra-sensitive molecular imaging. Nat. Med. 13, 95-99. doi: 10.1038/nm1467

Lee, J. S. (2011). Multiplexed detection of oligonucleotides with biobarcoded gold nanoparticle probes. Methods Mol. Biol. 726, 17-31. doi: 10.1007/978-1-61779052-2_2

Lee, M., and Kim, S. W. (2005). Polyethylene glycol-conjugated copolymers for plasmid DNA delivery. Pharm. Res. 22, 1-10. doi: 10.1007/s11095-004-9003-5

Levy, R., Thanh, N. T., Doty, R. C., Hussain, I., Nichols, R. J., Schiffrin, D. J., et al. (2004). Rational and combinatorial design of peptide capping ligands for gold nanoparticles. J. Am. Chem. Soc. 126, 10076-10084. doi: 10.1021/ja0487269

Li, D., Li, G. P., Guo, W. W., Li, P. C., Wang, E. K., and Wang, J. (2008). Glutathionemediated release of functional plasmid DNA from positively charged quantum dots. Biomaterials 29, 2776-2782. doi: 10.1016/j.biomaterials.2008.03.007

Li, J. M., Wang, Y. Y., Zhao, M. X., Tan, C. P., Li, Y. Q., Le, X. Y., et al. (2012). Multifunctional QD-based co-delivery of siRNA and doxorubicin to HeLa cells for reversal of multidrug resistance and real-time tracking. Biomaterials 33, 2780-2790. doi: 10.1016/j.biomaterials.2011.12.035

Li, J. M., Zhao, M. X., Su, H., Wang, Y. Y., Tan, C. P., Ji, L. N., et al. (2011). Multifunctional quantum-dot-based siRNA delivery for HPV18 E6 gene silence and intracellular imaging. Biomaterials 32, 7978-7987. doi: 10.1016/j.biomaterials.2011.07.011

Li, L., Daou, T. J., Texier, I., Tran, T. K. C., Nguyen, Q. L., and Reiss, P. (2009). Highly Luminescent CuInS2/ZnS Core/Shell Nanocrystals: cadmiumfree quantum dots for in vivo imaging. Chem. Mater. 21, 2422-2429. doi: $10.1021 / \mathrm{cm} 900103 \mathrm{~b}$

Li, S. D., and Huang, L. (2010). Stealth nanoparticles: high density but sheddable PEG is a key for tumor targeting. J. Control. Release 145, 178-181. doi: 10.1016/j.jconrel.2010.03.016

Li, W., Nicol, F., and Szoka, J. (2004). GALA: a designed synthetic pH-responsive amphipathic peptide with applications in drug and gene delivery. Adv. Drug. Deliv. Rev. 56, 967-985. doi: 10.1016/j.addr.2003.10.041

Lin, C. A., Sperling, R. A., Li, J. K., Yang, T. Y., Li, P. Y., Zanella, M., et al. (2008). Design of an amphiphilic polymer for nanoparticle coating and functionalization. Small 4, 334-341. doi: 10.1002/smll.200700654

Lin, Z. Y., Gao, S., Lin, J., Lin, W. L., Qiu, S. Y., Guo, L. H., et al. (2012). Visual detection of copper(II) based on the aggregation of gold nano-particles via click chemistry. Anal. Methods 4, 612-615. doi: 10.1039/c2ay05765d

Ling, Y., Wei, K., Luo, Y., Gao, X., and Zhong, S. (2011). Dual docetaxel/superparamagnetic iron oxide loaded nanoparticles for both targeting magnetic resonance imaging and cancer therapy. Biomaterials 32, 7139-7150. doi: 10.1016/j.biomaterials.2011.05.089

Liu, C., Zou, B., Rondinone, A. J., and Zhang, Z. J. (2000). Reverse micelle synthesis and characterization of superparamagnetic $\mathrm{MnFe} 2 \mathrm{O} 4$ spinel ferrite nanocrystallites. J. Phys. Chem. B 104, 1141-1145. doi: 10.1021/jp993552g

Liu, F. J., Laurent, S., Fattahi, H., Elst, L. V., and Muller, R. N. (2011). Superparamagnetic nanosystems based on iron oxide nanoparticles for biomedical imaging. Nanomedicine 6, 519-528. doi: 10.2217/nnm.11.16

Liu, J. A., Lau, S. K., Varma, V. A., Kairdolf, B. A., and Nie, S. M. (2010). Multiplexed detection and characterization of rare tumor cells in Hodgkin's lymphoma with multicolor quantum dots. Anal. Chem. 82, 6237-6243. doi: 10.1021/ac101065b

Liu, Y., Shipton, M. K., Ryan, J., Kaufman, E. D., Franzen, S., and Feldheim, D. L. (2007). Synthesis, stability, and cellular internalization of gold nanoparticles containing mixed peptide-poly(ethylene glycol) monolayers. Anal. Chem. 79, 2221-2229. doi: 10.1021/ac061578f

Liu, Y. D., Han, X. G., He, L., and Yin, Y. D. (2012). Thermoresponsive assembly of charged gold nanoparticles and their reversible tuning of plasmon 
coupling. Angew. Chem. Int. Ed. 51, 6373-6377. doi: 10.1002/anie.2012 01816

Louie, A. (2010). Multimodality imaging probes: design and challenges. Chem. Rev. 110, 3146-3195. doi: 10.1021/cr9003538

Lu, J., Jackson, J., Gleave, M., and Burt, H. (2008). The preparation and characterization of anti-VEGFR2 conjugated, paclitaxel-loaded PLLA or PLGA microspheres for the systemic targeting of human prostate tumors. Cancer Chemother. Pharmacol. 61, 997-1005. doi: 10.1007/s00280-007-0557-x

Ma, X., Zhao, Y., and Liang, X. J. (2011). Theranostic nanoparticles engineered for clinic and pharmaceutics. Acc. Chem. Res. 44, 1114-1122. doi: $10.1021 /$ ar2000056

Maldiney, T., Richard, C., Seguin, J., Wattier, N., Bessodes, M., and Scherman, D. (2011). Effect of core diameter, surface coating, and PEG chain length on the biodistribution of persistent luminescence nanoparticles in mice. ACS Nano 5 , 854-862. doi: 10.1021/nn101937h

Marradi, M., Chiodo, F., Garcia, I., and Penades, S. (2013). Glyconanoparticles as multifunctional and multimodal carbohydrate systems. Chem. Soc. Rev. 42, 4728-4745. doi: 10.1039/c2cs35420a

Martinez-Avila, O., Hijazi, K., Marradi, M., Clavel, C., Campion, C., Kelly, C., et al. (2009). Gold manno-glyconanoparticles: multivalent systems to block HIV-1 gp120 binding to the lectin DC-SIGN. Chemistry 15, 9874-9888. doi: 10.1002/chem. 200900923

Mattoussi, H., Mauro, J. M., Goldman, E. R., Anderson, G. P., Sundar, V. C., Mikulec, F. V., et al. (2000). Self-assembly of CdSe-ZnS quantum dot bioconjugates using an engineered recombinant protein. J. Am. Chem. Soc. 122 , 12142-12150. doi: 10.1021/ja002535y

Mayilo, S., Kloster, M. A., Wunderlich, M., Lutich, A., Klar, T. A., Nichtl, A., et al. (2009). Long-range fluorescence quenching by gold nanoparticles in a sandwich immunoassay for cardiac troponin T. Nano.Lett. 9, 4558-4563. doi: $10.1021 / \mathrm{nl} 903178 \mathrm{n}$

Means, G. E., and Feeney, R. E. (1990). Chemical modifications of proteins: history and applications. Bioconjug. Chem. 1, 2-12. doi: 10.1021/bc00001a001

Medarova, Z., Pham, W., Farrar, C., Petkova, V., and Moore, A. (2007). In vivo imaging of siRNA delivery and silencing in tumors. Nat. Med. 13, 372-377. doi: $10.1038 / \mathrm{nm} 1486$

Medintz, I. L., Mattoussi, H., and Clapp, A. R. (2008). Potential clinical applications of quantum dots. Int. J. Nanomed. 3, 151-167. doi: 10.1002/smll.201000279

Meldal, M., and Tornoe, C. W. (2008). Cu-catalyzed azide-alkyne cycloaddition. Chem. Rev. 108, 2952-3015. doi: 10.1021/cr0783479

Min, C., Shao, H., Liong, M., Yoon, T. J., Weissleder, R., and Lee, H. (2012). Mechanism of magnetic relaxation switching sensing. ACS Nano 6, 6821-6828. doi: $10.1021 / \mathrm{nn} 301615 \mathrm{~b}$

Minelli, C., Lowe, S. B., and Stevens, M. M. (2010). Engineering nanocomposite materials for cancer therapy. Small 6, 2336-2357. doi: 10.1002/smll.201000523

Mirkin, C. A., Letsinger, R. L., Mucic, R. C., and Storhoff, J. J. (1996). A DNA-based method for rationally assembling nanoparticles into macroscopic materials. Nature 382, 607-609. doi: 10.1038/382607a0

Molday, R. S., Yen, S. P. S., and Renbaum, A. (1977). Application of magnetic microspheres in labelling and separation of cells. Nature 268, 437-438. doi: $10.1038 / 268437 \mathrm{a} 0$

Montenegro, J. M., Grazu, V., Sukhanova, A., Agarwal, S., de la Fuente, J. M., Nabiev, I., et al. (2013). Controlled antibody/(bio-) conjugation of inorganic nanoparticles for targeted delivery. Adv. Drug. Deliv. Rev. 65, 677-688. doi: 10.1016/j.addr.2012.12.003

Moros, M., Hernaez, B., Garet, E., Dias, J. T., Saez, B., Grazu, V., et al. (2012). Monosaccharides versus PEG-functionalized NPs: influence in the cellular uptake. ACS Nano 6, 1565-1577. doi: 10.1021/nn204543c

Moros, M., Pelaz, B., Lopez-Larrubia, P., Garcia-Martin, M. L., Grazu, V., and de la Fuente, J. M. (2010). Engineering biofunctional magnetic nanoparticles for biotechnological applications. Nanoscale 2, 1746-1755. doi: 10.1039/c0nr00104j

Murcia, M. J., and Naumann, C. A. (2005). "Biofunctionalization of fluorescent nanoparticles," in Biofunctionalization of Nanomaterials, ed C. S. S. R. Kumar (Weinheim: Wiley-VCH), 1-40.

Murphy, C. J., Gole, A. M., Stone, J. W., Sisco, P. N., Alkilany, A. M., Goldsmith, E. C., et al. (2008). Gold nanoparticles in biology: beyond toxicity to cellular imaging. Acc. Chem. Res. 41, 1721-1730. doi: 10.1021/ar800035u

Murray, C. B., Norris, D. J., and Bawendi, M. G. (1993). Synthesis and characterization of nearly monodisperse $\mathrm{Cde}(\mathrm{e}=\mathrm{S}, \mathrm{Se}, \mathrm{Te})$ semiconductor nanocrystallites. J. Am. Chem. Soc. 115, 8706-8715. doi: 10.1021/ja00072a025
Mykhaylyk, O., Antequera, Y. S., Vlaskou, D., and Plank, C. (2007). Generation of magnetic nonviral gene transfer agents and magnetofection in vitro. Nat. Protocols 2, 2391-2411. doi: 10.1038/nprot.2007.352

Nakajima, N., and Ikada, Y. (1995). Mechanism of amide formation by carbodiimide for bioconjugation in aqueous media. Bioconjug. Chem. 6, 123-130. doi: 10.1021/bc00031a015

Nam, J. M., Stoeva, S. I., and Mirkin, C. A. (2004). Bio-bar-code-based DNA detection with PCR-like sensitivity. J. Am. Chem. Soc. 126, 5932-5933. doi: 10.1021/ja049384+

Nam, J. M., Thaxton, C. S., and Mirkin, C. A. (2003). Nanoparticle-based bio-bar codes for the ultrasensitive detection of proteins. Science 301, 1884-1886. doi: 10.1126/science. 1088755

Namiki, Y., Namiki, T., Yoshida, H., Ishii, Y., Tsubota, A., Koido, S., et al. (2009). A novel magnetic crystal-lipid nanostructure for magnetically guided in vivo gene delivery. Nat. Nanotech. 4, 598-606. doi: 10.1038/nnano.2009.202

Nativo, P., Prior, I. A., and Brust, M. (2008). Uptake and intracellular fate of surfacemodified gold nanoparticles. ACS Nano 2, 1639-1644. doi: 10.1021/nn800330a

Ni, J., Lipert, R. J., Dawson, G. B., and Porter, M. D. (1999). Immunoassay readout method using extrinsic Raman labels adsorbed on immunogold colloids. Anal. Chem. 71, 4903-4908. doi: 10.1021/ac990616a

Nobs, L., Buchegger, F., Gurny, R., and Allémann, E. (2004). Current methods for attaching targeting ligands to liposomes and nanoparticles. J. Pharm. Sci. 93, 1980-1992. doi: 10.1002/jps.20098

Oh, E., Hong, M. Y., Lee, D., Nam, S. H., Yoon, H. C., and Kim, H. S. (2005). Inhibition assay of biomolecules based on fluorescence resonance energy transfer (FRET) between quantum dots and gold nanoparticles. J. Am. Chem. Soc. 127, 3270-3271. doi: 10.1021/ja0433323

Oh, E., Susumu, K., Blanco-Canosa, J. B., Medintz, I. L., Dawson, P. E., and Mattoussi, H. (2010a). preparation of stable maleimide-functionalized au nanoparticles and their use in counting surface ligands. Small 6, 1273-1278. doi: 10.1002/smll.201000279

Oh, E., Susumu, K., Goswami, R., and Mattoussi, H. (2010b). One-phase synthesis of water-soluble gold nanoparticles with control over size and surface functionalities. Langmuir 26, 7604-7613. doi: 10.1021/la904438s

Osaki, F., Kanamori, T., Sando, S., Sera, T., and Aoyama, Y. (2004). A quantum dot conjugated sugar ball and its cellular uptake on the size effects of endocytosis in the subviral region. J. Am. Chem. Soc. 126, 6520-6521. doi: 10.1021/ja048792a

Otsuka, H., Akiyama, Y., Nagasaki, Y., and Kataoka, K. (2001). Quantitative and reversible lectin-induced association of gold nanoparticles modified with alpha-lactosyl-omega-mercapto-poly(ethylene glycol). J. Am. Chem. Soc. 123, 8226-8230. doi: 10.1021/ja010437m

Pandey, P., Singh, S. P., Arya, S. K., Gupta, V., Datta, M., Singh, S., et al. (2007). Application of thiolated gold nanoparticles for the enhancement of glucose oxidase activity. Langmuir 23, 3333-3337. doi: 10.1021/la062901c

Pankhurst, Q. A., Connolly, J., Jones, S. K., and Dobson, J. (2003). Applications of magnetic nanoparticles in biomedicine. J. Phys. D Appl. Phys. 36, R167-R181. doi: 10.1088/0022-3727/36/13/201

Pankhurst, Q. A., Thanh, N. T. K., Jones, S. K., and Dobson, J. (2009). Progress in applications of magnetic nanoparticles in biomedicine. J. Phys. D Appl. Phys 42:224001. doi: 10.1088/0022-3727/42/22/224001

Pellegrino, T., Kudera, S., Liedl, T., Munoz, J. A., Manna, L., and Parak, W. J. (2005). On the development of colloidal nanoparticles towards multifunctional structures and their possible use for biological applications. Small 1, 48-63. doi: 10.1002/smll.200400071

Pellegrino, T., Sperling, R. A., Alivisatos, A. P., and Parak, W. J. (2007). Gel electrophoresis of gold-DNA nanoconjugates. J. Biomed. Biotechnol. 2007:26796. doi: $10.1155 / 2007 / 26796$

Perez, J. M., Josephson, L., O’Loughlin, T., Hogemann, D., and Weissleder, R. (2002). Magnetic relaxation switches capable of sensing molecular interactions. Nat. Biotechnol. 20, 816-820. doi: 10.1038/nbt720

Petryayeva, E., and Krull, U. J. (2012). Quantum dot and gold nanoparticle immobilization for biosensing applications using multidentate imidazole surface ligands. Langmuir 28, 13943-13951. doi: 10.1021/la302985x

Plank, C., Zelphati, O., and Mykhaylyk, O. (2011). Magnetically enhanced nucleic acid delivery. Ten years of magnetofection-progress and prospects. Adv. Drug. Deliv. Rev. 63, 1300-1331. doi: 10.1016/j.addr.2011.08.002

Polo, E., Del, P. P., Pelaz, B., Grazu, V., and de la Fuente, J. M. (2013). Plasmonicdriven thermal sensing: ultralow detection of cancer markers. Chem. Commun. (Camb.) 49, 3676-3678. doi: 10.1039/c3cc39112d 
Pons, T., Medintz, I. L., Sapsford, K. E., Higashiya, S., Grimes, A. F., English, D. S., et al. (2007). On the quenching of semiconductor quantum dot photoluminescence by proximal gold nanoparticles. Nano Lett. 7, 3157-3164. doi: $10.1021 / \mathrm{nl} 071729+$

Poulose, A. C., Veeranarayanan, S., Mohamed, M. S., Raveendran, S., Nagaoka, Y., Yoshida, Y., et al. (2012). PEG Coated Biocompatible Cadmium Chalcogenide Quantum Dots for Targeted Imaging of Cancer Cells. J. Fluoresc. 22, 931-944. doi: 10.1007/s10895-011-1032-y

Prasuhn, D. E., Feltz, A., Blanco-Canosa, J. B., Susumu, K., Stewart, M. H., Mei, B. C., et al. (2010). Quantum dot peptide biosensors for monitoring caspase 3 proteolysis and calcium ions. ACS Nano 4, 5487-5497. doi: 10.1021/nn1 016132

Prijic, S., and Sersa, G. (2011). Magnetic nanoparticles as targeted delivery systems in oncology. Radiol. Oncol. 45, 1-16. doi: 10.2478/v10019-011-0001-z

Prow, T. W., Monteiro-Riviere, N. A., Inman, A. O., Grice, J. E., Chen, X. F., et al. (2012). Quantum dot penetration into viable human skin. Nanotoxicology 6, 173-185. doi: 10.3109/17435390.2011.569092

Puertas, S., Batalla, P., Moros, M., Polo, E., del Pino, P., Guisán, J. M., et al. (2011). Taking advantage of unspecific interactions to produce highly active magnetic nanoparticle-antibody conjugates. ACS Nano 5, 4521-4528. doi: $10.1021 / \mathrm{nn} 200019 \mathrm{~s}$

Putman, C. A. J., de Grooth, B. G., Hansma, P. K., van Hulst, N. F., and Greve, J. (1993). Immunogold labels: cell-surface markers in atomic force microscopy. Ultramicroscopy 48, 177-182. doi: 10.1016/0304-3991(93)90180-6

Ravi, S., Krishnamurthy, V. R., Caves, J. M., Haller, C. A., and Chaikof, E. L. (2012). Maleimide-thiol coupling of a bioactive peptide to an elastin-like protein polymer. Acta Biomaterialia 8, 627-635. doi: 10.1016/j.actbio.2011.10.027

Ray, P. C., Fortner, A., and Darbha, G. K. (2006). Gold nanoparticle based FRET assay for the detection of DNA cleavage. J. Phys. Chem. B 110, 20745-20748. doi: 10.1021/jp0651211

Reed, A. M., and Metallo, S. J. (2010). Oriented protein adsorption to gold nanoparticles through a genetically encodable binding motif. Langmuir 26, 18945-18950. doi: 10.1021/la1035135

Reynolds, A. J., Haines, A. H., and Russell, D. A. (2006). Gold glyconanoparticles for mimics and measurement of metal ion-mediated carbohydrate-carbohydrate interactions. Langmuir 22, 1156-1163. doi: 10.1021/la052261y

Reynolds, M., Marradi, M., Imberty, A., Penades, S., and Perez, S. (2012). Multivalent gold glycoclusters: high affinity molecular recognition by bacterial lectin PA-IL. Chem. A Eur. J. 18, 4264-4273. doi: 10.1002/chem.201102034

Rojo, J., Diaz, V., de la Fuente, J. M., Segura, I., Barrientos, A. G., Riese, H. H., et al. (2004). Gold glyconanoparticles as new tools in antiadhesive therapy. Chembiochem 5, 291-297. doi: 10.1002/cbic.200300726

Rosa, J., Conde, J., de la Fuente, J. M., Lima, J. C., and Baptista, P. V. (2012). Goldnanobeacons for real-time monitoring of RNA synthesis. Biosens. Bioelectron. 36, 161-167. doi: 10.1016/j.bios.2012.04.006

Rosa, J. P., Lima, J. C., and Baptista, P. V. (2011). Experimental photophysical characterization of fluorophores in the vicinity of gold nanoparticles. Nanotechnology 22:415202. doi: 10.1088/0957-4484/22/41/415202

Rosensweig, R. E. (2002). Heating magnetic fluid with alternating magnetic field. J. Magn. Magn. Mater. 252, 370-374. doi: 10.1016/S0304-8853(02)00706-0

Rostro-Kohanloo, B. C., Bickford, L. R., Payne, C. M., Day, E. S., Anderson, L. J. E., Zhong, M., et al. (2009). The stabilization and targeting of surfactantsynthesized gold nanorods. Nanotechnology 20:434005. doi: 10.1088/09574484/20/43/434005

Roullier, V., Clarke, S., You, C., Pinaud, F., Gouzer, G., Schaible, D., et al. (2009). High-affinity labeling and tracking of individual histidine-tagged proteins in live cells using $\mathrm{Ni} 2+$ tris-nitrilotriacetic acid quantum dot conjugates. Nano Lett. 9, 1228-1234. doi: 10.1021/nl9001298

Ruan, J., Song, H., Qian, Q. R., Li, C., Wang, K., Bao, C. C., et al. (2012). HER2 monoclonal antibody conjugated RNase-A-associated CdTe quantum dots for targeted imaging and therapy of gastric cancer. Biomaterials 33, 7093-7102. doi: 10.1016/j.biomaterials.2012.06.053

Ruoslahti, E., Bhatia, S. N., and Sailor, M. J. (2010). Targeting of drugs and nanoparticles to tumors. J. Cell Biol. 188, 759-768. doi: 10.1083/jcb.200910104

Sahoo, B., Sahu, S. K., and Pramanik, P. (2011). A novel method for the immobilization of urease on phosphonate grafted iron oxide nanoparticle. J. Mol. Catal. B Enzym. 69, 95-102. doi: 10.1016/j.molcatb.2011.01.001

Sam, S., Touahir, L., Salvador Andresa, J., Allongue, P., Chazalviel, J. N., GougetLaemmel, A. C., et al. (2009). Semiquantitative study of the EDC/NHS activation of acid terminal groups at modified porous silicon surfaces. Langmuir 26, 809-814. doi: 10.1021/la902220a

Santra, S., Kaittanis, C., and Perez, J. M. (2009). Aliphatic hyperbranched polyester: a new building block in the construction of multifunctional nanoparticles and nanocomposites. Langmuir 26, 5364-5373. doi: 10.1021/la9037843

Sanz, V., Conde, J., Hernandez, Y., Baptista, P. V., Ibarra, M. R., and de la Fuente, J. M. (2012). Effect of PEG biofunctional spacers and TAT peptide on dsRNA loading on gold nanoparticles. J. Nanopart. Res. 14, 1-9. doi: 10.1007/s11051012-0917-2

Sato, K., Hosokawa, K., and Maeda, M. (2003). Rapid aggregation of gold nanoparticles induced by non-cross-linking DNA hybridization. J. Am. Chem. Soc. 125, 8102-8103. doi: $10.1021 /$ ja034876s

Sawant, R. R., and Torchilin, V. P. (2012). Multifunctional nanocarriers and intracellular drug delivery. Curr. Opin. Solid State Mater. Sci. 16, 269-275. doi: 10.1016/j.cossms.2012.09.001

Scherer, F., Anton, M., Schillinger, U., Henke, J., Bergemann, C., Kruger, A., et al. (2002). Magnetofection: enhancing and targeting gene delivery by magnetic force in vitro and in vivo. Gene Ther. 9, 102-109. doi: 10.1038/sj.gt.33 01624

Schofield, C. L., Field, R. A., and Russell, D. A. (2007). Glyconanoparticles for the colorimetric detection of cholera toxin. Anal.Chem. 79, 1356-1361. doi: $10.1021 / \mathrm{ac} 061462 \mathrm{j}$

Schofield, C. L., Haines, A. H., Field, R. A., and Russell, D. A. (2006). Silver and gold glyconanoparticles for colorimetric bioassays. Langmuir 22, 6707-6711. doi: 10.1021/la060288r

Schultz, S., Smith, D. R., Mock, J. J., and Schultz, D. A. (2000). Single-target molecule detection with nonbleaching multicolor optical immunolabels. Proc. Natl. Acad. Sci. U.S.A. 97, 996-1001. doi: 10.1073/pnas.97.3.996

Sheehan, J. C., Preston, J., and Cruickshank, P. A. (1965). A rapid synthesis of oligopeptide derivatives without isolation of intermediates. J. Am. Chem. Soc. 87, 2492-2493. doi: 10.1021/ja01089a034

Shemetov, A. A., Nabiev, I., and Sukhanova, A. (2012). Molecular interaction of proteins and peptides with nanoparticles. ACS Nano 6, 4585-4602. doi: $10.1021 / \mathrm{nn} 300415 \mathrm{x}$

Shen, H., Jawaid, A. M., and Snee, P. T. (2009). Poly(ethylene glycol) Carbodiimide coupling reagents for the biological and chemical functionalization of watersoluble nanoparticles. ACS Nano 3, 915-923. doi: 10.1021/nn800870r

Shinchi, H., Wakao, M., Nakagawa, S., Mochizuki, E., Kuwabata, S., and Suda Y. (2012). Stable sugar-chain-immobilized fluorescent nanoparticles for probing lectin and cells. Chem. Asian J. 7, 2678-2682. doi: 10.1002/asia.2012 00362

Shvedova, A. A., Kagan, V. E., and Fadeel, B. (2010). Close encounters of the small kind: adverse effects of man-made materials interfacing with the nanocosmos of biological systems. Annu. Rev. Pharmacol. Toxicol. 50, 63-88. doi: 10.1146/annurev.pharmtox.010909.105819

Simpson, C. A., Agrawal, A. C., Balinski, A., Harkness, K. M., and Cliffel, D. E. (2011). Short-chain PEG mixed monolayer protected gold clusters increase clearance and red blood cell counts. ACS Nano 5, 3577-3584. doi: $10.1021 / \mathrm{nn} 103148 \mathrm{x}$

Singh, B. R., Singh, B. N., Khan, W., Singh, H. B., and Naqvi, A. H. (2012) ROS-mediated apoptotic cell death in prostate cancer LNCaP cells induced by biosurfactant stabilized CdS quantum dots. Biomaterials 33, 5753-5767. doi: 10.1016/j.biomaterials.2012.04.045

Singh, M. P., and Strouse, G. F. (2010). Involvement of the LSPR spectral overlap for energy transfer between a dye and au nanoparticle. J. Am. Chem. Soc. 132, 9383-9391. doi: 10.1021/ja1022128

Skaff, H., and Emrick, T. (2003). The use of 4-substituted pyridines to afford amphiphilic, pegylated cadmium selenide nanoparticles. Chem. Commun. 52 53. doi: 10.1039/b208718a

Smith, A. M., Dave, S., Nie, S. M., True, L., and Gao, X. H. (2006). Multicolor quantum dots for molecular diagnostics of cancer. Expert Rev. Mol. Diagn. 6 , 231-244. doi: 10.1586/14737159.6.2.231

Smith, A. M., and Nie, S. (2012). Compact quantum dots for single-molecule imaging. J. Vis. Exp. 68:4236. doi: 10.3791/4236

Smith, A. M., Wen, M. M., and Nie, S. (2010). Imaging dynamic cellular events with quantum dots The bright future. Biochem. (Lond.) 32:12.

So, M. K., Loening, A. M., Gambhir, S. S., and Rao, J. H. (2006a). Creating self-illuminating quantum dot conjugates. Nat. Protoc. 1, 1160-1164. doi: $10.1038 /$ nprot.2006.162 
So, M. K., Xu, C. J., Loening, A. M., Gambhir, S. S., and Rao, J. H. (2006b). Selfilluminating quantum dot conjugates for in vivo imaging. Nat. Biotechnol. 24, 339-343. doi: $10.1038 /$ nbt1188

Sperling, R. A., and Parak, W. J. (2010). Surface modification, functionalization and bioconjugation of colloidal inorganic nanoparticles. Philos. Trans. A Math. Phys. Eng. Sci. 368, 1333-1383. doi: 10.1098/rsta.2009.0273

Sperling, R. A., Pellegrino, T., Li, J. K., Chang, W. H., and Parak, W. J. (2006). Electrophoretic separation of nanoparticles with a discrete number of functional groups. Adv. Funct. Mater. 16, 943-948. doi: 10.1002/adfm.2005 00589

Sperling, R. A., Rivera, G. P., Zhang, F., Zanella, M., and Parak, W. J. (2008). Biological applications of gold nanoparticles. Chem. Soc. Rev. 37, 1896-1908. doi: 10.1039/b712170a

Srinivasan, C., Lee, J., Papadimitrakopoulos, F., Silbart, L. K., Zhao, M. H., and Burgess, D. J. (2006). Labeling and intracellular tracking of functionally active plasmid DNA with semiconductor quantum dots. Mol. Ther. 14, 192-201. doi: 10.1016/j.ymthe.2006.03.010

Storhoff, J. J., Lucas, A. D., Garimella, V., Bao, Y. P., and Muller, U. R. (2004) Homogeneous detection of unamplified genomic DNA sequences based on colorimetric scatter of gold nanoparticle probes. Nat. Biotechnol. 22, 883-887. doi: 10.1038/nbt977

Strozyk, M. S., Chanana, M., Pastoriza-Santos, I., Perez-Juste, J., and Liz-Marzan, L. M. (2012). Protein/polymer-based dual-responsive gold nanoparticles with pH-dependent thermal sensitivity. Adv. Funct. Mater. 22, 1436-1444. doi: 10.1002/adfm.201102471

Sudhagar, P., Gonzalez-Pedro, V., Mora-Sero, I., Fabregat-Santiago, F., Bisquert, J., and Kang, Y. S. (2012). Interfacial engineering of quantum dot-sensitized $\mathrm{TiO} 2$ fibrous electrodes for futuristic photoanodes in photovoltaic applications. J. Mater. Chem. 22, 14228-14235. doi: 10.1039/c2jm31599h

Sugahara, K. N., Teesalu, T., Karmali, P. P., Kotamraju, V. R., Agemy, L., Girard, O. M., et al. (2009). Tissue-penetrating delivery of compounds and nanoparticles into tumors. Cancer Cell 16, 510-520. doi: 10.1016/j.ccr.2009.10.013

Surendiran, A., Sandhiya, S., Pradhan, S. C., and Adithan, C. (2009). Novel applications of nanotechnology in medicine. Indian J. Med. Res. 130, 689-701.

Susumu, K., Uyeda, H. T., Medintz, I. L., Pons, T., Delehanty, J. B., and Mattoussi, H. (2007). Enhancing the stability and biological functionalities of quantum dots via compact multifunctional ligands. J. Am. Chem. Soc. 129, 13987-13996. doi: 10.1021/ja0749744

Svobodova, Z., Reza, M. M., Jankovicova, B., Esselmann, H., Verpillot, R., Otto, M., et al. (2012). Development of a magnetic immunosorbent for on-chip preconcentration of amyloid beta isoforms: representatives of Alzheimer's disease biomarkers. Biomicrofluidics 6, 24126-2412612. doi: 10.1063/1.4722588

Tan, W. B., Jiang, S., and Zhang, Y. (2007). Quantum-dot based nanoparticles for targeted silencing of HER2/neu gene via RNA interference. Biomaterials 28, 1565-1571. doi: 10.1016/j.biomaterials.2006.11.018

Tang, B., Zhang, N., Chen, Z., Xu, K., Zhuo, L., An, L., et al. (2008). Probing hydroxyl radicals and their imaging in living cells by use of FAM-DNA-Au nanoparticles. Chemistry 14, 522-528. doi: 10.1002/chem.200700455

Thaxton, C. S., Georganopoulou, D. G., and Mirkin, C. A. (2006). Gold nanoparticle probes for the detection of nucleic acid targets. Clin. Chim. Acta 363, 120-126. doi: 10.1016/j.cccn.2005.05.042

Thomas, M., and Klibanov, A. M. (2003). Conjugation to gold nanoparticles enhances polyethylenimine's transfer of plasmid DNA into mammalian cells. Proc. Natl. Acad. Sci. U.S.A. 100, 9138-9143. doi: 10.1073/pnas.12336 34100

van der Voort, D., Pelsers, M. M., Korf, J., Hermens, W. T., and Glatz, J. F. C. (2004). A continuous displacement immunoassay for human heart-type fatty acid-binding protein in plasma. J. Immunol. Methods 295, 1-8. doi: 10.1016/j.jim.2004.08.012

van der Zee, J. (2002). Heating the patient: a promising approach? Ann. Oncol. 13, 1173-1184. doi: 10.1093/annonc/mdf280

Verma, A., and Stellacci, F. (2010). Effect of surface properties on nanoparticle-cell interactions. Small 6, 12-21. doi: 10.1002/smll.200901158

Vertegel, A. A., Siegel, R. W., and Dordick, J. S. (2004). Silica nanoparticle size influences the structure and enzymatic activity of adsorbed lysozyme. Langmuir 20, 6800-6807. doi: 10.1021/la0497200

Voliani, V., Ricci, F., Signore, G., Nifosi, R., Luin, S., and Beltram, F. (2011). Multiphoton molecular photorelease in click-chemistry-functionalized gold nanoparticles. Small 7, 3271-3275. doi: 10.1002/smll.201101753 von Maltzahn, G., Ren, Y., Park, J. H., Min, D. H., Kotamraju, V. R., Jayakumar, J., et al. (2008). In vivo tumor cell targeting with click nanoparticles. Bioconjug. Chem. 19, 1570-1578. doi: 10.1021/bc800077y

Wagner, F. E., Haslbeck, S., Stievano, L., Calogero, S., Pankhurst, Q. A., and Martinek, K. P. (2000). Before striking gold in gold-ruby glass. Nature 407, 691-692. doi: 10.1038/35037661

Wahajuddin and Arora, S. (2012). Superparamagnetic iron oxide nanoparticles: magnetic nanoplatforms as drug carriers. Int. J. Nanomed. 7, 3445-3471. doi: 10.2147/IJN.S30320

Wang, J., Xu, J., Goodman, M. D., Chen, Y., Cai, M., Shinar, J., et al. (2008). A simple biphasic route to water soluble dithiocarbamate functionalized quantum dots. J. Mater. Chem. 18, 3270-3274. doi: 10.1039/b803618g

Wang, Q., Chan, T. R., Hilgraf, R., Fokin, V. V., Sharpless, K. B., and Finn, M. G. (2003). Bioconjugation by copper(I)-catalyzed azide-alkyne [3+2] cycloaddition. J. Am. Chem. Soc. 125, 3192-3193. doi: 10.1021/ja021381e

Wang, T., and Guo, Z. J. (2006). Copper in medicine: homeostasis, chelation therapy and antitumor drug design. Curr. Med. Chem. 13, 525-537. doi: $10.2174 / 092986706776055742$

Wang, Z., Levy, R., Fernig, D. G., and Brust, M. (2005). The peptide route to multifunctional gold nanoparticles. Bioconjug. Chem. 16, 497-500. doi: 10.1021/bc050047f

Watson, J. D., and Crick, F. H. (1953). Molecular structure of nucleic acids; a structure for deoxyribose nucleic acid. Nature 171, 737-738. doi: 10.1038/171737a0

Weissleder, R., Kelly, K., Sun, E. Y., Shtatland, T., and Josephson, L. (2005). Cell-specific targeting of nanoparticles by multivalent attachment of small molecules. Nat. Biotechnol. 23, 1418-1423. doi: 10.1038/nbt1159

Weller, H. (1993). Colloidal semiconductor Q-particles-chemistry in the transition region between solid-state and molecules. Angew. Chem. Int. Ed. Engl. 32, 41-53. doi: 10.1002/anie.199300411

Wolcott, A., Gerion, D., Visconte, M., Sun, J., Schwartzberg, A., Chen, S. W., et al. (2006). Silica-coated CdTe quantum dots functionalized with thiols for bioconjugation to IgG proteins. J. Phys. Chem. B 110, 5779-5789. doi: 10.1021/jp057435z

Wu, S. C., Ng, K. K. S., and Wong, S. L. (2009b). Engineering monomeric streptavidin and its ligands with infinite affinity in binding but reversibility in interaction. Proteins 77, 404-412. doi: 10.1002/prot.22446

Wu, S. M., Zhang, Z. L., Wang, X. D., Zhang, M. X., Peng, J., Xie, Z. X., et al. (2009a). Quantum dot-ferrichrome bioprobes for recognition of pseudomonas fluorescens. J. Phys. Chem. C 113, 9169-9174. doi: 10.1021/jp901221h

Wu, X. Y., Liu, H. J., Liu, J. Q., Haley, K. N., Treadway, J. A., Larson, J. P., et al. (2003). Immunofluorescent labeling of cancer marker Her2 and other cellular targets with semiconductor quantum dots. Nat. Biotechnol. 21, 41-46. doi: $10.1038 / \mathrm{nbt} 764$

Wu, Z. S., Jiang, J. H., Fu, L., Shen, G. L., and Yu, R. Q. (2006). Optical detection of DNA hybridization based on fluorescence quenching of tagged oligonucleotide probes by gold nanoparticles. Anal. Biochem. 353, 22-29. doi: 10.1016/j.ab.2006.01.018

Xia, Z. Y., Xing, Y., So, M. K., Koh, A. L., Sinclair, R., and Rao, J. H. (2008). Multiplex detection of protease activity with quantum dot nanosensors prepared by intein-mediated specific bioconjugation. Anal. Chem. 80, 8649-8655. doi: $10.1021 / \mathrm{ac} 801562 \mathrm{f}$

Xie, J., Xu, C., Kohler, N., Hou, Y., and Sun, S. (2007). Controlled PEGylation of monodisperse $\mathrm{Fe} 3 \mathrm{O} 4$ nanoparticles for reduced non-specific uptake by macrophage cells. Adv. Mater. 19, 3163-3166. doi: 10.1002/adma.200701975

Xing, Y., Smith, A. M., Agrawal, A., Ruan, G., and Nie, S. (2006). Molecular profiling of single cancer cells and clinical tissue specimens with semiconductor quantum dots. Int. J. Nanomed. 1, 473-481. doi: 10.2147/nano.2006.1.4.473

Xu, J., Yin, W., Zhang, Y., Yi, J., Meng, M., Wang, Y., et al. (2012). Establishment of magnetic beads-based enzyme immunoassay for detection of chloramphenicol in milk. Food Chem. 134, 2526-2531. doi: 10.1016/j.foodchem.2012.04.083

$\mathrm{Xu}$, S., Kumar, S., and Nann, T. (2006). Rapid synthesis of high-quality InP nanocrystals. J. Am. Chem. Soc. 128, 1054-1055. doi: 10.1021/ja057676k

Xu, X., Daniel, W. L., Wei, W., and Mirkin, C. A. (2010). Colorimetric $\mathrm{Cu}(2+)$ detection using DNA-modified gold-nanoparticle aggregates as probes and click chemistry. Small 6, 623-626. doi: 10.1002/smll.200901691

Yallapu, M. M., Othman, S. F., Curtis, E. T., Gupta, B. K., Jaggi, M., and Chauhan, S. C. (2011). Multi-functional magnetic nanoparticles for magnetic resonance imaging and cancer therapy. Biomaterials 32, 1890-1905. doi: 10.1016/j.biomaterials.2010.11.028 
Yang, Y., Cui, X. K., Zhong, M., and Li, Z. J. (2012a). Study of carbohydrate-protein interactions using glyco-QDs with different fluorescence emission wavelengths. Carbohydr. Res. 361, 189-194. doi: 10.1016/j.carres.2012.08.018

Yang, Y., Lan, J., Xu, Z., Chen, T., Zhao, T., Cheng, T., et al. (2012b). Toxicity and biodistribution of aqueous synthesized $\mathrm{ZnS}$ and $\mathrm{ZnO}$ quantum dots in mice. Nanotoxicology 8, 107-116. doi: 10.3109/17435390.2012.760014

Ye, M., Zhang, Y. Y., Li, H. T., Zhang, Y. Q., Tan, P., Tang, H., et al. (2009). A novel method for the detection of point mutation in DNA using single-base-coded CdS nanoprobes. Biosens. Bioelectron. 24, 2339-2345. doi: 10.1016/j.bios.2008.12.002

Yezhelyev, M. V., Qi, L. F., O’Regan, R. M., Nie, S., and Gao, X. H. (2008). Protonsponge coated quantum dots for siRNA delivery and intracellular imaging. J. Am. Chem. Soc. 130, 9006-9012. doi: 10.1021/ja800086u

Yoo, D., Lee, J. H., Shin, T. H., and Cheon, J. (2011). Theranostic magnetic nanoparticles. Acc. Chem. Res. 44, 863-874. doi: 10.1021/ar200085c

Zhang, B. B., Cheng, J., Li, D. N., Liu, X. H., Ma, G. P., and Chang, J. (2008). A novel method to make hydrophilic quantum dots and its application on biodetection. Mater. Sci. Eng. B Adv. 149, 87-92. doi: 10.1016/j.mseb.2007.12.009

Zhang, C. Y., and Hu, J. (2010). Single quantum dot-based nanosensor for multiple DNA detection. Anal. Chem. 82, 1921-1927. doi: 10.1021/ac9026675

Zhang, C. Y., Yeh, H. C., Kuroki, M. T., and Wang, T. H. (2005a). Single-quantumdot-based DNA nanosensor. Nat. Mater. 4, 826-831. doi: 10.1038/nmat1508

Zhang, P. F., Liu, S. H., Gao, D. Y., Hu, D. H., Gong, P., Sheng, Z. H., et al. (2012a). Click-functionalized compact quantum dots protected by multidentate-imidazole ligands: conjugation-ready nanotags for living-virus labeling and imaging. J. Am. Chem. Soc. 134, 8388-8391. doi: 10.1021/ja302367s

Zhang, S. X., Wang, N., Yu, H. J., Niu, Y. M., and Sun, C. Q. (2005b). Covalent attachment of glucose oxidase to an Au electrode modified with gold nanoparticles for use as glucose biosensor. Bioelectrochemistry 67, 15-22. doi: 10.1016/j.bioelechem.2004.12.002

Zhang, T., Wu, Y. P., Pan, X. M., Zheng, Z. H., Ding, X. B., and Peng, Y. X. (2009). An approach for the surface functionalized gold nanoparticles with $\mathrm{pH}$ responsive polymer by combination of RAFT and click chemistry. Eur. Polym. J. 45, 1625-1633. doi: 10.1016/j.eurpolymj.2009.03.016

Zhang, X., Servos, M. R., and Liu, J. (2012b). Surface science of DNA adsorption onto citrate-capped gold nanoparticles. Langmuir 28, 3896-3902. doi: 10.1021/la205036p

Zhao, E. Y., Zhao, Z. X., Wang, J. C., Yang, C. H., Chen, C. J., Gao, L. Y., et al. (2012a). Surface engineering of gold nanoparticles for in vitro siRNA delivery. Nanoscale 4, 5102-5109. doi: 10.1039/c2nr31290e

Zhao, Q., Wang, L. N., Cheng, R., Mao, L. D., Arnold, R. D., Howerth, E. W., et al. (2012b). Magnetic nanoparticle-based hyperthermia for head \& neck cancer in mouse models. Theranostics 2, 113-121. doi: 10.7150/thno.3854
Zhao, Y., Zhao, L. J., Zhou, L. J., Zhi, Y., Xu, J. M., Wei, Z., et al. (2010). Quantum dot conjugates for targeted silencing of bcr/abl gene by RNA interference in human myelogenous leukemia K562 cells. J. Nanosci. Nanotechnol. 10, 5137-5143. doi: 10.1166/jnn.2010.2396

Zhou, D. J., Ying, L. M., Hong, X., Hall, E. A., Abell, C., and Klenerman, D. (2008a). A compact functional quantum dot-DNA conjugate: preparation, hybridization, and specific label-free DNA detection. Langmuir 24, 1659-1664. doi: 10.1021/la703583u

Zhou, M., Nakatani, E., Gronenberg, L. S., Tokimoto, T., Wirth, M. J., Hruby, V. J., et al. (2007). Peptide-labeled quantum dots for imaging GPCRs in whole cells and as single molecules. Bioconjug. Chem. 18, 323-332. doi: 10.1021/ bc0601929

Zhou, Y., Wang, S. X., Zhang, K., and Jiang, X. Y. (2008b). Visual detection of copper(II) by azide- and alkyne-functionalized gold nanoparticles using click chemistry. Angew. Chem. Int. Ed. Engl. 47, 7454-7456. doi: 10.1002/anie.200802317

Zhu, J., Waengler, C., Lennox, R. B., and Schirrmacher, R. (2012a). Preparation of water-soluble maleimide-functionalized $3 \mathrm{~nm}$ gold nanoparticles: a new bioconjugation template. Langmuir 28, 5508-5512. doi: 10.1021/ la300316j

Zhu, K., Zhang, Y., He, S., Chen, W. W., Shen, J. Z., Wang, Z., et al. (2012b). Quantification of proteins by functionalized gold nanoparticles using click chemistry. Anal. Chem. 84, 4267-4270. doi: 10.1021/ac3010567

Zuo, G., Huang, Q., Wei, G., Zhou, R., and Fang, H. (2010). Plugging into proteins: poisoning protein function by a hydrophobic nanoparticle. ACS Nano 4, 7508-7514. doi: 10.1021/nn101762b

Conflict of Interest Statement: The authors declare that the research was conducted in the absence of any commercial or financial relationships that could be construed as a potential conflict of interest.

Received: 24 April 2014; accepted: 24 June 2014; published online: 15 July 2014. Citation: Conde J, Dias JT, Grazú V, Moros M, Baptista PV and de la Fuente JM (2014) Revisiting 30 years of biofunctionalization and surface chemistry of inorganic nanoparticles for nanomedicine. Front. Chem. 2:48. doi: 10.3389/fchem.2014.00048

This article was submitted to Chemical Engineering, a section of the journal Frontiers in Chemistry.

Copyright (c) 2014 Conde, Dias, Grazú, Moros, Baptista and de la Fuente. This is an open-access article distributed under the terms of the Creative Commons Attribution License (CC BY). The use, distribution or reproduction in other forums is permitted, provided the original author(s) or licensor are credited and that the original publication in this journal is cited, in accordance with accepted academic practice. No use, distribution or reproduction is permitted which does not comply with these terms. 